\title{
Analysis of the 30B UF 6 Container for Use with Increased Enrichment
}

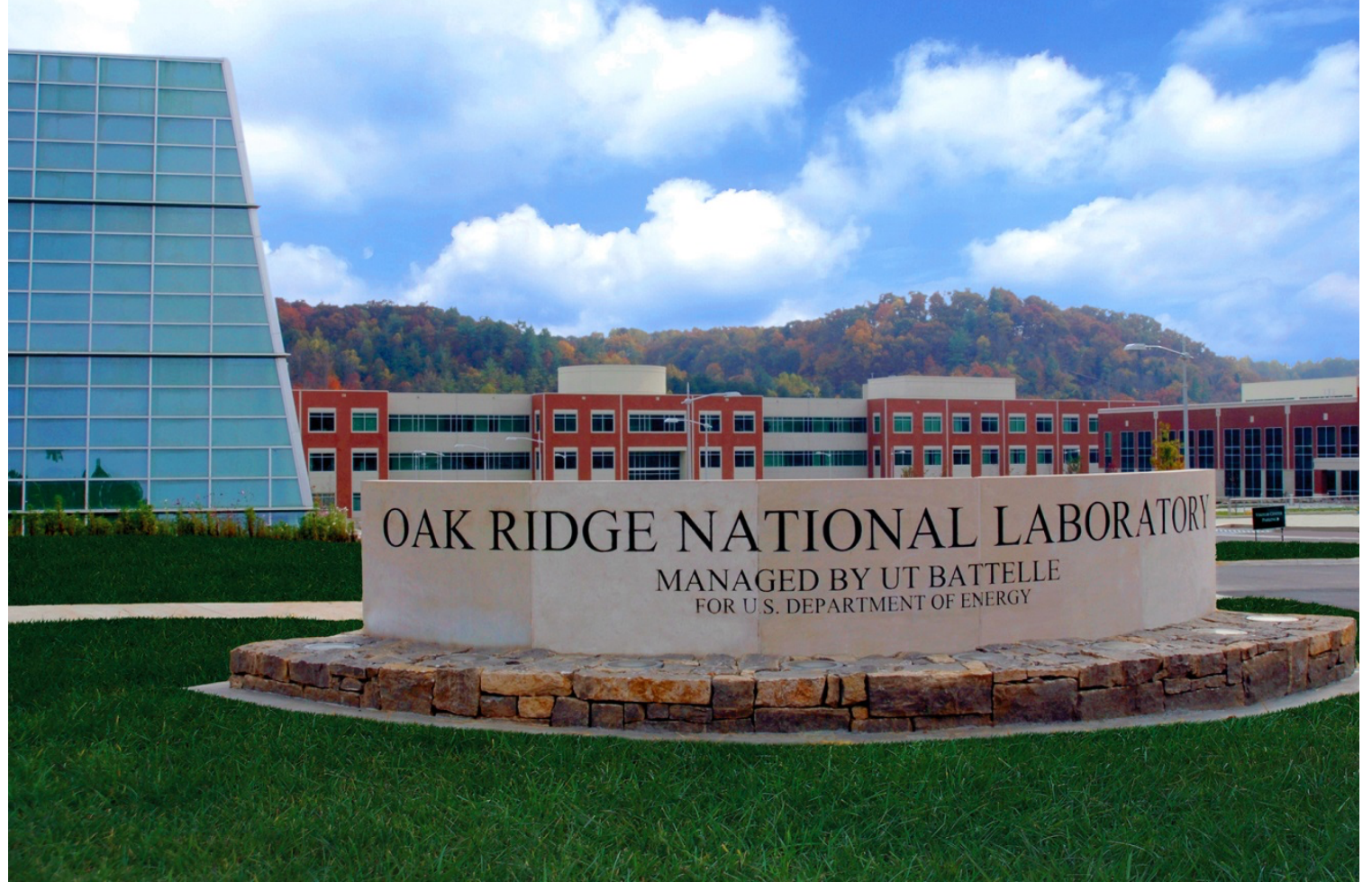

Ellen M. Saylor

Alexander Lang

B.J. Marshall

Robert Hall

Approved for public release.

Distribution is unlimited.

May 2021 


\title{
DOCUMENT AVAILABILITY
}

Reports produced after January 1, 1996, are generally available free via US Department of Energy (DOE) SciTech Connect.

Website www.osti.gov

Reports produced before January 1, 1996, may be purchased by members of the public from the following source:

\author{
National Technical Information Service \\ 5285 Port Royal Road \\ Springfield, VA 22161 \\ Telephone 703-605-6000 (1-800-553-6847) \\ TDD 703-487-4639 \\ Fax 703-605-6900 \\ E-mail info@ntis.gov \\ Website http://classic.ntis.gov/
}

Reports are available to DOE employees, DOE contractors, Energy Technology Data Exchange representatives, and International Nuclear Information System representatives from the following source:

Office of Scientific and Technical Information

PO Box 62

Oak Ridge, TN 37831

Telephone 865-576-8401

Fax 865-576-5728

E-mail reports@osti.gov

Website http://www.osti.gov/contact.html

This report was prepared as an account of work sponsored by an agency of the United States Government. Neither the United States Government nor any agency thereof, nor any of their employees, makes any warranty, express or implied, or assumes any legal liability or responsibility for the accuracy, completeness, or usefulness of any information, apparatus, product, or process disclosed, or represents that its use would not infringe privately owned rights. Reference herein to any specific commercial product, process, or service by trade name, trademark, manufacturer, or otherwise, does not necessarily constitute or imply its endorsement, recommendation, or favoring by the United States Government or any agency thereof. The views and opinions of authors expressed herein do not necessarily state or reflect those of the United States Government or any agency thereof. 
Nuclear Energy and Fuel Cycle Division

\title{
ANALYSIS OF THE 30B UF 6 CONTAINER FOR USE WITH INCREASED ENRICHMENT
}

\author{
Ellen M. Saylor \\ Alexander Lang \\ B.J. Marshall \\ Robert Hall
}

May 2021

Prepared by

OAK RIDGE NATIONAL LABORATORY

Oak Ridge, TN 37831-6283

managed by

UT-BATTELLE LLC

for the

US DEPARTMENT OF ENERGY

under contract DE-AC05-00OR22725 



\section{CONTENTS}

CONTENTS

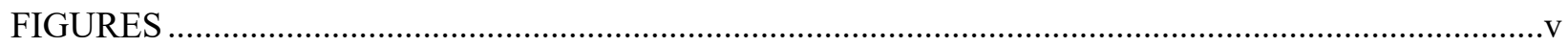

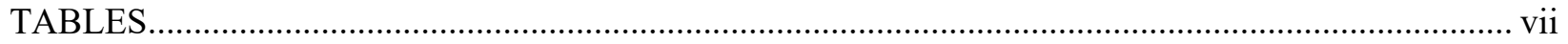

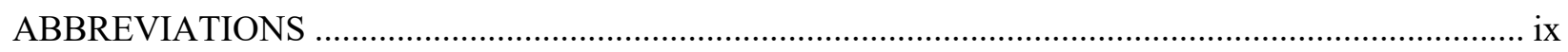

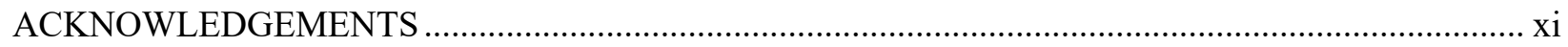

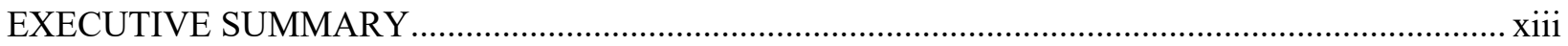

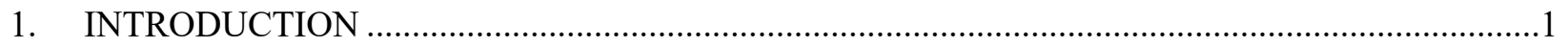

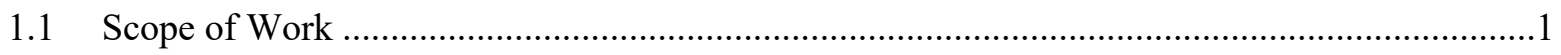

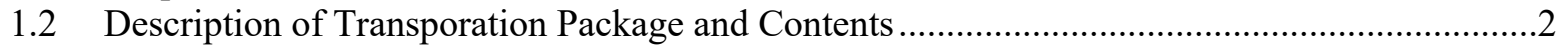

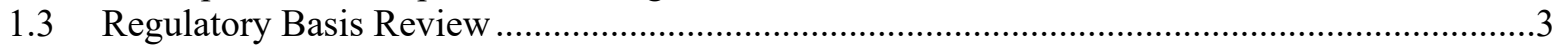

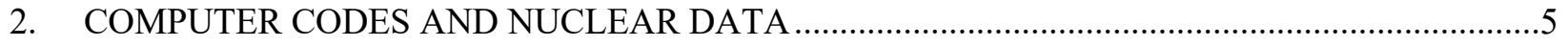

2.1 CSAS6

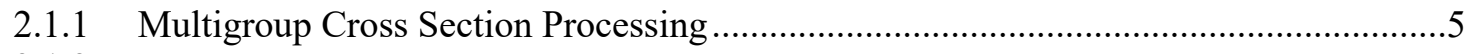

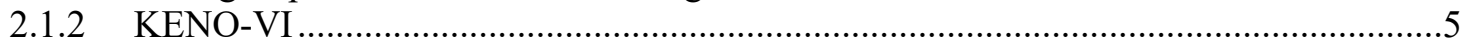

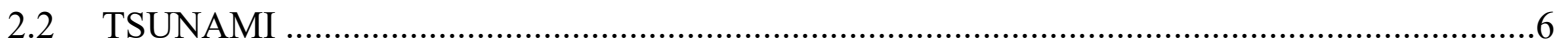

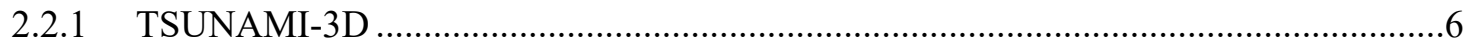

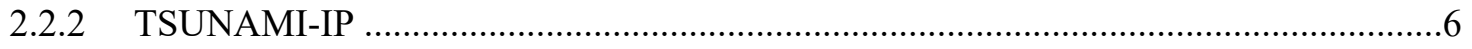

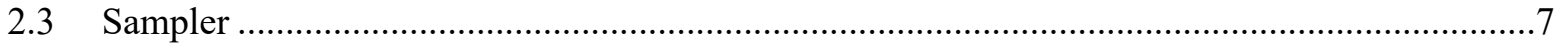

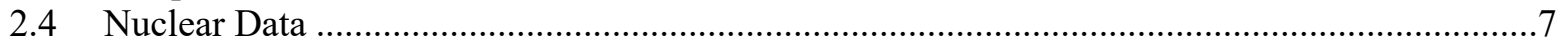

2.4.1 252-Group Library Based on ENDF/B-VII.1 (v7.1-252) ........................................

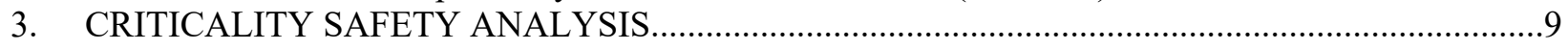

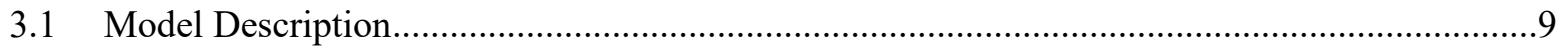

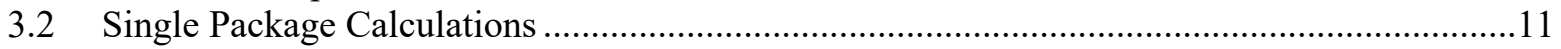

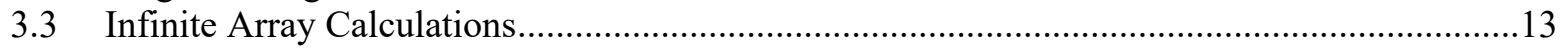

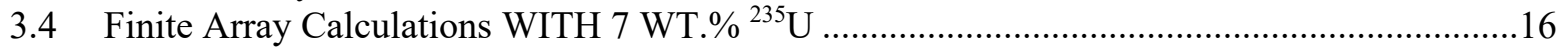

3.4.1 Hypothetical Accident Condition Array ................................................................16

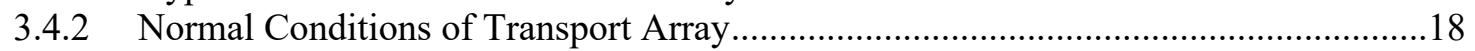

3.5 FINITE ARRAY CALCULATIONS FOR VARIOUS ${ }^{235}$ U ENRICHMENTS.....................20

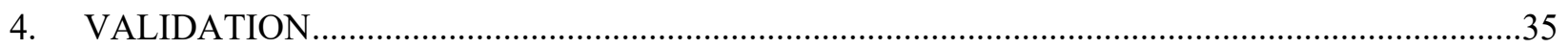

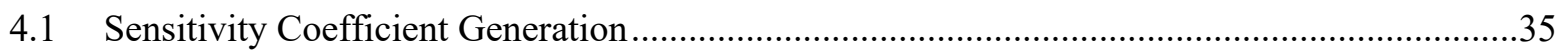

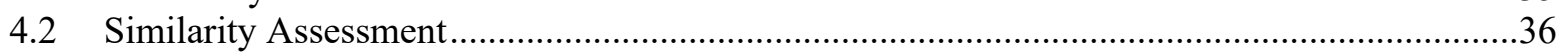

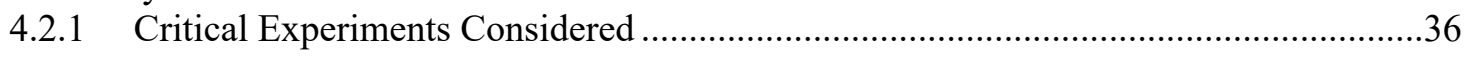

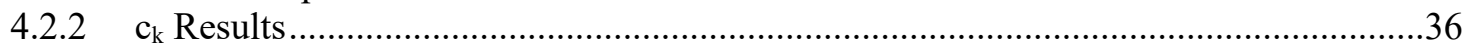

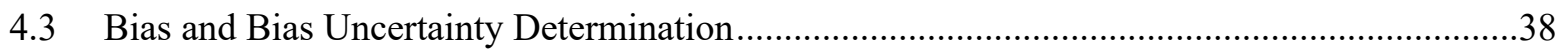

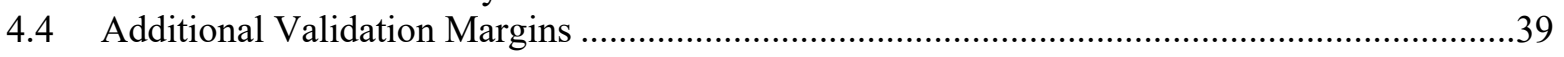

$4.5 c_{\mathrm{k}}$ COMPARISONS BETWEEN SINGLE CYLINDER MODELS .....................................40

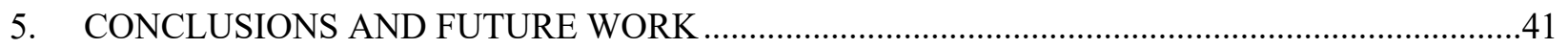

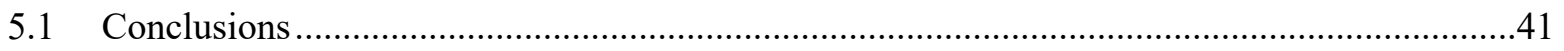

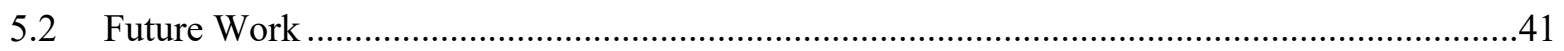

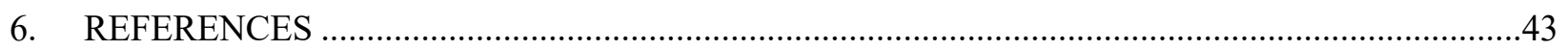

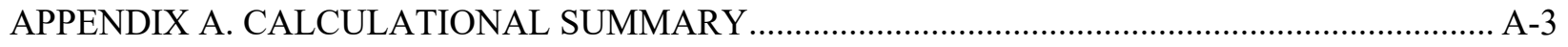





\section{FIGURES}

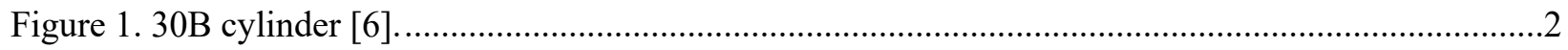

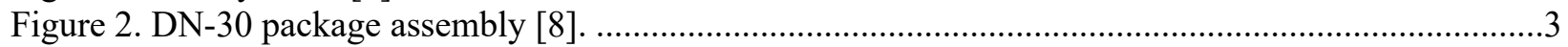

Figure 3. KENO-VI model of a single 30B cylinder with overpack and full water reflection...................10

Figure 4. $k_{\text {eff }}$ values as a function of $\mathrm{UF}_{6}$ enrichment and $\mathrm{UF}_{6}$ density for single $30 \mathrm{~B}$ cylinders

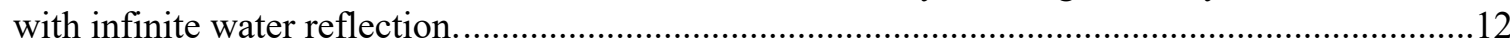

Figure $5 . k_{\text {eff }}$ values as a function of $\mathrm{UF}_{6}$ enrichment and $\mathrm{UF}_{6}$ density for single $30 \mathrm{~B}$ cylinders

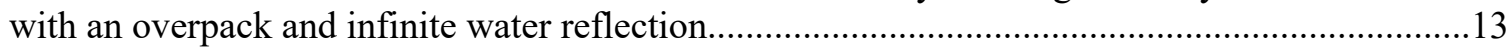

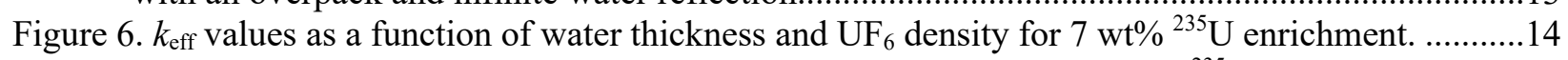

Figure 7. $k_{\text {eff }}$ values as a function of water thickness and $\mathrm{UF}_{6}$ density for $10 \mathrm{wt} \%{ }^{235} \mathrm{U}$ enrichment. ...........14

Figure $8 . k_{\text {eff }}$ values as a function of ${ }^{235} \mathrm{U}$ and $\mathrm{UF}_{6}$ density for a $1 \mathrm{~cm}$ water film around the

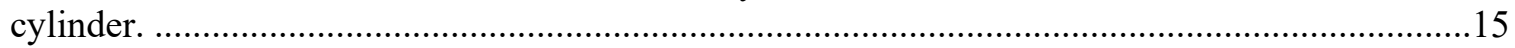

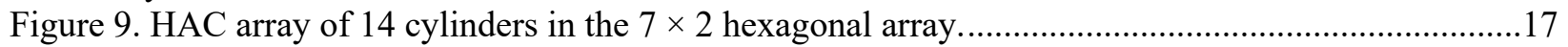

Figure 10. HAC array showing locations of HUR spheres within the $30 \mathrm{~B}$ cylinders. ..............................17

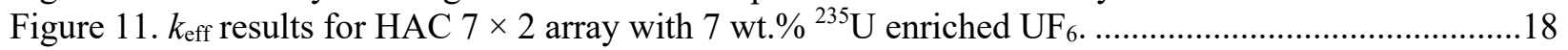

Figure 12. NCT array of 38 cylinders in $19 \times 2$ hexagonal array (left) and showing HUR spheres

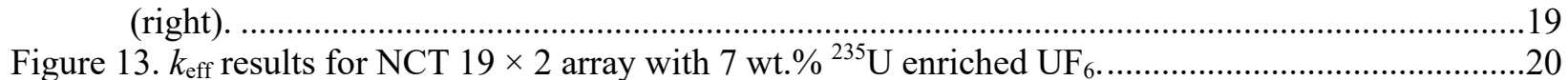

Figure 14. $k_{\text {eff }}$ results for HAC $7 \times 2$ array with variable ${ }^{235} \mathrm{U}$ enrichments. .........................................21

Figure 15. $k_{\text {eff }}$ results for HAC $7 \mathrm{x} 1$ array with variable ${ }^{235} \mathrm{U}$ enrichments...........................................22

Figure 16. $k_{\text {eff }}$ results for HAC $7 \times 1$ array with variable ${ }^{235} \mathrm{U}$ enrichments and axially centered

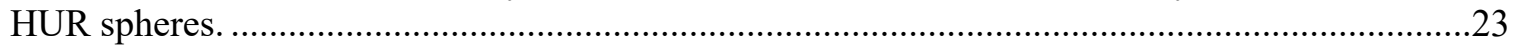

Figure 17. $3 \times 2$ HAC array with HUR sphere towards the adjacent cylinder ends...............................24

Figure 18. $k_{\text {eff }}$ results for HAC $3 \times 2$ array with variable ${ }^{235} \mathrm{U}$ enrichments and HUR spheres at

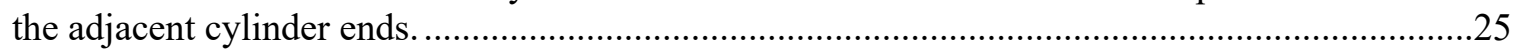

Figure 19. $3 \times 1$ HAC array with axially centered HUR spheres. .........................................................26

Figure $20 . k_{\text {eff }}$ results for HAC $3 \times 1$ array with variable ${ }^{235} \mathrm{U}$ enrichments and axially centered

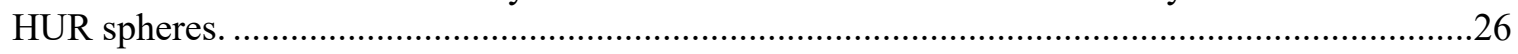

Figure $21.2 \times 2$ HAC array with axially centered HUR spheres. .....................................................27

Figure 22. $k_{\text {eff }}$ results for HAC $2 \times 2$ array with variable ${ }^{235} \mathrm{U}$ enrichments and axially centered

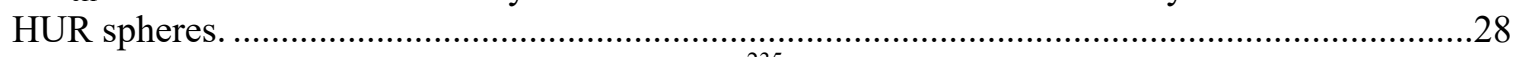

Figure 23. $k_{\text {eff }}$ results for HAC $2 \times 1$ array with variable ${ }^{235} \mathrm{U}$ enrichments and axially centered HUR spheres.

Figure $24 . k_{\text {eff }}$ results for HAC $1 \times 2$ array with variable ${ }^{235} \mathrm{U}$ enrichments and axially centered HUR spheres. .

Figure 25. $k_{\text {eff }}$ results for HAC $1 \times 2$ array with variable ${ }^{235} U$ enrichments and HUR spheres at the adjacent cylinder ends.

Figure 26. $k_{\text {eff }}$ results for HAC $1 \times 1$ array with variable ${ }^{235} \mathrm{U}$ enrichments and axially centered HUR sphere

Figure 27. $c_{k}$ values for all experiments compared to the HAC $7 \times 2$ array with 7 wt. $\%{ }^{235} \mathrm{U}$ enrichment.

Figure 28. $\mathrm{c}_{\mathrm{k}}$ Trending analysis plot for the HAC $7 \times 2$ array with $7 \mathrm{wt} . \% \mathrm{UF}_{6}$. 



\section{TABLES}

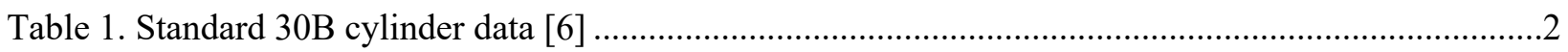

Table 2. $k_{\text {eff }}$ values for single 30B cylinders with infinite water reflection ..........................................11

Table 3. Values for single 30B cylinders with an overpack and infinite water reflection........................12

Table 4. $k_{\text {eff }}$ Values for infinite arrays with 7 wt. $\%{ }^{235} \mathrm{U}$ enrichment......................................................15

Table 5. $k_{\text {eff }}$ Values for infinite arrays with $10 \mathrm{wt.} \%{ }^{235} \mathrm{U}$ enrichment.................................................15

Table 6. $k_{\text {eff }}$ Values for infinite arrays with $1 \mathrm{~cm}$ water film around the cylinder ...................................15

Table 7. $k_{\text {eff }}$ Values for $7 \times 2$ array model with 7 wt. $\%{ }^{235} \mathrm{U}$ enrichment................................................18

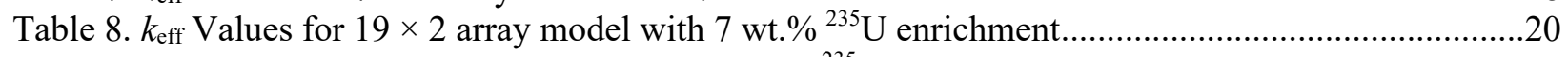

Table 9. $k_{\text {eff }}$ Values for $7 \times 2$ array model with variable ${ }^{235} \mathrm{U}$ enrichment ..............................................21

Table 10. $k_{\text {eff }}$ values for $7 \times 1$ array model with variable ${ }^{235} \mathrm{U}$ enrichment ...............................................22

Table 11. $k_{\text {eff }}$ Values for $7 \mathrm{x} 1$ Array Model with Variable ${ }^{235} \mathrm{U}$ Enrichment and axially centered

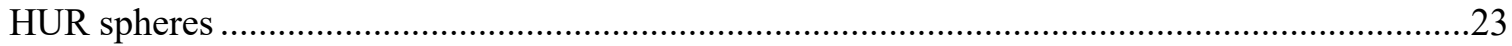

Table 12. $k_{\text {eff }}$ values for $3 \times 2$ array model with variable ${ }^{235} \mathrm{U}$ enrichment ...........................................25

Table 13 . $k_{\text {eff }}$ values for $3 \times 1$ array model with variable ${ }^{235} \mathrm{U}$ enrichment and axially centered

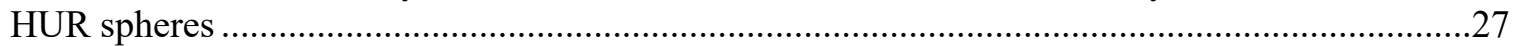

Table 14. $k_{\text {eff }}$ values for $2 \times 2$ array model with variable ${ }^{235} \mathrm{U}$ enrichment and axially centered HUR

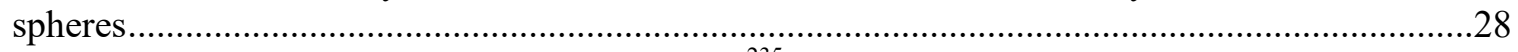

Table $15 . k_{\text {eff }}$ values for $2 \times 1$ array model with variable ${ }^{235} \mathrm{U}$ enrichment and axially centered HUR spheres

Table 16. $k_{\text {eff }}$ values for $1 \times 2$ array with variable ${ }^{235} \mathrm{U}$ enrichment and axially centered HUR spheres

Table 17. $k_{\text {eff }}$ values for $1 \times 2$ array with variable ${ }^{235} \mathrm{U}$ enrichments and HUR spheres at the adjacent cylinder ends

Table 18. $k_{\text {eff }}$ values for $1 \times 1$ array with variable ${ }^{235} \mathrm{U}$ enrichment and axially centered HUR

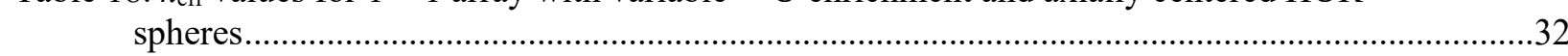

Table 19. $k_{\text {eff }}$ and EALF values for $1 \times 1$ arrays with different HUR considerations ................................33

Table 20. Nuclides with the highest sensitivities from the HAC $7 \times 2$ array with 7 wt. $\%{ }^{235} \mathrm{U}$

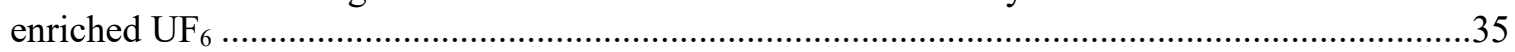

Table 21. Experiments with $c_{k}$ values in excess of 0.7 for the HAC $7 \times 2$ array with $7 \mathrm{wt} . \%{ }^{235} \mathrm{U}$

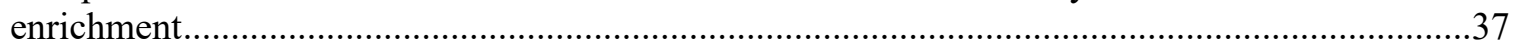

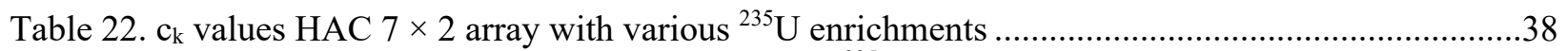

Table 23. $c_{k}$ values $1 \times 1$ array, no HUR present, various ${ }^{235} \mathrm{U}$ enrichments ........................................40

Table 24. $c_{k}$ values $1 \times 1$ array, HUR sphere, various ${ }^{235} U$ enrichments ............................................40

Table 25. $c_{\mathrm{k}}$ values $1 \times 1$ array, HUR sphere with spherical HF shell, various ${ }^{235} \mathrm{U}$ enrichments...............40

Table 23. Maximum $k_{\text {eff }}$ values for select ${ }^{235} \mathrm{U}$ enrichments in varying-size arrays .................................41 



\section{ABBREVIATIONS}

1D one-dimensional

2D two-dimensional

3D three-dimensional

ANSI American National Standards Institute

CE continuous energy

CFR US Code of Federal Regulations

$\mathrm{CoC} \quad$ certificate of compliance

CSAS Criticality Safety Analysis Sequence

CSI Criticality Safety Index

DoD US Department of Defense

DOT US Department of Transportation

EALF energy of the average lethargy causing fission

ENDF Evaluated Nuclear Data File

GAIN Gateway for Accelerated Innovation in Nuclear

HAC hypothetical accident conditions

HALEU high-assay low-enriched uranium

HUR hydrogenated uranium residue

ICSBEP International Criticality Safety Benchmark Evaluation

IAEA International Atomic Energy Agency

$k_{\text {eff }} \quad$ k-effective

LWR light-water reactor

MG multigroup

NEI Nuclear Energy Institute

NCT normal conditions of transport

NRC US Nuclear Regulatory Commission

PSP protective structural packaging

SAR safety analysis report

SARP safety analysis report for packaging

SDF sensitivity data file

S/U sensitivity and uncertainty

TSUNAMI Tools for Sensitivity and Uncertainty Analysis Methodology Implementation USL upper subcritical limit

USPS US Postal Service 



\section{ACKNOWLEDGEMENTS}

Support for this work was provided by the Gateway for Accelerated Innovation in Nuclear (GAIN) Initiative, in collaboration with the Nuclear Energy Institute, NRC Office of Nuclear Regulatory Research and the Office of Nuclear Material Safety and Safeguards. The authors would like to thank many ORNL staff members for their feedback on the contents and presentation in this report. 



\section{EXECUTIVE SUMMARY}

Commercial light-water reactor (LWR) operators and fuel vendors are pursuing advancements in fuel and reactor design that include increasing ${ }^{235} \mathrm{U}$ enrichment from low enrichment $\left(<5 \mathrm{wt} . \%{ }^{235} \mathrm{U}\right)$ to lowenriched uranium $+(\mathrm{LEU}+)\left(10 \mathrm{wt} . \%>{ }^{235} \mathrm{U}>5 \mathrm{wt} . \%\right)$ and high-assay low-enriched uranium (HALEU) (20 wt. $\left.\%>{ }^{235} \mathrm{U}>10 \mathrm{wt} . \%\right)$. These advancements will necessitate the ability to transport LEU+ and HALEU fuel materials. Assessment of Existing Transportation Packages for Use with HALEU

(ORNL/TM-2020/1725 [1]) assesses the potential to use currently licensed transportation packages for the transportation of HALEU by evaluating a representative package for each uranium fuel form category (for example, oxide and/or metal in fuel assemblies, fuel pins, powder, pellets, and uranium hexafluoride $\left[\mathrm{UF}_{6}\right]$.) This report expands on the $\mathrm{UF}_{6}$ analysis.

This work was performed under a Memorandum Purchase Order (SOW-17759) and was requested through the Gateway for Accelerated Innovation in Nuclear (GAIN) Initiative. GAIN's primary objective is to provide the nuclear industry and entrepreneurs with a single point of access to the national laboratory system and its expertise and research tools. This study was performed in collaboration with representatives from the Nuclear Energy Institute (NEI) and the US Nuclear Regulatory Commission (NRC).

The $\mathrm{UF}_{6}$ study described in the ORNL assessment [1] evaluated the DN-30 package $[2,3]$. The primary objectives of this effort were to determine whether the existing package design could be used to transport (and store) $30 \mathrm{~B}$ cylinders containing $\mathrm{UF}_{6}$ in the LEU+ and HALEU enrichment range, what limitations might be required (i.e., smaller maximum transportation array size), and whether adequate applicable benchmark critical experiments could be identified for computer code validation. The study described here extends the DN-30 package work.

The ORNL assessment analyzed arrays at certain ${ }^{235} \mathrm{U}$ enrichments under hypothetical accident conditions. Arrays considered include a $7 \times 2$ array of cylinders with $5.8 \mathrm{wt} . \%{ }^{235} \mathrm{U}$, a $3 \times 2$ array of cylinders with 6.7 wt. $\%{ }^{235} \mathrm{U}, 1 \times 2$ array of cylinders with $9.5 \mathrm{wt} . \%{ }^{235} \mathrm{U}$, and a $1 \times 1$ array with 12.5 wt. $\%{ }^{235} \mathrm{U}$. This analysis considers fully reflected single cylinders, with and without a generic overpack, infinite arrays, and finite arrays $(7 \times 2,7 \times 1,3 \times 2,3 \times 1,2 \times 2,2 \times 1,1 \times 2$, and $1 \times 1$, all with enrichments ranging from 6 to $20 \mathrm{wt} . \%)$. This analysis also discusses applicable margins based on validation results.

Based on the results documented in this report, $30 \mathrm{~B}$ cylinders with $\mathrm{UF}_{6}$ enriched up to $10 \mathrm{wt} . \%{ }^{235} \mathrm{U}$ are expected to be able to be proven safe to store and ship with some configuration control. 



\section{INTRODUCTION}

Commercial light-water reactor (LWR) operators and fuel vendors are pursuing advancements in fuel and reactor design that include increasing ${ }^{235} \mathrm{U}$ enrichment from low enrichment $\left(<5 \mathrm{wt} . \%{ }^{235} \mathrm{U}\right)$ to lowenriched uranium $+(\mathrm{LEU}+)\left(10 \mathrm{wt} . \%>{ }^{235} \mathrm{U}>5 \mathrm{wt} . \%\right)$ and high-assay low-enriched uranium (HALEU) (20 wt. $\%>{ }^{235} \mathrm{U}>10 \mathrm{wt} . \%$ ). These advancements will necessitate the ability to transport HALEU fuel materials. Assessment of Existing Transportation Packages for Use with HALEU (ORNL/TM-2020/1725 [1]) assesses the potential to use currently licensed transportation packages for the transportation of HALEU by evaluating a representative package for each uranium fuel form category (for example, oxide and/or metal in fuel assemblies, fuel pins, powder, pellets, and uranium hexafluoride [UF 6 ].) This report expands on the $\mathrm{UF}_{6}$ analysis.

This work was performed under a Memorandum Purchase Order (SOW-17759) and was requested through the Gateway for Accelerated Innovation in Nuclear (GAIN) Initiative. GAIN's primary objective is to provide the nuclear industry and entrepreneurs with a single point of access to the national laboratory system and its expertise and research tools. This study was performed in collaboration with representatives from the Nuclear Energy Institute (NEI) and the US Nuclear Regulatory Commission (NRC).

The $\mathrm{UF}_{6}$ study described in the ORNL assessment [1] evaluated the DN-30 package $[2,3]$. The primary objectives of this effort were to determine whether the existing package design could be used to transport $30 \mathrm{~B}$ cylinders containing $\mathrm{UF}_{6}$ in the HALEU enrichment range, what limitations might be required (i.e., smaller maximum transportation array size), and whether adequate applicable benchmark critical experiments could be identified for computer code validation. The study described here extends the DN30 package work. The ORNL assessment analyzed arrays at certain ${ }^{235} \mathrm{U}$ enrichments under hypothetical accident conditions. Arrays considered include a $7 \times 2$ array of cylinders with $5.8 \mathrm{wt} . \%{ }^{235} \mathrm{U}$, a $3 \times 2$ array of cylinders with $6.7 \mathrm{wt} . \%{ }^{235} \mathrm{U}, 1 \times 2$ array of cylinders with $9.5 \mathrm{wt} . \%{ }^{235} \mathrm{U}$, and a $1 \times 1$ array with 12.5 wt. $\%{ }^{235} \mathrm{U}$. This analysis considers fully reflected single cylinders, with and without a generic overpack, infinite arrays, and finite arrays $(7 \times 2,7 \times 1,3 \times 2,2 \times 2,2 \times 1,1 \times 2$, and $1 \times 1$, all with enrichments ranging from 6 to $20 \mathrm{wt} . \%$ ). This analysis also discusses applicable margins based on validation results.

Section 1 describes the scope of work, the transportation package (30B cylinder and overpack container), and existing transportation regulations. The computer codes and nuclear data used are discussed in Section 2. Section 3 contains the calculation analysis including reflected single cylinders with and without an overpack, infinite arrays, and finite arrays, all with ${ }^{235} \mathrm{U}$ enrichments ranging from 6 to $20 \mathrm{wt} . \%$. The calculation validation is addressed in Section 4, and Section 5 discusses conclusions and future work.

\subsection{SCOPE OF WORK}

The scope of this work included evaluation of $30 \mathrm{~B}$ cylinders containing $\mathrm{UF}_{6}$ with ${ }^{235} \mathrm{U}$ enrichments ranging from 6 to $20 \mathrm{wt} . \%$ in a representative transportation overpack in comparison with the complete set of regulatory requirements. This required analysis of a single package, an array of packages under normal conditions of transport (NCT), and an array of packages under hypothetical accident conditions (HAC).

The SCALE [4] code suite was used for this criticality safety analysis. The KENO-VI / Criticality Safety Analysis Sequence 6 (CSAS6) was used to determine subcritical array sizes at the various levels of enrichment. The Tools for Sensitivity and Uncertainty Analysis Methodology Implementation (TSUNAMI [5]) sequence (a suite of sensitivity and uncertainty [S/U] tools) was used to identify applicable benchmark critical experiments and to approximate the code bias and bias uncertainty for limiting configurations. 


\subsection{DESCRIPTION OF TRANSPORATION PACKAGE AND CONTENTS}

The American National Standard for Nuclear Materials - Uranium Hexafluoride - Packagings for Transport (American National Standards Institute [ANSI] N14.1-2019) [6] provides criteria for packagings used for $\mathrm{UF}_{6}$ transport. The largest size cylinder currently approved for the maximum ${ }^{235} \mathrm{U}$ enrichment of $5 \mathrm{wt} . \%$ is the $30 \mathrm{~B}$ cylinder (or the $30 \mathrm{C}-30 \mathrm{~B}$ cylinder, retrofitted with a credited water-tight valve protective cover assembly). Standard cylinder data from ANSI N14.1-2019 are provided in Table 1. Figure 1 shows the longitudinal section view as presented in ANSI N14.1-2019.

Table 1. Standard 30B cylinder data [6]

\begin{tabular}{lc}
\hline Cylinder data & Value \\
\hline Material of construction & Steel \\
Nominal diameter & $30 \mathrm{in} .(76.2 \mathrm{~cm})$ \\
Minimum volume & $26 \mathrm{ft}^{3}\left(0.736 \mathrm{~m}^{3}\right)$ \\
Maximum fill limit & $5,020 \mathrm{lb}(2,277 \mathrm{~kg})$ \\
Nominal cylinder wall thickness & $1 / 2$ in. $(1.27 \mathrm{~cm})$ \\
Minimum cylinder wall thickness & $5 / 16$ in. $(0.79375 \mathrm{~cm})$ \\
Maximum heel quantity & $25.0 \mathrm{lb}(11.3 \mathrm{~kg})$ \\
\hline
\end{tabular}

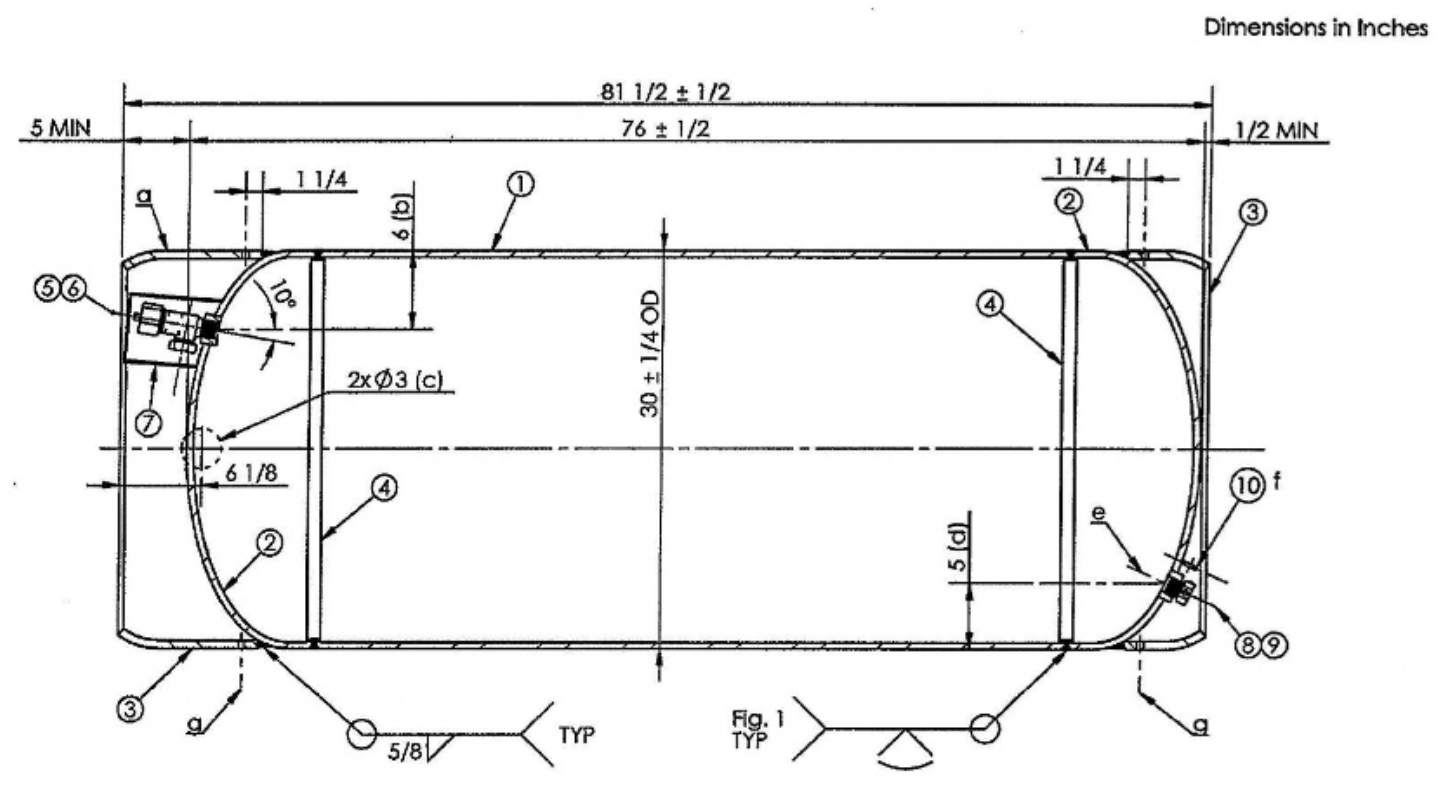

Figure 1. 30B cylinder [6].

For over-the-road transport, the 30B cylinder is placed inside a protective structural packaging (PSP - the overpack). The DN-30 by Daher Nuclear Technologies [2] and the UX-30 by Columbia Hi Tech [7] are two examples of overpacks. There are no specific requirements for size, shape, or material for the overpacks, except that they must be designed to protect the 30B cylinder under all test conditions required for over-the-road certification $[9,10]$, as described in Section 1.3 below. Typically, an overpack consists of two thin metal shells with a type of energy-absorbing, insulating foam material. Figure 2 is an illustration of the DN-30 package. 


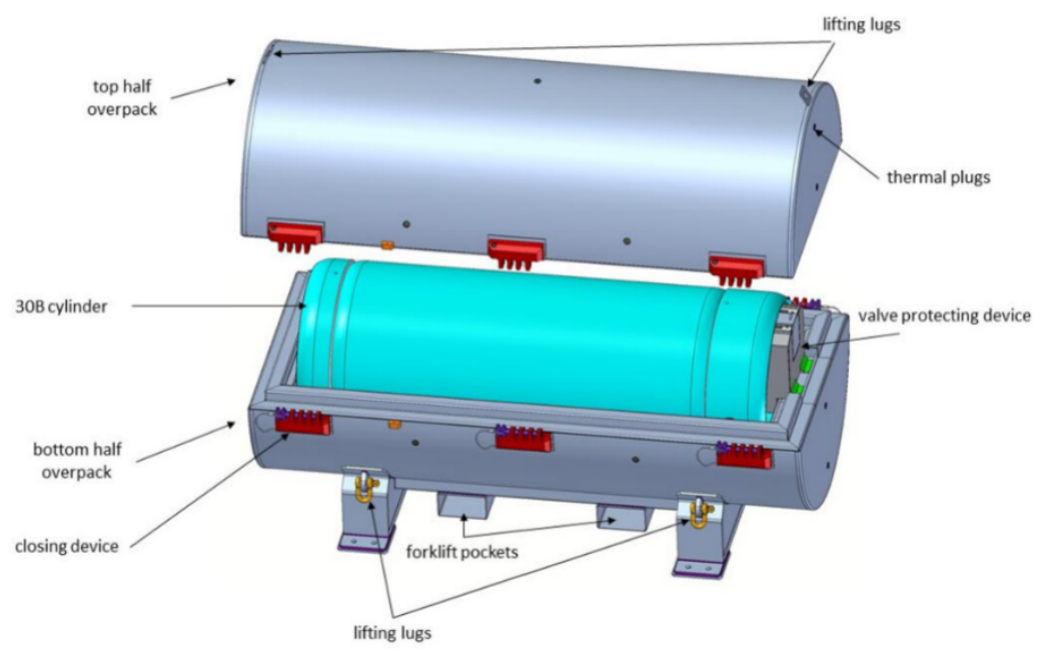

Figure 2. DN-30 package assembly [8].

The $\mathrm{UF}_{6}$ contents in the $30 \mathrm{~B}$ cylinder are limited to a maximum allowed loading of 2,277 $\mathrm{kg}$, which includes up to $11.4 \mathrm{~kg}$ of hydrogenated uranium residue (HUR, or heels). The minimum $\mathrm{UF}_{6}$ purity is $99.5 \%$, which correlates to a maximum $\mathrm{H} / \mathrm{U}$ ratio of 0.088 . For modeling purposes, the impurities were conservatively modeled as pure $\mathrm{HF}$, consistent with existing analyses [2, 7].

\subsection{REGULATORY BASIS REVIEW}

Regulating the transportation of radioactive materials involves the US Department of Transportation, the NRC, the International Atomic Energy Agency (IAEA), the Department of Defense (DoD), and the US Postal Service (USPS). A transportation package's safety analysis report for packaging (SARP) documents the evaluation of the container and its contents and demonstrates safety compliance in accordance with applicable regulations. Transportation regulations are codified in the US Code of Federal Regulations (CFR) [9, 10].

This report does not address how an increase in the allowed $\mathrm{UF}_{6}$ enrichment affects compliance with all of these transportation regulations. It only addresses those requirements related to the proof of criticality safety for transport found in CFR Title 10, Energy, Chapter 1, "Nuclear Regulatory Commission," Part 71, "Packaging and Transportation of Radioactive Material" [9]. The specific sections of 10 CFR Part 71 considered herein include $§ 71.55$, "General Requirements for Fissile Material Packages," §71.59, "Standards for Arrays of Fissile Material Packages", §71.71, "Normal Conditions of Transport," and $\S 71.73$, "Hypothetical Accident Conditions."

In general, 10 CFR 71.55 addresses the subcriticality of a single package, and it describes the conditions and configurations that must be considered. Once such condition is that a package must remain subcritical if water leaks into the containment system (b). This section also includes an exception (g) to this requirement for $\mathrm{UF}_{6}$ having an enrichment of up to $5 \mathrm{wt} . \%$ (under certain conditions). This study assumes that this exception will be extended for $\mathrm{UF}_{6}$ in the HALEU range of enrichments.

10 CFR 71.59, "Standards for Arrays of Fissile Material Packages," addresses the criticality safety for arrays of packages that may be transported in a single conveyance through the use of the Criticality Safety Index (CSI). The CSI is used to determine how many packages may be shipped in a nonexclusive or 
exclusive use conveyance. A package is assigned a CSI value based on the array size that the SARP demonstrates to be subcritical under the prescribed conditions (NCT and HAC). The SARP analysis derives array sizes based on the number $N$, such that five times $N$ undamaged packages (packages that must survive the normal conditions of transport tests described in 10 CFR 71.71) - with nothing between the packages - is subcritical, and two times $N$ damaged packages (packages that must survive the hypothetical accident conditions of transport tests described in 10 CFR 71.73 with optimum interspersed moderation) remain subcritical. Damaged packages typically have slightly different configurations compared to undamaged packages due to their condition after being subjected to the respective tests described in 10 CFR 71.71 and 71.73. A package's CSI is then the number 50 divided by the smaller $N$ [9]. If the NCT $N$ is different from the HAC $N$, the smaller $N$ is used since it results in a conservative, more restrictive CSI. An infinite array results in a CSI of 0.0. Package(s) with a CSI sum that is equal to or less than 50 may be shipped in a nonexclusive or exclusive use conveyance. Package(s) with a CSI sum greater than 50 but less than or equal to 100 must be shipped in an exclusive use conveyance. 


\section{COMPUTER CODES AND NUCLEAR DATA}

This section includes a general overview of the SCALE codes and data used in the calculations, along with a description of the methods used in validation. A more complete description of the codes and data is available in the SCALE manual [4].

\subsection{CSAS6}

\subsubsection{Multigroup Cross Section Processing}

The CSAS6 sequence uses the XSProc module to process multigroup (MG) cross sections and to provide the appropriate resonance corrections to the group-average cross section values used in the threedimensional (3D) transport calculation. The corrections are necessary to account for the impact of resonances on group-average cross sections. The impact of an individual resonance on the group-average cross section is determined by the size of the resonance, the isotopic number density of the resonance material, and the flux level at the energy of the resonance. Simplified one-dimensional (1D) models are used to solve representative unit cell problems to approximate the energy-dependent flux in the full transport problem. The flux from the 1D unit cell calculation is used to collapse the cross section data to a set of group-average values that can be used in a MG transport calculation. When appropriate, lattice effect corrections are also applied to the cross sections.

XSProc performs resonance self-shielding calculations based on the Bondarenko method with the methods previously implemented in the BONAMI module. The Bondarenko method is typically used in the unresolved resonance energy range and is based on the narrow resonance approximation. The Bondarenko approach is simple and fast, and it is most accurate and useful at high energies. It is therefore well suited and appropriate for use in the unresolved energy range.

In the resolved resonance range, XSProc generates a neutron spectrum based on a transport theory solution in one or two dimensions using a combination of MG and pointwise data. This function was previously performed by the CENTRM module. As mentioned above, most of these calculations are performed using the 1D discrete ordinates method. In the CSAS sequences, the detailed flux solutions are used to generate resonance self-shielded MG cross sections. The energy mesh is typically very fine, on the order of 10,000 to 70,000 points, and it provides precise treatment in the resolved resonance range. This detailed treatment also allows for the incorporation of effects of overlapping resonances from different nuclides in the same mixture. With these techniques, the energy fidelity of continuous energy (CE) treatment is preserved, even when performing MG calculations.

\subsubsection{KENO-VI}

KENO-VI solves the k-effective $\left(k_{\text {eff }}\right)$ eigenvalue problem in three dimensions using the Monte Carlo method. KENO-VI has been used for this purpose in the SCALE system for many years and has been employed in criticality safety analyses at sites around the world. KENO-VI can represent systems of significant geometric complication using a set of predefined geometry objects specified to define regions. In addition, generalized quadratic surfaces can be supplied to define regions of space that are not well described by any of the predefined shapes. KENO-VI also supports rotation and therefore allows bodies to be oriented in directions that are not parallel to the major coordinate axes. The range of arrays that can be used includes cuboidal arrays, triangular or hexagonal arrays, and dodecahedral arrays. Intersecting geometry definitions can be supplied for exact modeling of features such as pipe junctions. 


\subsection{TSUNAMI}

The SCALE S/U analysis sequences, or TSUNAMI, quantify the predicted change in $k$ eff, reaction rates, or the reactivity differences that result from changes in the energy-dependent, nuclide-reaction-specific cross section data, whether CE or MG. The sensitivity data are useful because they indicate the differences in system $k_{\text {eff }}$ that would result from small changes in the underlying nuclear data. The sensitivity data can be used to quantify nuclear data uncertainties and to assess similarity between pairs of systems based on the shared nuclear data-induced uncertainty. This shared data uncertainty is expected to be a strong indicator of applicable benchmark experiments for use in validation of neutron transport methods. The two modules used in this report are TSUNAMI-3D and TSUNAMI-IP, both of which are described in more detail below.

\subsubsection{TSUNAMI-3D}

The TSUNAMI-3D sequence is used for 3D cross section sensitivity generation in S/U analysis. The sequence provides automated processing of material input and cross section data, neutron transport, calculation of sensitivity coefficients (i.e., sensitivity of $k_{\text {eff }}$ to nuclear data variation), and determination of uncertainty in $k_{\text {eff }}$ caused by cross section covariances. Sensitivities based on the fluxes calculated by KENO are written to a sensitivity data file (SDF) containing the nuclide-, energy-, and reaction-dependent $k_{\text {eff }}$ sensitivity coefficients. These energy-dependent sensitivities are determined for each nuclide in the model using first-order perturbation theory. SCALE 6.2.4 can generate sensitivity data using either CE or MG methods, but only MG calculations are used or reported in this work. Further details of the MG sensitivity calculation methodologies are available in Section 6 of the SCALE 6.2.4 manual [4].

\subsubsection{TSUNAMI-IP}

The TSUNAMI-IP sequence provides a range of S/U analysis capabilities in SCALE 6.2.4 [4]. It is used in this work primarily to calculate the integral parameter $\mathrm{c}_{\mathrm{k}}$ for critical experiment selection. These calculations rely on nuclear covariance data; the SCALE 6.2.4 covariance data used in this work are discussed below in Section 2.4.1.1. Additional details are available in Section 6.5.1 of the SCALE 6.2.4 manual.

TSUNAMI-IP is used to evaluate the similarity of critical experiments and application models and to determine uncertainties in system reactivity due to cross section covariance data. The similarity metric calculated here is $\mathrm{c}_{\mathrm{k}}$, which is the correlation coefficient of the effect of nuclear data uncertainty on $k_{\text {eff }}$ of the application and experiment. $c_{k}$ can be determined by dividing the covariance between the experiment and application by the product of the uncertainties in the experiment and the application [5], as shown in Eq. (1),

$$
c_{k}=\frac{\sigma_{\mathrm{App} \operatorname{Exp}}^{2}}{\sigma_{\mathrm{App}} \sigma_{\operatorname{Exp}}},
$$

where: $c_{\mathrm{k}}$ is the similarity between an application and an experiment,

$\sigma_{\text {AppExp }}^{2}$ is the covariance between the application and the experiment,

$\sigma_{\mathrm{App}}$ is the uncertainty in the application $k_{\mathrm{eff}}$ resulting from cross section covariances

(uncertainties), and

$\sigma_{\text {Exp }}$ is the uncertainty in the experiment $k_{\text {eff }}$ caused by cross section covariances (uncertainties).

In essence, $\mathrm{c}_{\mathrm{k}}$ is the fraction of the cross section-induced uncertainty in $k_{\text {eff }}$ that is shared by two systems. A $c_{k}$ value of 1 indicates that the $k_{\text {eff }}$ values for two compared systems would be affected identically by 
nuclear data errors, which are the primary contributors to the computational method's bias. A $c_{k}$ value $\geq$ 0.8 is considered to have a high enough degree of similarity to be acceptable for use in validation studies [5]; this value is used as the cutoff for the acceptably similar experiments identified in Section 4.2 below.

TSUNAMI-IP can also generate additional inputs to be used with the Upper Subcritical Limit Statistics (USLSTATS) program, a statistical analysis program distributed with SCALE. USLSTATS can then be used to perform a trending analysis on the $c_{k}$ value (or any other parameter suitable for trending analysis) to calculate a bias and bias uncertainty.

\subsection{SAMPLER}

Sampler (Section 6.7 of [4]) is referred to as a super-sequence within SCALE because it wraps around other sequences, such as CSAS, and perturbs inputs. Sampler has two modes: (1) uncertainty quantification via random sampling, and (2) parametric analysis via sweeping through parameter space. In this work, the second option was used extensively to explore parameter space for $\mathrm{UF}_{6}$ enrichment, along with many of the other variables impacting system reactivity. These additional variables include the $\mathrm{UF}_{6}$ density and interstitial water film thicknesses. Sampler creates entire SCALE inputs - in this case CSAS6 inputs - with each combination of variable parameters, allowing for a single user's input to generate a large number of SCALE inputs covering the entire desired space. Further discussion of similar analyses using the Sampler parametric capability for nuclear criticality analyses is presented in a paper by Marshall et al. [11].

\subsection{NUCLEAR DATA}

Two different types of nuclear data are used in this work: (1) best-estimate values of interaction cross sections, neutron multiplicity, and fission neutron energy distribution, and (2) covariance data related to the uncertainties in these data. The best-estimate values are used in neutron transport calculations to determine system $k_{\text {eff }}$ values. The covariance data, as discussed previously, are used to assess nuclear data induced uncertainty and therefore system similarity assessments.

\subsubsection{2-Group Library Based on ENDF/B-VII.1 (v7.1-252)}

The SCALE system is distributed with several cross section libraries, as documented in [4]. This work is based on an MG neutron library for criticality safety and reactor physics containing 252 energy groups, aliased in SCALE input as v7.1-252. The 252-group structure, based on Evaluated Nuclear Data File (ENDF)/B-VII.1 [4] was developed to adequately capture spectral and temperature effects important in reactor systems and was processed with newer, improved procedures compared to those in prior libraries based on ENDF/B-VII.0 [4]. One of these improvements is the increase of the thermal scattering cutoff from 3 to $5 \mathrm{eV}$. This improvement is relevant for many of the calculations performed in this work because of the intermediate neutron energy spectrum present in the system. The base weighting function has also been updated. This library's performance is documented in the SCALE 6.2.2 validation report [12] for a wide range of systems. No changes were made to the code or data in the upgrades from SCALE versions 6.2.2 and 6.2.4 that would have significant impacts on the performance of the code and the nuclear data library.

\subsubsection{Covariance library}

The uncertainty in the computed $k_{\text {eff }}$ values that results from the uncertainties in the cross section data is used to assess the similarity of application models and benchmark experiments for validation. The cross section uncertainties are obtained from the SCALE 56-group covariance data library-a comprehensive library with 401 materials in the SCALE 56-group energy structure based on ENDF/B-VII.1 [4]. The 
SCALE covariance library data correspond to relative uncertainties assembled from a variety of sources, including evaluations from ENDF/B-VII.1, ENDF/B-VI, JENDL-4.0, and many approximated uncertainties from a collaborative project performed by Brookhaven National Laboratory, Los Alamos National Laboratory, and Oak Ridge National Laboratory (ORNL) [13]. Even with this level of curation, no covariance data are available for some energy ranges for some nuclide/reaction pairs, and some data for threshold reactions can be unrealistic near the threshold value. These issues are identified in TSUNAMI-IP, and the flawed data are patched with default covariance values. The default values are assumed to be fully correlated with the thermal, intermediate, and fast regions but uncorrelated between the energy ranges. The default value used for the thermal range is $5 \%$; for the intermediate range it is $10 \%$, and for the fast range it is $40 \%$. These default values are expected to be used only for a limited number of groups for a limited number of nuclide/reaction pairs and should not play a significant role in $\mathrm{c}_{\mathrm{k}}$ calculations.

There is no "true" uncertainty that can be defined unambiguously for nuclear data. While differences in nuclear data evaluations directly impact calculations that can be affirmed by comparisons with benchmark experiments, it is more difficult to quantify the reliability of uncertainty estimates. In general, the SCALE covariance library should provide a conservative assessment of the data uncertainties' impact on $k_{\text {eff, }}$ because the ENDF/B-VII.1 covariance data are not adjusted in the same way as the best-estimate data. Therefore, critical experiment benchmarks are used to tune the best-estimate evaluation of the cross sections, but this additional information is ignored in the assessment of uncertainties [14]. Nevertheless, the SCALE covariance library is deemed a reasonable representation of the nuclear data uncertainties. 


\section{CRITICALITY SAFETY ANALYSIS}

\subsection{MODEL DESCRIPTION}

Transportation regulations [9] require evaluation of a single package in isolation under NCT and HAC and package arrays under NCT and HAC analysis. This evaluation considered increased enrichments for all of these configurations.

The nonproprietary DN30 SARP [2] does not provide sample inputs or sufficient details to identically replicate the calculational models. Likewise, the UX30 SARP [7] does not provide sample inputs. The models for this evaluation were based on the HAC models developed for ORNL's Assessment of Existing Transportation Packages for Use with HALEU (ORNL/TM-2020/1725) [1]. Key aspects of the models include:

- The $30 \mathrm{~B}$ cylinder volume is maximized by using the minimum wall thickness and the maximum cylinder dimensions with the cylinder modeled as carbon steel (SCALE standard material carbonsteel).

- $\mathrm{UF}_{6}$ is modeled with a purity of $99.5 \mathrm{wt} . \% \mathrm{UF}_{6}$ containing $0.5 \mathrm{wt} . \% \mathrm{HF}(\mathrm{H} / \mathrm{U}$ of 0.88$)$, with varying densities.

- Overpacks are typically made of two thin metal shells with a type of energy-absorbing insulating foam material in between and can be cylindrical or rectangular in shape. The overpack is assumed to collapse into close proximity to the 30B cylinder wall (no foam material) for modeling purposes. As in the DN-30 analysis, only the overpack's stainless-steel walls were modeled in this analysis, resulting in a combined steel thickness of $0.5 \mathrm{~cm}$ as a right circular cylinder around the 30B cylinder (SCALE standard material SS304). This generic overpack model of a close-fitting right circular cylinder does not credit a specific overpack design with the presence of the inner foam-like material or the full spacing provided by the overpack. The exact overpack shape, shell thicknesses, and foam-like material composition are expected to vary between manufacturers/owners, and the foam-like material composition may be proprietary.

- Modeling conservatisms include removing all of the foam material and the spacing it provides between $30 \mathrm{~B}$ cylinders. Adding foam material and/or crediting the spacing provided would decrease the interaction between cylinders.

A cutaway rendering of a single 30B cylinder with a generic overpack is shown in Figure 3. Consistent with the DN-30 analysis, single package models do not include HUR. The dark blue region on the interior of the cylinder is the $\mathrm{UF}_{6}$, the aqua colored area is the carbon steel wall of the cylinder, the red cylinder outline is the overpack, the gray indicates the gap between the 30B cylinder and the overpack (modeled as void here), and the yellow region is the full water reflection outside the overpack. 

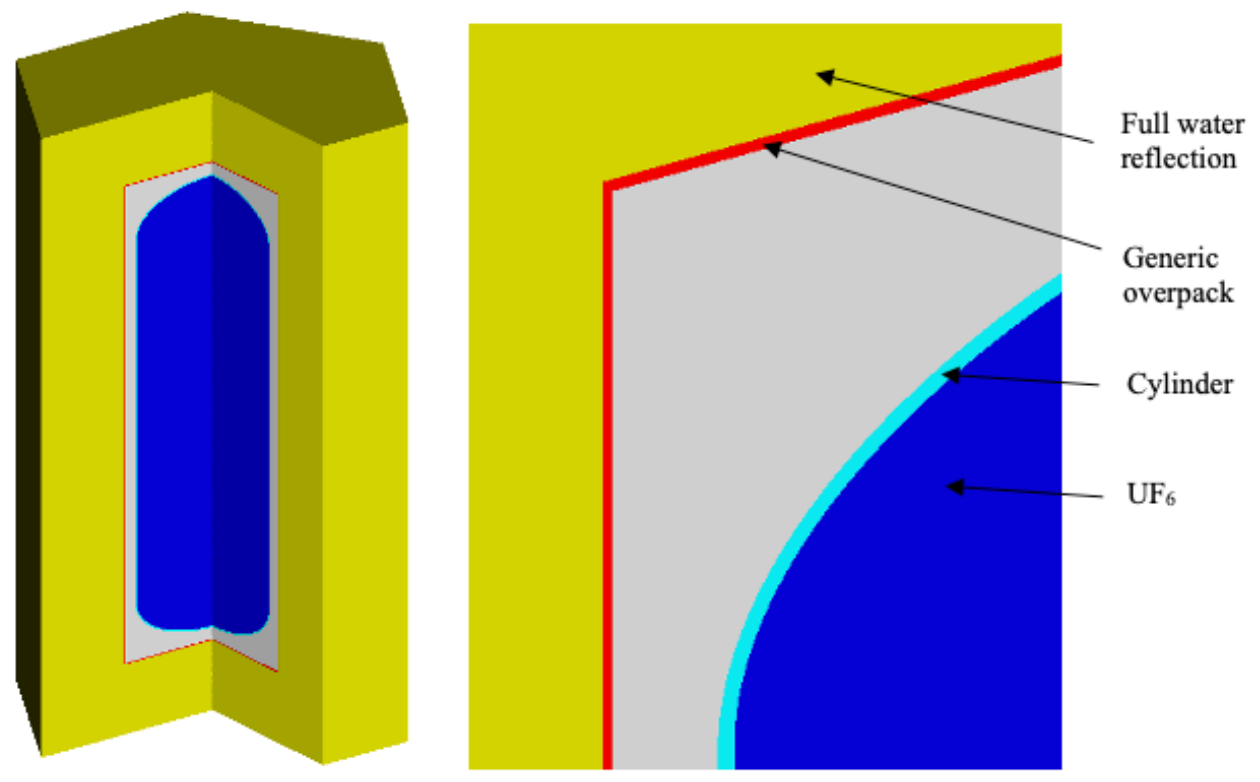

Figure 3. KENO-VI model of a single 30B cylinder with overpack and full water reflection.

The consideration of HUR in the 30B cylinder model has evolved over the years. The 1991 analysis supporting the current UX30 safety basis [15] does not specifically model any HUR in the cylinders; the DN-30 analysis considers HUR in the array configurations. Recently published papers on the nature of these residues are listed and described below:

- Begue, L., Milin, M., Caplin, G., and Evo, S., "Nuclear Criticality Safety of Enriched UF 6 Cylinders," PATRAM 2013: describes how the formation of limited hydrated complexes of $\mathrm{UO}_{2} \mathrm{~F}_{2}\left(\mathrm{UO}_{2} \mathrm{~F}_{2} * X \mathrm{H}_{2} \mathrm{O}\right)$ were observed in different experiments, with the $\mathrm{H} / \mathrm{U}$ ratio depending on conditions in the fuel cycle facilities and during transport (varying waters of hydration, $X$ ), with a maximum $\mathrm{H} / \mathrm{U}$ ratio assumed to be less than 11 [16].

- O’Connor, G., "Regulatory Criticality Safety Review of Uranium Hexafluoride Transport Package Applications," PATRAM 2013: states that in the view of the UK Competent Authority, some of the most conservative assumptions could be relaxed (for example, a smaller maximum $\mathrm{H} / \mathrm{U}$ ratio) [17].

- Rezgui, S. and Hilbert, F., "Criticality Analyses of Enriched Uranium-Hexafluoride Containing Impurities," PATRAM 2013: discusses the DN30B model with the complex spherical configuration and describes how the optimum HUR configuration and placement were determined [18].

- Milin, M., Rannou, J., Viaulle, L., Caplin, G., and Evo, S., "Hydration of Uranium Residues Contained in Enriched UF 6 Cylinders," PATRAM 2016: justifies a bounding H/U ratio of 6 for uranium residues [19].

The DN-30 SARP includes these references as part of its basis for developing its complex HUR spherical arrangement. The HUR model presented in ORNL's Assessment of Existing Transportation Packages for Use with HALEU [1] mimics the DN-30 model. The HUR model consists of multiple spherical layers; the inner layer is an $11.4 \mathrm{~kg}$ sphere of $\mathrm{UO}_{2} \mathrm{~F}_{2} * 3 \mathrm{H}_{2} \mathrm{O}$ (with a density of $6.3 \mathrm{~g} / \mathrm{cm}^{3}$ [20]) surrounded by a spherical layer of $\mathrm{UF}_{6}$, which is in turn surrounded by a spherical layer of HF (HF acid with a density of $1.15 \mathrm{~g} / \mathrm{cm}^{3}$, SCALE standard material $h$ facid). The amount of HF in the spherical shell layer thickness and placement was determined through parameter studies to maximize the system $k_{\text {eff. }}$. The HF 
representing the $\mathrm{UF}_{6}$ impurities is still included as part of the $\mathrm{UF}_{6}$ loading as an additional conservatism. This results in additional HF being included in the model.

Of the referenced 30B cylinder package SARPS [2, 7], the HUR considerations are very different. The UX30 basis does not consider HUR in its analysis. The DN-30 basis conservatively models the HUR as an optimally shaped sphere placed to maximize interaction and system $k_{\text {eff. }}$ The DN-30 adds conservatism with its impurity modeling. In both SARPS, the impurities (modeled as HF) are included as part of the $\mathrm{UF}_{6}$. The DN-30 analysis adds additional HF as a spherical shell around the HUR sphere, with the shell thickness and spacing determined through parameter studies to maximize the system $k_{\text {eff. }}$.

Given the different densities of the HUR, HF, and $\mathrm{UF}_{6}$, in this evaluation, the HF spherical shell layer is not considered a realistic configuration. Therefore, the HUR is modeled as a single sphere with the HF mixed homogeneously throughout the $\mathrm{UF}_{6}$. Select cases will include the HF spherical shell layer consistent with the ORNL assessment [1] models for comparison.

\subsection{SINGLE PACKAGE CALCULATIONS}

For single package calculations, a 30B cylinder was modeled with and without an overpack. For both configurations, the $\mathrm{UF}_{6}$ enrichment was varied from 6 to $20 \mathrm{wt} . \%$, and the $\mathrm{UF}_{6}$ density was varied from 2.5 to $5.5 \mathrm{~g} / \mathrm{cm}^{3}$. Consistent with the DN-30 analysis, single package models did not consider HUR. Both configurations included infinite water reflection modeled as a $30 \mathrm{~cm}$ thick water reflector. The overpack model includes a $5 \mathrm{~cm}$ gap between the cylinder and the overpack (modeled as void). Results are presented in Table 2 and Figure 4 (infinite water reflected cylinder) and Table 3 and Figure 5 (infinite water reflected cylinder with overpack). Entries shaded in blue have $k_{\text {eff }}$ values greater than 1.0, and those shaded in gray have $k_{\text {eff }}$ values between 0.95 and 1.0. The Monte Carlo statistical uncertainty in the $k_{\text {eff }}$ values is not presented in the results, but all calculations in this study were run until an uncertainty of $0.05 \% \Delta k(50 \mathrm{pcm})$ was achieved.

Table 2. $k_{\text {eff }}$ values for single 30B cylinders with infinite water reflection

\begin{tabular}{ccccc}
\hline \multirow{2}{*}{$\begin{array}{c}\text { UF } \\
\text { (wt.\%) }\end{array}$} & \multicolumn{4}{c}{$\mathbf{U F}_{\mathbf{6}}$ density $\left(\mathbf{g} / \mathbf{c m}^{\mathbf{3}}\right)$} \\
\cline { 2 - 5 } & $\mathbf{2 . 5}$ & $\mathbf{3 . 5}$ & $\mathbf{4 . 5}$ & $\mathbf{5 . 5}$ \\
\hline 6 & 0.5049 & 0.5600 & 0.6053 & 0.6401 \\
7 & 0.5274 & 0.5889 & 0.6393 & 0.6801 \\
8 & 0.5458 & 0.6143 & 0.6704 & 0.7166 \\
9 & 0.5651 & 0.6380 & 0.6992 & 0.7489 \\
10 & 0.5825 & 0.6611 & 0.7262 & 0.7798 \\
12 & 0.6129 & 0.7016 & 0.7763 & 0.8366 \\
15 & 0.6533 & 0.7561 & 0.8422 & 0.9091 \\
20 & 0.7127 & 0.8354 & 0.9348 & 1.0119 \\
\hline
\end{tabular}




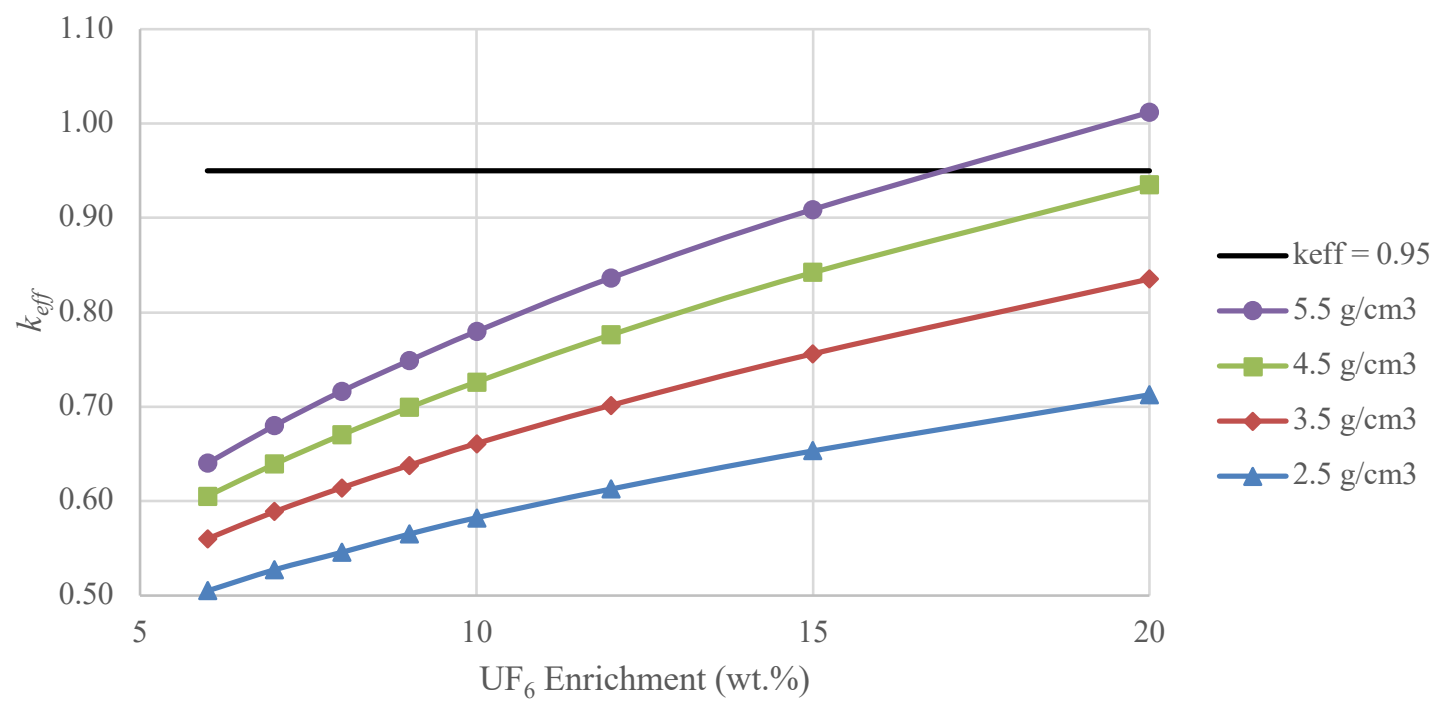

Figure 4. $\boldsymbol{k}_{\text {eff }}$ values as a function of $\mathrm{UF}_{6}$ enrichment and $\mathrm{UF}_{6}$ density for single $30 \mathrm{~B}$ cylinders with infinite water reflection.

Table 3. Values for single 30B cylinders with an overpack and infinite water reflection

\begin{tabular}{ccccc}
\hline UF & enrichment & \multicolumn{4}{c}{$\mathbf{U F}_{\mathbf{6}}$ density $\mathbf{( g / \mathbf { c m } ^ { \mathbf { 3 } } )}$} \\
\cline { 2 - 5 } (wt.\%) & $\mathbf{2 . 5}$ & $\mathbf{3 . 5}$ & $\mathbf{4 . 5}$ & $\mathbf{5 . 5}$ \\
\hline 6 & 0.4203 & 0.4928 & 0.5536 & 0.6041 \\
7 & 0.4426 & 0.5227 & 0.5898 & 0.6461 \\
8 & 0.4625 & 0.5492 & 0.6238 & 0.6823 \\
9 & 0.4801 & 0.5747 & 0.6545 & 0.7170 \\
10 & 0.4977 & 0.5996 & 0.6835 & 0.7497 \\
12 & 0.5295 & 0.6419 & 0.7362 & 0.8079 \\
15 & 0.5737 & 0.7005 & 0.8048 & 0.8843 \\
20 & 0.6363 & 0.7849 & 0.9021 & 0.9889 \\
\hline
\end{tabular}




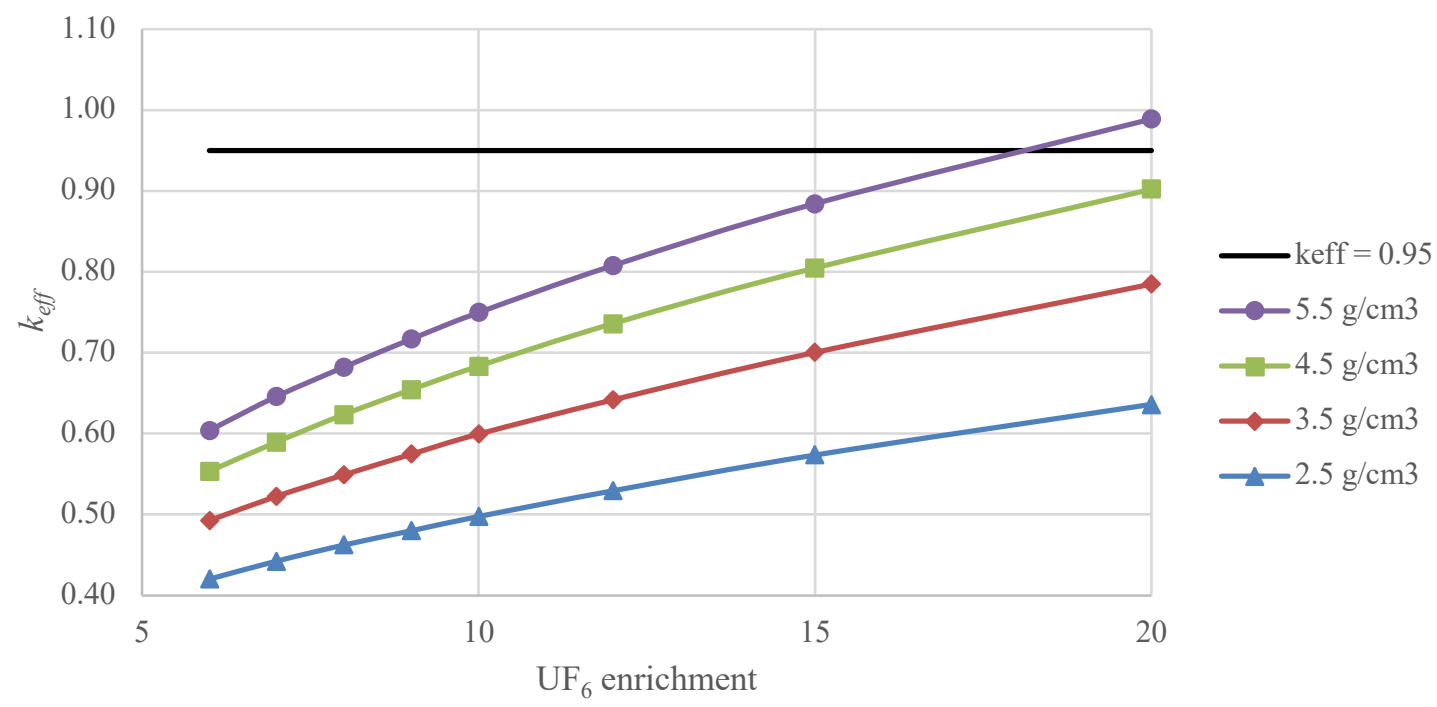

Figure 5. $k_{\text {eff }}$ values as a function of $\mathrm{UF}_{6}$ enrichment and $\mathrm{UF}_{6}$ density for single $30 \mathrm{~B}$ cylinders with an overpack and infinite water reflection.

For single $30 \mathrm{~B}$ cylinders, $k_{\text {eff }}$ increased with both increasing $\mathrm{UF}_{6}$ density and $\mathrm{UF}_{6}$ enrichment. Enrichments greater than $15 \mathrm{wt} \%$, with $k_{\text {eff }}$ values greater than 0.95 , indicate infinite arrays will not be acceptable under NCT or HAC

\subsection{INFINITE ARRAY CALCULATIONS}

The parametric capability within the Sampler sequence (described in Section 2.3) was used to generate models of an infinite array of 30B cylinders with variations of multiple parameters, including:

- $\mathrm{UF}_{6}$ enrichment

- $\mathrm{UF}_{6}$ density

- Water layer (film) thickness around the 30B cylinder (between the cylinder and the overpack)

- Density of water film

The enrichment was varied from 6 to $10 \mathrm{wt} . \%{ }^{235} \mathrm{U}$, and the $\mathrm{UF}_{6}$ density was varied between 2 and $5.5 \mathrm{~g} / \mathrm{cm}^{3}$. As with the single package models, the infinite arrays did not consider HUR. The enrichment range was determined based on scoping calculations that indicated an infinite array of 30B cylinders achieved supercriticality $\left(k_{\text {eff }}\right.$ values greater than 1.0$)$ within this range; higher enrichments were thus not studied in this phase of the work. This range of $\mathrm{UF}_{6}$ densities spans the material density from liquid to full theoretical density as a solid. The water film thickness around the $30 \mathrm{~B}$ was varied from 0 to $5 \mathrm{~cm}$, with densities of $0.25,0.5,0.75$, and $1.0 \mathrm{~g} / \mathrm{cm}^{3}$. The existing SARPs indicate that the array $k_{\text {eff }}$ peaks with a film thickness between 0.5 and $5 \mathrm{~cm}$ thick. No overpack was modeled for these cases.

Selected results generated in this study are illustrated in Figures 6-8. The infinite array $k_{\text {eff }}$ values are shown in Figure 6 for 7 wt. $\%{ }^{235} \mathrm{U}$ enrichment and in Figure 7 for $10 \mathrm{wt} . \%{ }^{235} \mathrm{U}$ enrichment. The results show that array $k_{\text {eff }}$ peaks with a film thickness of about $1 \mathrm{~cm}$ (slightly less). Full density water was shown to be bounding in scoping calculations. Figure 8 shows the $k_{\text {eff }}$ values for the infinite array with a $1 \mathrm{~cm}$ water thickness around the cylinder as a function of $\mathrm{UF}_{6}$ enrichment and $\mathrm{UF}_{6}$ density. The $k_{\text {eff }}$ values presented in the figures are provided in Tables $4-6$, and all the $k_{\text {eff }}$ values for this study are provided in 
Appendix A. Entries shaded in blue have $k_{\text {eff }}$ values greater than 1.0, and those shaded in gray have $k_{\text {eff }}$ values between 0.95 and 1.0. The Monte Carlo statistical uncertainty in the $k_{\text {eff }}$ values is not presented in the tables, but all calculations in this study were run until an uncertainty of $0.05 \% \Delta k(50 \mathrm{pcm}) \mathrm{was}$ achieved.

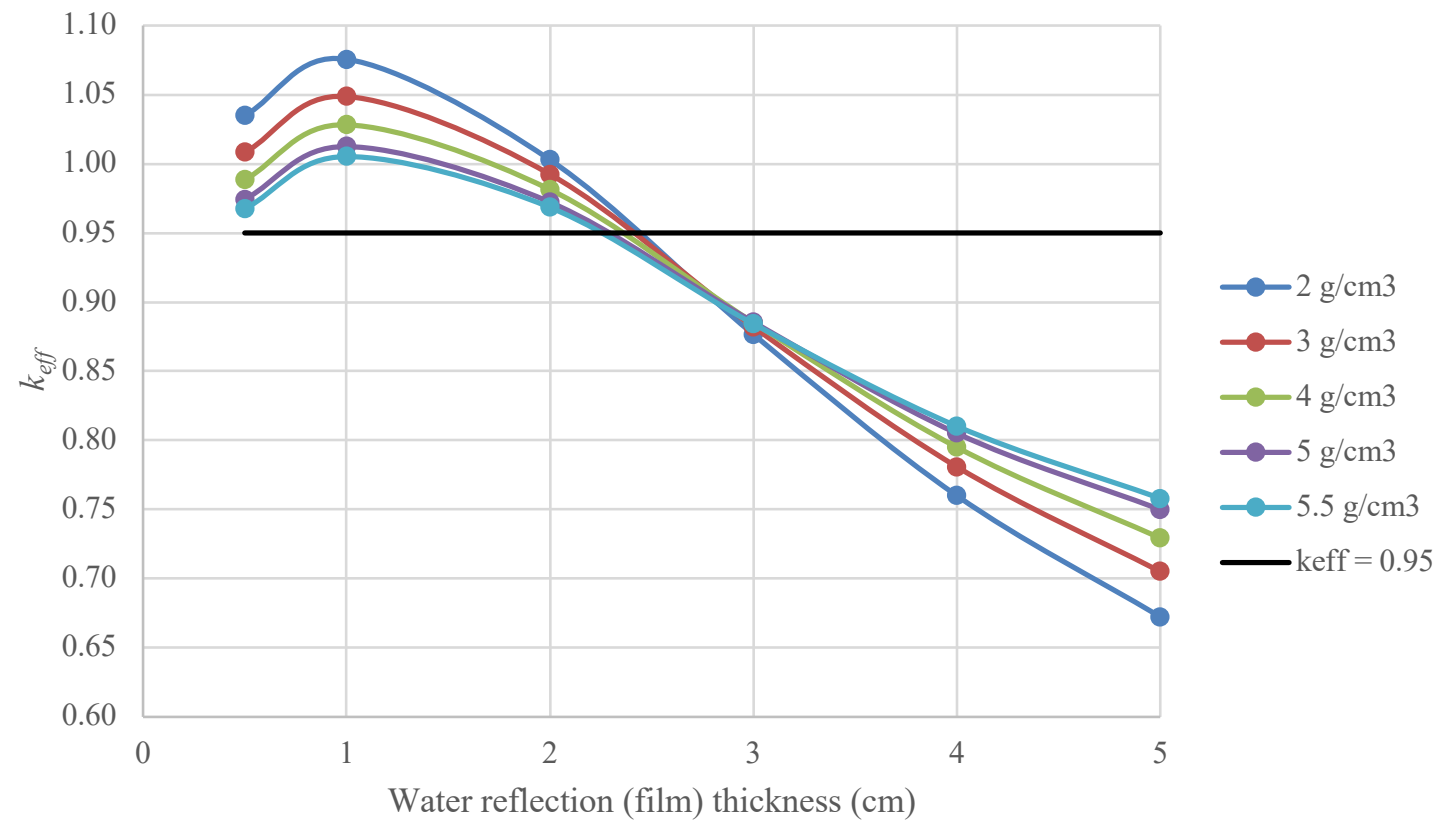

Figure 6. $k_{\text {eff }}$ values as a function of water thickness and $U F_{6}$ density for $7 \mathrm{wt} \%{ }^{235} \mathrm{U}$ enrichment.

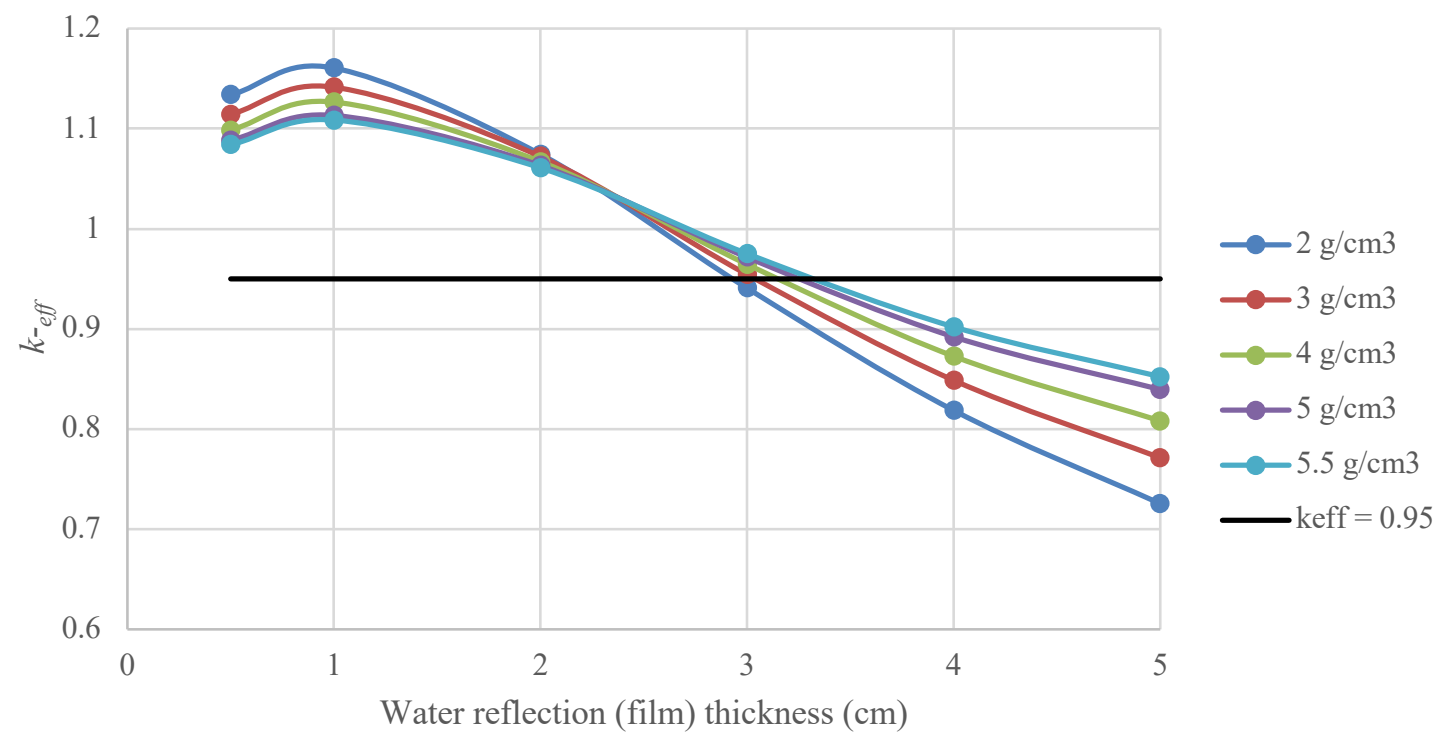

Figure 7. $k_{\text {eff }}$ values as a function of water thickness and $U F_{6}$ density for $10 \mathrm{wt} \%{ }^{235} U$ enrichment. 


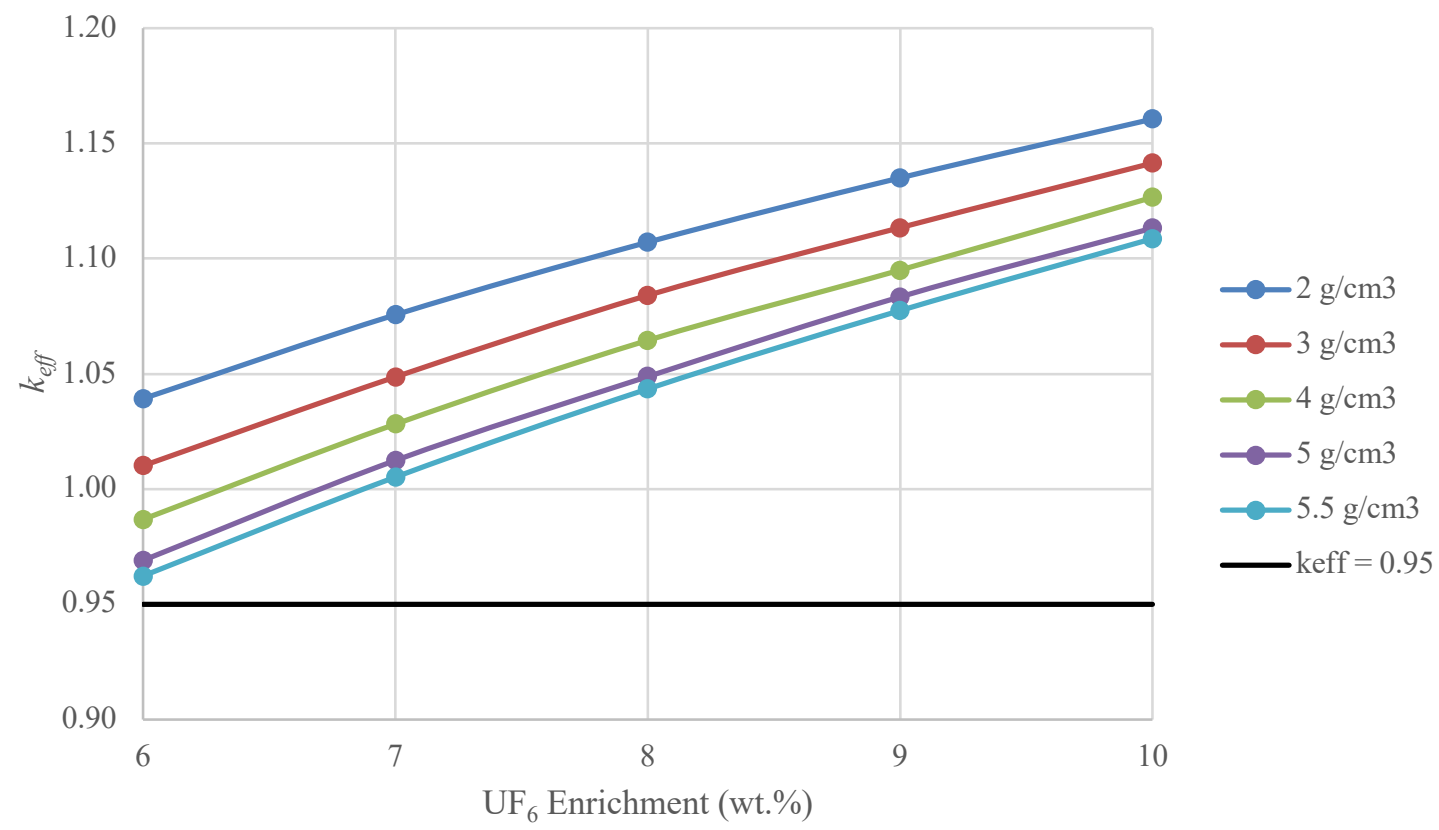

Figure 8. $k_{\text {eff }}$ values as a function of ${ }^{235} U$ and $U F_{6}$ density for a $1 \mathrm{~cm}$ water film around the cylinder.

Table 4. $k_{\text {eff }}$ Values for infinite arrays with $7 \mathrm{wt} . \%{ }^{235} \mathrm{U}$ enrichment

\begin{tabular}{cccccc}
\hline Film thickness & \multicolumn{5}{c}{$\mathbf{U F}_{\mathbf{6}}$ density $\left(\mathbf{g} / \mathbf{c m}^{\mathbf{3}}\right)$} \\
\cline { 2 - 6 }$(\mathbf{c m})$ & $\mathbf{2}$ & $\mathbf{3}$ & $\mathbf{4}$ & $\mathbf{5}$ & $\mathbf{5 . 5}$ \\
\hline 0.5 & 1.03490 & 1.00819 & 0.98850 & 0.97437 & 0.96748 \\
1 & 1.07563 & 1.04867 & 1.02819 & 1.01244 & 1.00521 \\
2 & 1.00291 & 0.99244 & 0.98138 & 0.97226 & 0.96849 \\
3 & 0.87668 & 0.88217 & 0.88519 & 0.88555 & 0.88426 \\
4 & 0.76002 & 0.78089 & 0.79502 & 0.80510 & 0.81024 \\
5 & 0.67241 & 0.70511 & 0.72936 & 0.74995 & 0.75807 \\
\hline
\end{tabular}

Table 5. $k_{\text {eff }}$ Values for infinite arrays with $10 \mathrm{wt} . \%{ }^{235} \mathrm{U}$ enrichment

\begin{tabular}{cccccc}
\hline \multirow{2}{*}{$\begin{array}{c}\text { Film thickness } \\
\text { (cm) }\end{array}$} & $\mathbf{5}$ & $\mathbf{3}$ & $\mathbf{U}$ & $\mathbf{5}$ & $\mathbf{5 . 5}$ \\
\cline { 2 - 6 } & 1.13380 & 1.11438 & 1.09864 & 1.08837 & 1.08385 \\
0.5 & 1.16055 & 1.14145 & 1.12660 & 1.11323 & 1.10866 \\
1 & 1.07439 & 1.07211 & 1.06706 & 1.06316 & 1.06086 \\
2 & 0.94075 & 0.95436 & 0.96451 & 0.97153 & 0.97519 \\
3 & 0.81863 & 0.84869 & 0.87272 & 0.89213 & 0.90204 \\
4 & 0.72553 & 0.77130 & 0.80817 & 0.83949 & 0.85235 \\
5 & \multicolumn{5}{c}{} \\
\hline
\end{tabular}

Table 6. $k_{\text {eff }}$ Values for infinite arrays with $1 \mathrm{~cm}$ water film around the cylinder

\begin{tabular}{cccccc}
\hline \multirow{2}{*}{$\begin{array}{c}\text { UF } \\
\text { (wt.\%) }\end{array}$} & \multicolumn{5}{c}{$\mathbf{U F}_{\mathbf{6}}$ density $\left(\mathbf{g} / \mathbf{c m}^{\mathbf{3}}\right)$} \\
\cline { 2 - 6 } & $\mathbf{2}$ & $\mathbf{3}$ & $\mathbf{4}$ & $\mathbf{5}$ & $\mathbf{5 . 5}$ \\
\hline 6 & 1.03926 & 1.01013 & 0.98683 & 0.96907 & 0.96232 \\
7 & 1.07563 & 1.04867 & 1.02819 & 1.01244 & 1.00521 \\
8 & 1.10713 & 1.08406 & 1.06455 & 1.04881 & 1.04346 \\
9 & 1.13504 & 1.11344 & 1.09504 & 1.08341 & 1.07746 \\
10 & 1.16055 & 1.14145 & 1.12660 & 1.11323 & 1.10866 \\
\hline
\end{tabular}


For the infinite arrays, $k_{\text {eff }}$ increased with increasing $\mathrm{UF}_{6}$ enrichment with $k_{\text {eff }}$ peaking with a film thickness of about $1 \mathrm{~cm}$ (slightly less). Below a film thickness of $3 \mathrm{~cm}$, the lower densities have higher $k_{\text {eff }}$ values. The DN-30 and ORNL assessment contain similar results and show that with HUR present in the cylinders, $k_{\text {eff }}$ increased with increasing density in the infinite arrays. These results indicate that higher enrichments will need to look at smaller, finite arrays in order to be considered acceptable under NCT or HAC.

\subsection{FINITE ARRAY CALCULATIONS WITH 7 WT. $\%{ }^{235} \mathrm{U}$}

The Assessment of Existing Transportation Packages for Use with HALEU (ORNL/TM-2020/1725) analysis used the HAC model for its array calculations since the DN-30 SARP determined the HAC model to be the bounding configuration (model with the collapsed overpack and the spherical HUR configuration). With this in mind, the studies documented here also start with the HAC model. To minimize the number of parameter studies, an $N$ and an enrichment were determined for a starting configuration based on the ORNL/TM-2020/1725 results. The array size will then be increased or decreased as necessary to maximize acceptability under NCT and HAC. For the array size, $N$ was chosen to be 7, with the HAC array being $2 N(14)$, and the NCT array being $5 N(35)$. A discussion of $N$ and the required array sizes for NCT and HAC analyses is included above in Section 1.3. The starting enrichment was set at $7 \mathrm{wt} . \%$.

\subsubsection{Hypothetical Accident Condition Array}

The HAC array of 14 cylinders was modeled as a $7 \times 2$ hexagonal array, as shown in Figure 9. For the $\mathrm{HAC}$, the overpack is assumed to collapse into close proximity to the $30 \mathrm{~B}$ cylinder wall (no foam material) for modeling purposes. The HUR sphere is included in the model, and the spheres are located within each cylinder to maximize interaction between the spheres. Axially, the spheres in the lower cylinders are pushed to the tops of the cylinders and the spheres in the upper cylinders are pushed to the bottoms of the cylinders. Radially, the outer cylinders are paired so that HUR spheres are directly adjacent to each other. The HUR sphere in the central cylinder is centered. The configuration of the HUR spheres is shown in Figure 10. The array was evaluated with the $\mathrm{UF}_{6}$ density varying from 2.5 to 5.5 $\mathrm{g} / \mathrm{cm}^{3}$ and the water film thickness around the 30B (inside the collapsed overpack) varying from 0 to $5 \mathrm{~cm}$ thick, with the overpack close fitting to the water. 

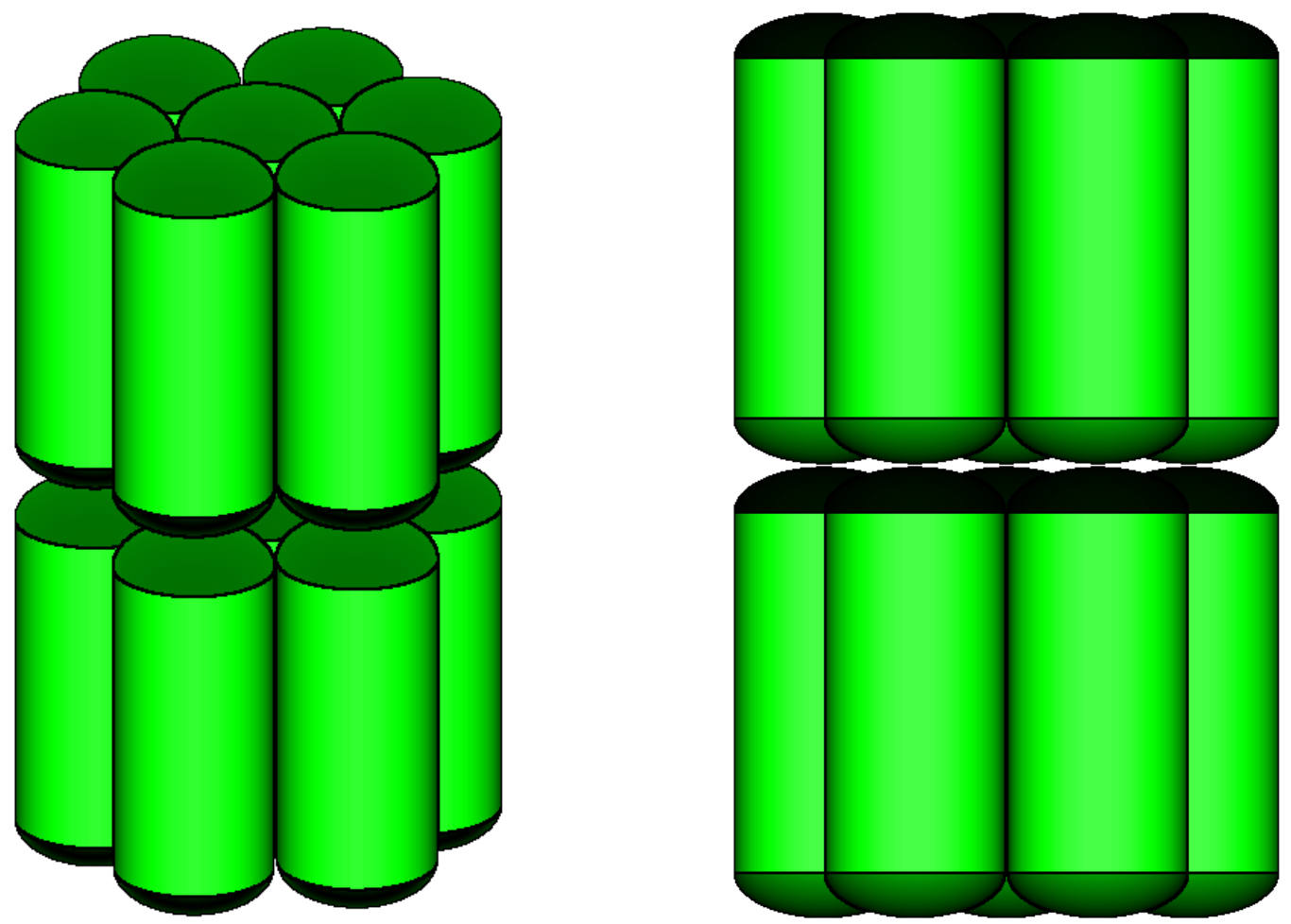

Figure 9. HAC array of 14 cylinders in the $7 \times 2$ hexagonal array.
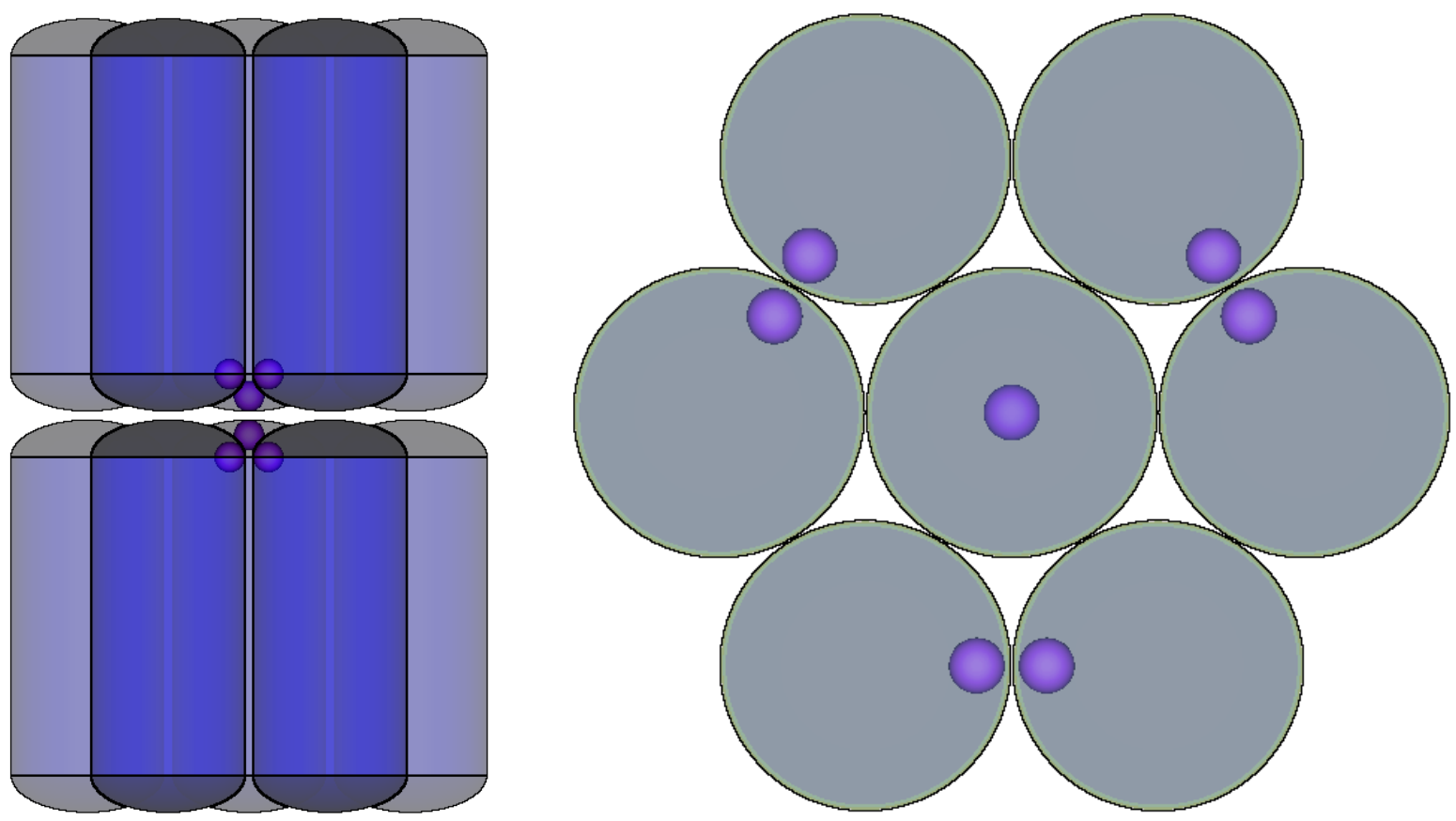

Figure 10. HAC array showing locations of HUR spheres within the 30B cylinders. 
The results of this series of calculations are shown in Figure 11, and the $k_{\text {eff }}$ values are provided in Table 7. Initially, the cylinder reactivity increases slightly with increasing water film thickness, but it decreases at thicknesses beyond $0.6 \mathrm{~cm}$. At these greater thicknesses, the interstitial water acts to isolate the cylinders. At the lower thicknesses, the water provides additional moderation and enhances the coupling of adjacent HUR spheres in different cylinders. As expected, $k_{\text {eff }}$ increases with increasing $\mathrm{UF}_{6}$ density. The highest $k_{\text {eff }}$ value from this study is $0.88171 \pm 0.0003$, which indicates that enrichments of $7 \mathrm{wt} . \%$ ${ }^{235} \mathrm{U}$ may be feasible in a 30B cylinder. More detailed analysis is required to confirm this conclusion, including a validation of the computational method and the associated derivation of an upper subcritical limit (USL).The Monte Carlo statistical uncertainty in the $k_{\text {eff }}$ values is not presented in the tables, but all calculations in this study were run until an uncertainty of $0.03 \% \Delta k(30 \mathrm{pcm})$ was achieved.

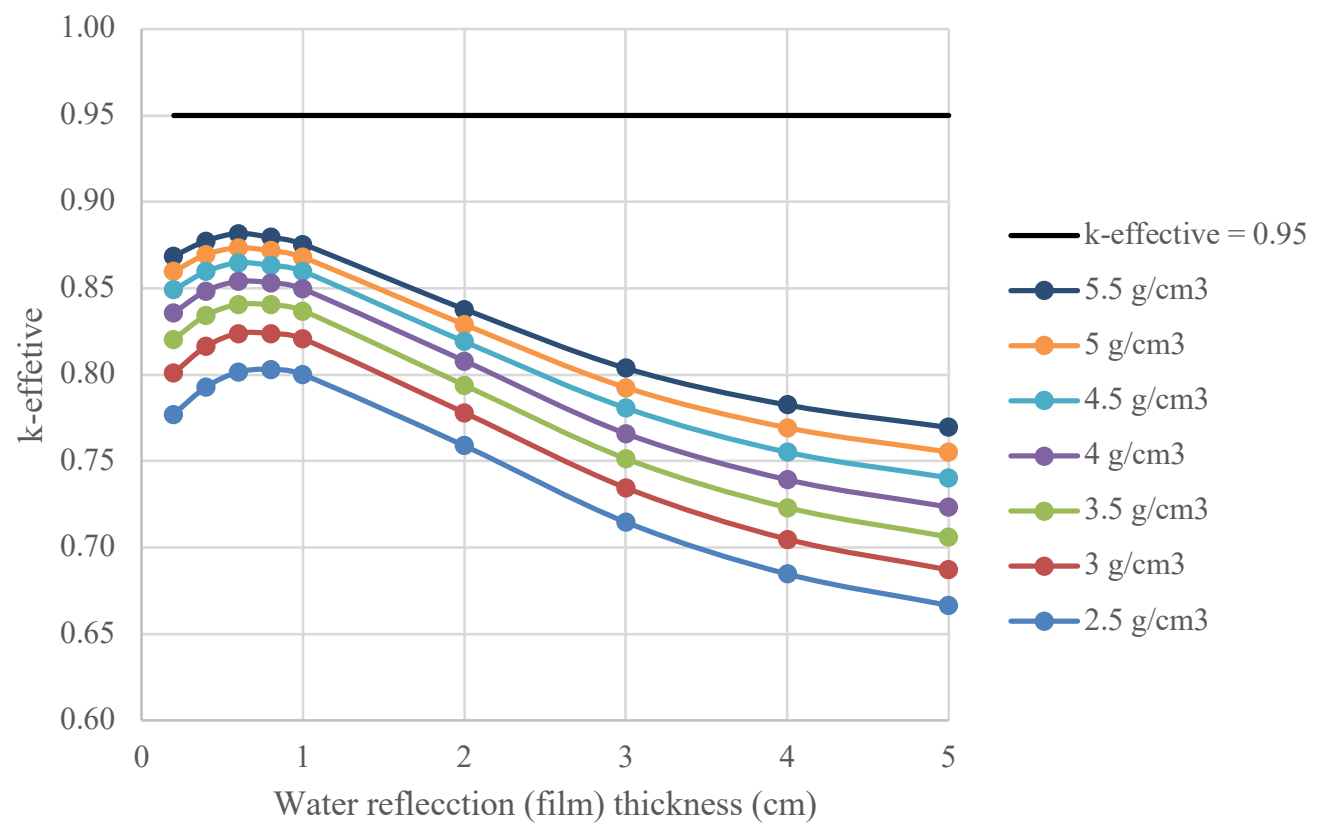

Figure 11. $k_{\text {eff }}$ results for $\mathrm{HAC}_{7} \times 2$ array with $7 \mathrm{wt.} \%{ }^{235} \mathrm{U}$ enriched $\mathrm{UF}_{6}$.

Table 7. $k_{\text {eff }}$ Values for $7 \times 2$ array model with 7 wt. $\%{ }^{235} U$ enrichment

\begin{tabular}{cccccccc}
\hline Film thickness & \multicolumn{7}{c}{$\mathbf{U F}_{\mathbf{6}} \mathbf{d e n s i t y}\left(\mathbf{g} / \mathbf{c m}^{\mathbf{3}}\right)$} \\
\cline { 2 - 8 }$(\mathbf{c m})$ & $\mathbf{2 . 5}$ & $\mathbf{3}$ & $\mathbf{3 . 5}$ & $\mathbf{4}$ & $\mathbf{4 . 5}$ & $\mathbf{5 . 0}$ & $\mathbf{5 . 5}$ \\
\hline 0.2 & 0.77717 & 0.80096 & 0.82054 & 0.83584 & 0.84913 & 0.85978 & 0.86867 \\
0.4 & 0.79289 & 0.81638 & 0.83432 & 0.84855 & 0.85965 & 0.86953 & 0.87744 \\
0.6 & 0.80150 & 0.82391 & 0.84064 & 0.85390 & 0.86476 & 0.87338 & $\mathbf{0 . 8 8 1 7 1}$ \\
0.8 & 0.80312 & 0.82385 & 0.84041 & 0.85327 & 0.86323 & 0.87174 & 0.87945 \\
1 & 0.80008 & 0.82075 & 0.83698 & 0.84958 & 0.85977 & 0.86791 & 0.87553 \\
2 & 0.75890 & 0.77803 & 0.79397 & 0.80802 & 0.81915 & 0.82907 & 0.83793 \\
3 & 0.71470 & 0.73458 & 0.75145 & 0.76597 & 0.78074 & 0.79260 & 0.80376 \\
4 & 0.68471 & 0.70487 & 0.72314 & 0.73926 & 0.75517 & 0.76934 & 0.78250 \\
5 & 0.66655 & 0.68713 & 0.70616 & 0.72345 & 0.74041 & 0.75527 & 0.76949 \\
\hline
\end{tabular}

\subsubsection{Normal Conditions of Transport Array}

The NCT array is modeled as 38 cylinders in a $19 \times 2$ hexagonal array, as shown on in Figure 12 . The minimum NCT array size for NCT is $5 N$, which would be 35 cylinders in this case. The use of this array 
is slightly conservative, and a future study could investigate which three cylinders could be removed from the array while maintaining the maximum reactivity. This was not investigated in this work since the effect would be small. Modeling a three high array was also not studied, due to the larger increase in $\mathrm{z}$ compared to the smaller decreases in $\mathrm{x}$ and $\mathrm{y}$ increasing the overall leakage of the system. The HUR sphere is included in the model, with the spheres located within each cylinder to maximize interaction between the spheres. Axially, the spheres in the lower cylinders are pushed to the tops of the cylinders and the spheres in the upper cylinders are pushed to the bottoms of the cylinders. Radially, cylinders in the outer two rows are grouped in threes so that HUR spheres are collected adjacent to each other. The HUR sphere is centered in the central cylinder. The configuration of the HUR spheres is shown on the right of Figure 12. The array was evaluated with $U_{6}$ density varying from 3.5 to $5.5 \mathrm{~g} / \mathrm{cm}^{3}$ and the water film thickness around the 30B (inside the collapsed overpack) varying from 0 to $1 \mathrm{~cm}$ thick. Based on the HAC results, water film thicknesses greater than $1 \mathrm{~cm}$ were not considered. The overpack was conservatively modeled the same as it was for the HAC (collapsed with no foam material present). Including the full overpack would increase the distance between the cylinders (and HUR spheres) and decrease interaction-similar to the effect of water film thicknesses larger than $1 \mathrm{~cm}$.
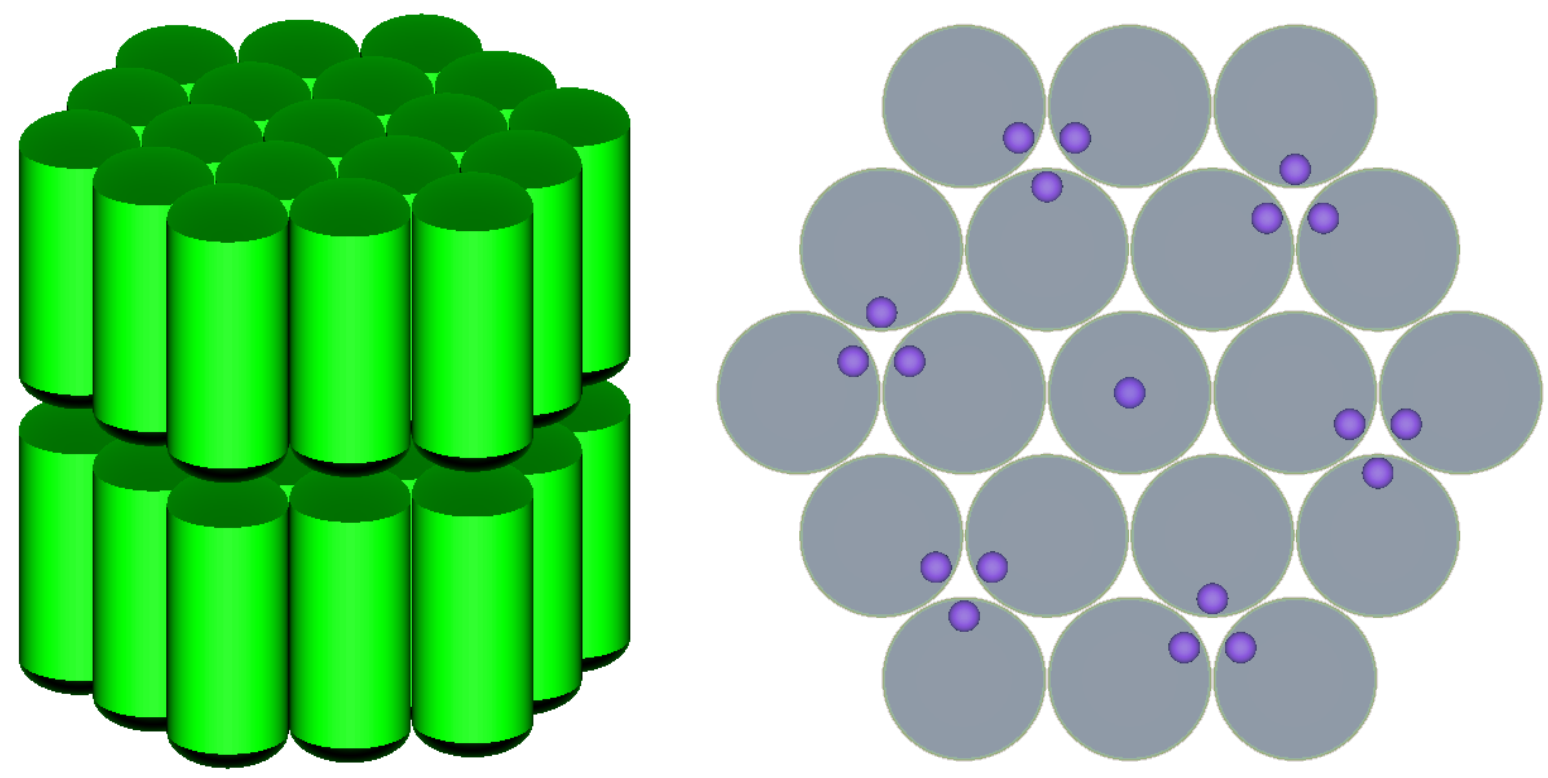

Figure 12. NCT array of 38 cylinders in $19 \times 2$ hexagonal array (left) and showing HUR spheres (right).

The results of this series of calculations are shown in Figure 13, and the $k_{\text {eff }}$ values are provided in Table 8. As with the HAC results presented in Section 3.4.1, there is an initial increase in system $k_{\text {eff }}$ that reaches a maximum value at a film thickness of approximately $0.6 \mathrm{~cm}$. Also, as discussed above, this increase is a result of additional moderation; at greater water film thicknesses, the interstitial water acts more to isolate adjacent cylinders and HUR spheres. The system reactivity is fairly constant for the different $\mathrm{UF}_{6}$ densities, indicating that the HUR spheres are driving $k_{\text {eff. The Monte Carlo statistical }}$ uncertainty in the $k_{\text {eff }}$ values is not presented in the tables, but all calculations in this study were run until an uncertainty of $0.03 \% \Delta k(30 \mathrm{pcm})$ was achieved. The highest $k_{\text {eff }}$ value from this study is $0.91054 \pm$ 0.0003 , indicating that enrichments of $7 \mathrm{wt} . \%{ }^{235} \mathrm{U}$ may be feasible in a $30 \mathrm{~B}$ cylinder. More detailed analysis is required to confirm this conclusion, including a validation of the computational method and the associated derivation of an upper subcritical limit (USL).

For these models, the NCT models do have higher $k_{\text {eff }}$ values than the HAC models, but they are modeled with the HAC collapsed overpack configuration. Adding actual overpack dimensions will increase the 
spacing between the cylinders, thereby decreasing the interaction, which is expected to yield lower $k_{\text {eff }}$ values.

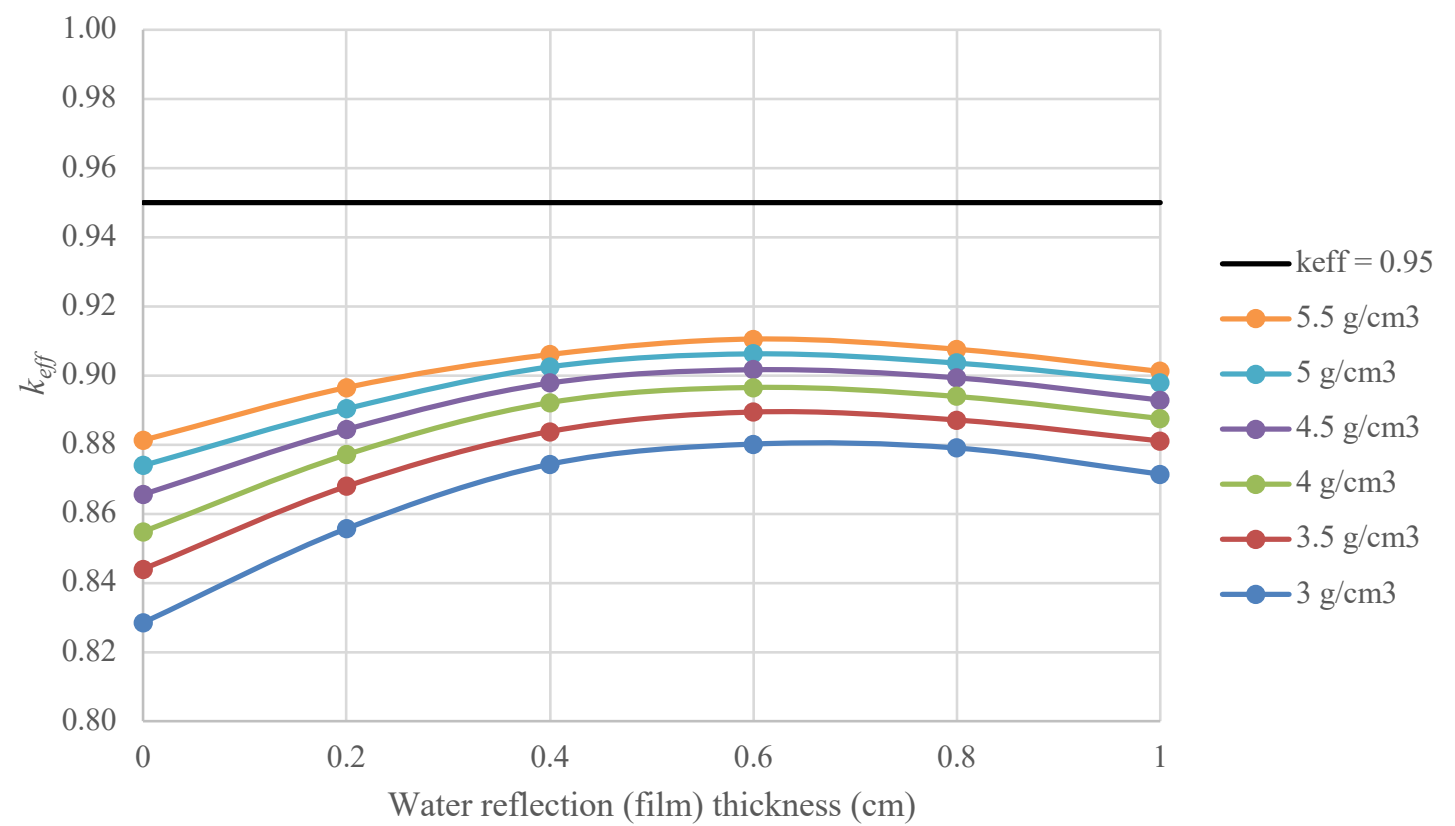

Figure 13. $k_{\text {eff }}$ results for NCT $19 \times 2$ array with 7 wt. $\%{ }^{235} \mathrm{U}$ enriched $\mathrm{UF}_{6}$.

Table 8. $k_{\text {eff }}$ Values for $19 \times 2$ array model with $7 \mathrm{wt} . \%{ }^{235} \mathrm{U}$ enrichment

\begin{tabular}{ccccccc}
\hline Film thickness & \multicolumn{6}{c}{$\mathbf{U F}_{\mathbf{6}}$ density $\left(\mathbf{g} / \mathbf{c m}^{\mathbf{3}}\right)$} \\
\cline { 2 - 7 }$(\mathbf{c m})$ & $\mathbf{3 . 0}$ & $\mathbf{3 . 5}$ & $\mathbf{4 . 0}$ & $\mathbf{4 . 5}$ & $\mathbf{5 . 0}$ & $\mathbf{5 . 5}$ \\
\hline 0.0 & 0.82850 & 0.84400 & 0.85481 & 0.86557 & 0.87394 & 0.88126 \\
0.2 & 0.85569 & 0.86792 & 0.87710 & 0.88440 & 0.89037 & 0.89650 \\
0.4 & 0.87432 & 0.88379 & 0.89217 & 0.89780 & 0.90250 & 0.90607 \\
0.6 & 0.88016 & 0.88943 & 0.89653 & 0.90166 & 0.90625 & $\mathbf{0 . 9 1 0 5 4}$ \\
0.8 & 0.87901 & 0.88712 & 0.89392 & 0.89931 & 0.90358 & 0.90759 \\
1.0 & 0.87145 & 0.88106 & 0.88754 & 0.89289 & 0.89789 & 0.90116 \\
\hline
\end{tabular}

\subsection{FINITE ARRAY CALCULATIONS FOR VARIOUS ${ }^{235}$ U ENRICHMENTS}

Results so far have indicated that in order for higher enriched $\mathrm{UF}_{6}\left(\mathrm{UF}_{6}\right.$ enriched to the HALEU range of enrichments) to be proven subcritical for transportation in existing $30 \mathrm{~B}$ cylinders, at a minimum, the maximum allowed transportation array must be reduced, with the respective container CSI increased. The HAC $7 \times 2$ array study was expanded to include enrichments up to $20 \mathrm{wt} . \%$. Additional studies analyzed the same span of enrichments $(6,7,8,9,10,12,15$, and $20 \mathrm{wt} . \%)$ in reduced size arrays. The $\mathrm{UF}_{6}$ density was held constant at $5.5 \mathrm{~g} / \mathrm{cm}^{3}$ for all of the cases. This $\mathrm{UF}_{6}$ density was shown to be limiting, as described above in Section 3.4.1, and it was the only density used here to minimize the number of calculations. The water film thickness around the cylinder was varied from 0.2 to $5 \mathrm{~cm}$. The overpack was modeled immediately adjacent to the water film thickness around the cylinder (the gap between the cylinder and overpack varied with the water film thickness). 
The results of this series of calculations are shown in Figure 14, and the $k_{\text {eff }}$ values are provided in Table 9. In general, system $k_{\text {eff }}$ decreases with increasing interstitial water film thickness at thicknesses greater than about $0.6 \mathrm{~cm}$, which is consistent with the behavior exhibited by lower enrichments. Entries shaded in blue have $k_{\text {eff }}$ values greater than 1.0, and those shaded in gray have $k_{\text {eff }}$ values between 0.95 and 1.0. The Monte Carlo statistical uncertainty in the $k_{\text {eff }}$ values is not presented in the tables, but all calculations in this study were run until an uncertainty of $0.03 \% \Delta k(30 \mathrm{pcm})$ was achieved. The system $k_{\text {eff }}$ value reaches $0.91450 \pm 0.0003$ at $8 \mathrm{wt} . \%{ }^{235} \mathrm{U}$, and it reaches $0.94552 \pm 0.0003$ at $9 \mathrm{wt} . \%$, indicating that this analysis approach (array size) would not support licensing of 30B cylinders with enrichments significantly above 7 or $8 \mathrm{wt} . \%{ }^{235} \mathrm{U}$.

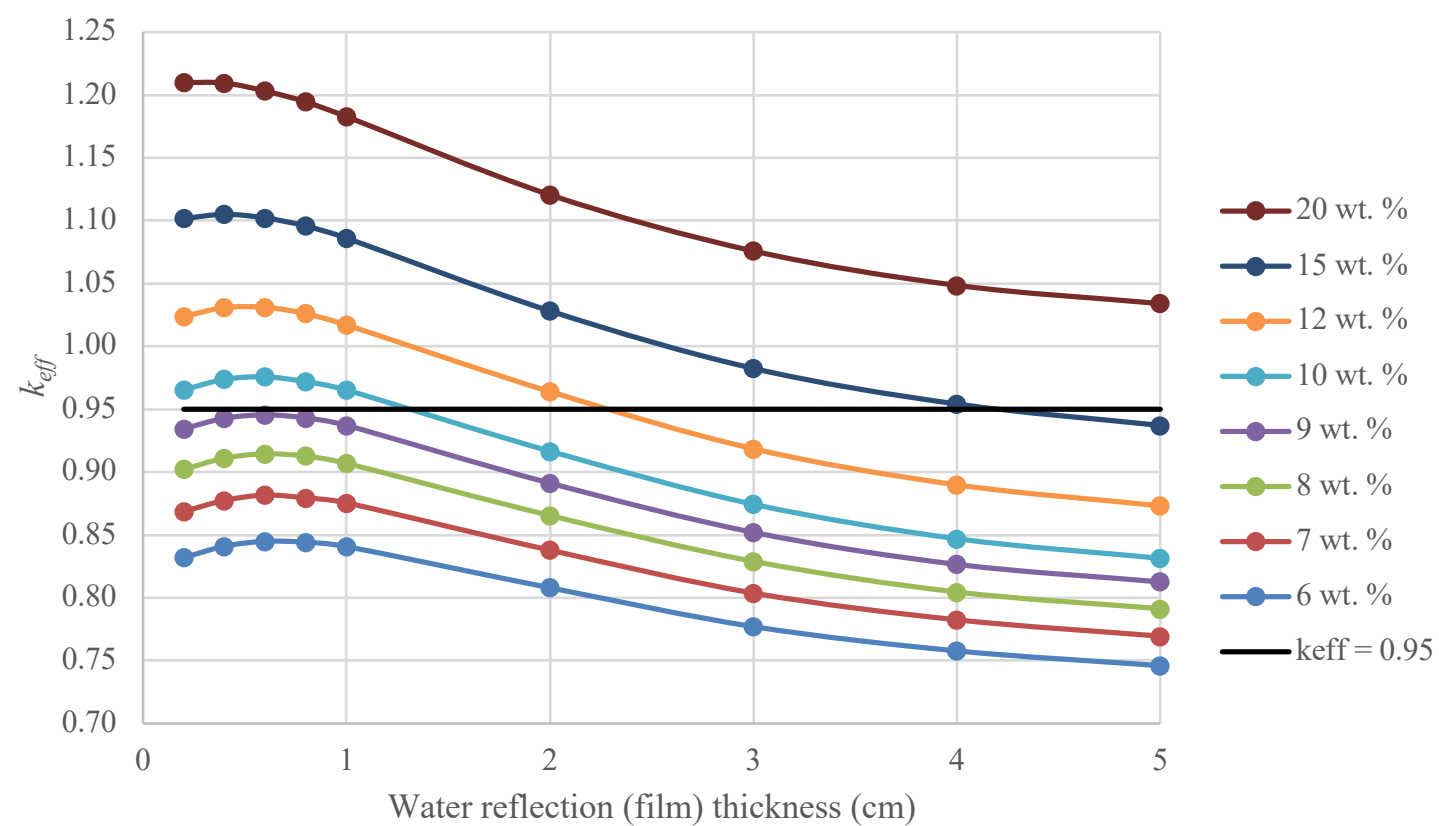

Figure 14. $k_{\text {eff }}$ results for HAC $7 \times 2$ array with variable ${ }^{235} \mathrm{U}$ enrichments.

Table 9. $k_{\text {eff }}$ Values for $7 \times 2$ array model with variable ${ }^{235} \mathrm{U}$ enrichment

\begin{tabular}{ccccccccc}
\hline \multirow{2}{*}{$\begin{array}{c}\text { Film thickness } \\
\text { (cm) }\end{array}$} & $\mathbf{6}$ & $\mathbf{7}$ & $\mathbf{8}$ & $\mathbf{9}$ & $\mathbf{1 0}$ & $\mathbf{1 2}$ & $\mathbf{1 5}$ & $\mathbf{2 0}$ \\
\cline { 2 - 9 } & $\mathbf{6}$ & $\mathbf{2 3 5}$ enrichment (wt.\%) \\
0.2 & 0.83191 & 0.86867 & 0.90209 & 0.93450 & 0.96547 & 1.02379 & 1.10169 & 1.20993 \\
0.4 & 0.84103 & 0.87744 & 0.91111 & 0.94280 & 0.97375 & 1.03084 & 1.10506 & 1.20951 \\
0.6 & 0.84491 & 0.88171 & 0.91450 & 0.94552 & 0.97576 & 1.03105 & 1.10218 & 1.20317 \\
0.8 & 0.84420 & 0.87945 & 0.91274 & 0.94309 & 0.97191 & 1.02608 & 1.09578 & 1.19455 \\
1 & 0.84078 & 0.87553 & 0.90697 & 0.93717 & 0.96528 & 1.01707 & 1.08612 & 1.18284 \\
2 & 0.80801 & 0.83793 & 0.86548 & 0.89124 & 0.91666 & 0.96403 & 1.02820 & 1.12057 \\
3 & 0.77709 & 0.80376 & 0.82901 & 0.85205 & 0.87443 & 0.91857 & 0.98248 & 1.07589 \\
4 & 0.75777 & 0.78250 & 0.80461 & 0.82661 & 0.84702 & 0.88988 & 0.95419 & 1.04857 \\
5 & 0.74604 & 0.76949 & 0.79134 & 0.81266 & 0.83143 & 0.87319 & 0.93713 & 1.03406 \\
\hline
\end{tabular}

The first reduced size array to be considered was a $7 \times 1$ array. The same range of parameters is considered for the $7 \times 1$ array as that which was used in the $7 \times 2$ array, with results shown in Figure 15 , and $k_{\text {eff }}$ values provided in Table 10. Entries shaded in blue have $k_{\text {eff }}$ values greater than 1.0, and those shaded in gray have $k_{\text {eff }}$ values between 0.95 and 1.0. The Monte Carlo statistical uncertainty in the $k_{\text {eff }}$ values is not presented in the tables, but all calculations in this study were run until an uncertainty of 
$0.03 \% \Delta k(30 \mathrm{pcm})$ was achieved. The $k_{\mathrm{eff}}$ values are similar to the results for the $7 \times 2$ array. In all of these cases, the HUR sphere was placed at the end of the 30B cylinder, just as it is in the multi-tier arrays.

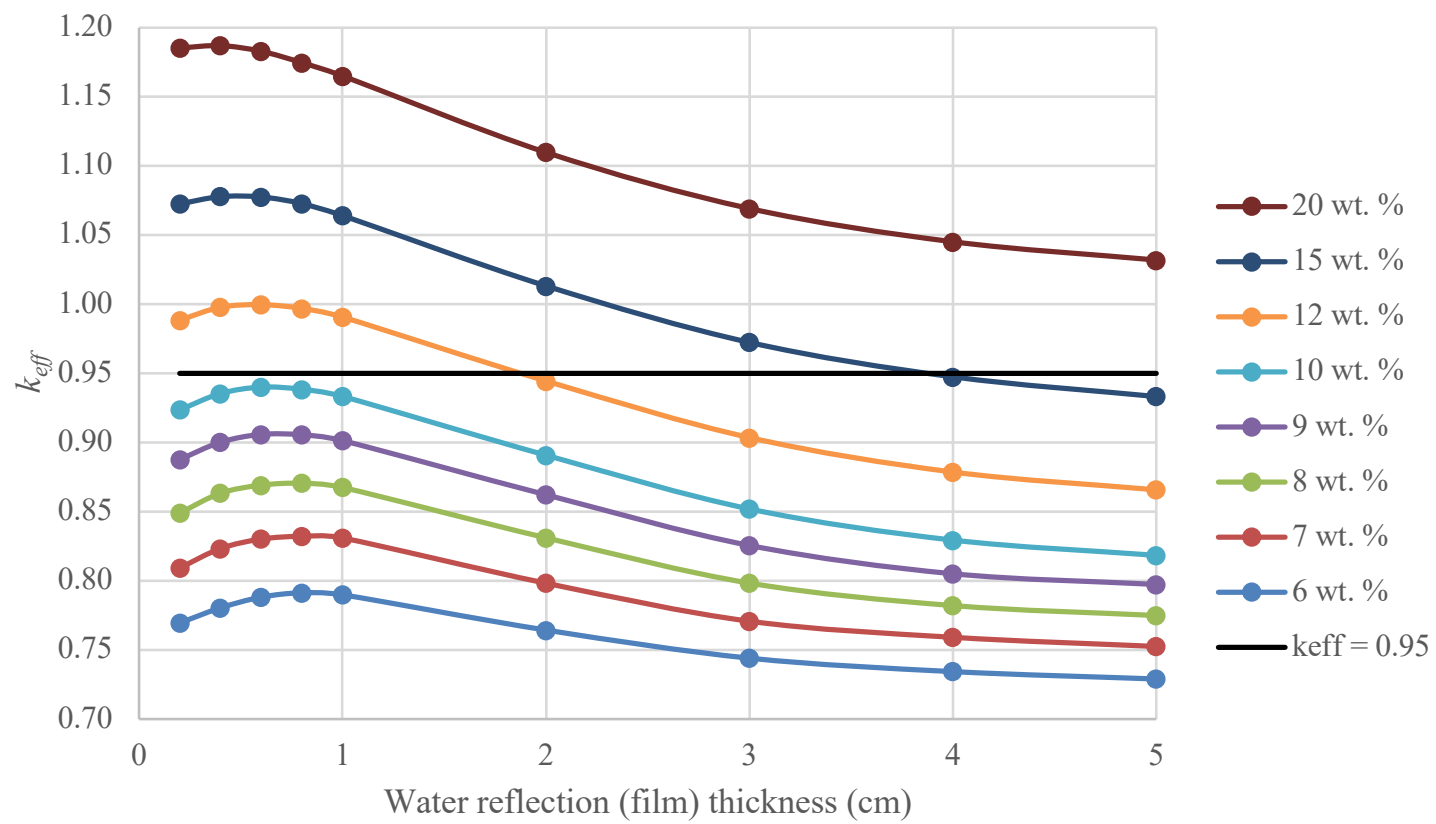

Figure 15. $k_{\text {eff }}$ results for $\mathrm{HAC} 7 \mathrm{x} 1$ array with variable ${ }^{235} \mathrm{U}$ enrichments.

Table 10. $k_{\text {eff }}$ values for $7 \times 1$ array model with variable ${ }^{235} \mathrm{U}$ enrichment

\begin{tabular}{|c|c|c|c|c|c|c|c|c|}
\hline \multirow{2}{*}{$\begin{array}{l}\text { Film thickness } \\
\text { (cm) }\end{array}$} & \multicolumn{8}{|c|}{${ }^{235} \mathrm{U}$ enrichment (wt.\%) } \\
\hline & 6 & 7 & 8 & 9 & 10 & 12 & 15 & 20 \\
\hline 0.2 & 0.76954 & 0.80927 & 0.84906 & 0.88772 & 0.92361 & 0.98853 & 1.07261 & 1.18535 \\
\hline 0.4 & 0.78040 & 0.82332 & 0.86332 & 0.90019 & 0.93543 & 0.99781 & 1.07781 & 1.18701 \\
\hline 0.6 & 0.78817 & 0.83016 & 0.86916 & 0.90586 & 0.94006 & 0.99968 & 1.07757 & 1.18295 \\
\hline 0.8 & 0.79132 & 0.83217 & 0.87053 & 0.90559 & 0.93850 & 0.99699 & 1.07279 & 1.17472 \\
\hline 1 & 0.78985 & 0.83096 & 0.86749 & 0.90138 & 0.93334 & 0.99075 & 1.06414 & 1.16515 \\
\hline 2 & 0.76438 & 0.79828 & 0.83111 & 0.86225 & 0.89086 & 0.94453 & 1.01328 & 1.10984 \\
\hline 3 & 0.74405 & 0.77078 & 0.79835 & 0.82558 & 0.85198 & 0.90359 & 0.97241 & 1.06925 \\
\hline 4 & 0.73433 & 0.75914 & 0.78208 & 0.80510 & 0.82944 & 0.87866 & 0.94753 & 1.04520 \\
\hline 5 & 0.72899 & 0.75251 & 0.77490 & 0.79736 & 0.81840 & 0.86578 & 0.93325 & 1.03199 \\
\hline
\end{tabular}

Since there is only one tier in the $7 \times 1$ array, the study was performed again with the spheres moved to the axial center of the cylinders to determine any effects. The results, shown in Figure 16 and Table 11, are even more similar to those with the $7 \times 2$ array, demonstrating that the HUR spheres are driving system reactivity and that axial leakage from these spheres does not have a significant impact. 


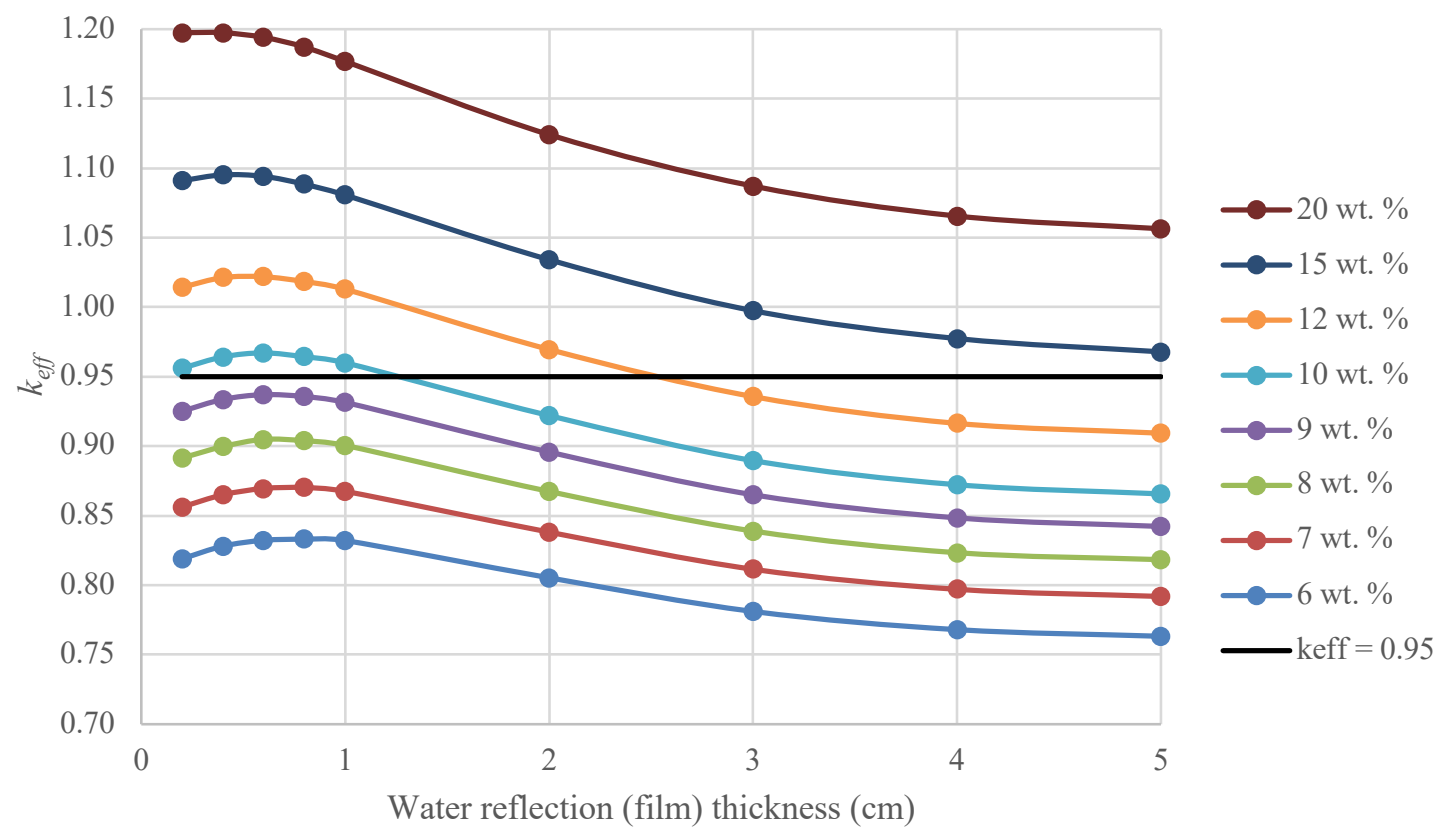

Figure 16. $k_{\text {eff }}$ results for $\mathrm{HAC} 7 \times 1$ array with variable ${ }^{235} \mathrm{U}$ enrichments and axially centered HUR spheres.

Table 11. $k_{\text {eff }}$ Values for $7 \times 1$ Array Model with Variable ${ }^{235} U$ Enrichment and axially centered HUR spheres

\begin{tabular}{ccccccccc}
\hline Film thickness & \multicolumn{7}{c}{${ }^{235} \mathbf{U}$ enrichment (wt.\%) } \\
\cline { 2 - 9 }$(\mathbf{c m})$ & $\mathbf{6}$ & $\mathbf{7}$ & $\mathbf{8}$ & $\mathbf{9}$ & $\mathbf{1 0}$ & $\mathbf{1 2}$ & $\mathbf{1 5}$ & $\mathbf{2 0}$ \\
\hline 0.2 & 0.81901 & 0.85630 & 0.89154 & 0.92521 & 0.95611 & 1.01437 & 1.09106 & 1.19750 \\
0.4 & 0.82808 & 0.86504 & 0.89971 & 0.93364 & 0.96425 & 1.02130 & 1.09521 & 1.19746 \\
0.6 & 0.83230 & 0.86957 & 0.90492 & 0.93708 & 0.96711 & 1.02189 & 1.09412 & 1.19411 \\
0.8 & 0.83304 & 0.87023 & 0.90392 & 0.93570 & 0.96431 & 1.01840 & 1.08845 & 1.18717 \\
1 & 0.83214 & 0.86752 & 0.90056 & 0.93149 & 0.96000 & 1.01293 & 1.08068 & 1.17685 \\
2 & 0.80534 & 0.83818 & 0.86746 & 0.89581 & 0.92203 & 0.96959 & 1.03416 & 1.12414 \\
3 & 0.78112 & 0.81147 & 0.83897 & 0.86508 & 0.88965 & 0.93568 & 0.99749 & 1.08714 \\
4 & 0.76804 & 0.79705 & 0.82339 & 0.84844 & 0.87229 & 0.91641 & 0.97744 & 1.06557 \\
5 & 0.76326 & 0.79190 & 0.81839 & 0.84227 & 0.86570 & 0.90935 & 0.96789 & 1.05643 \\
\hline
\end{tabular}

Less conservative analyses, particularly evaluation of the HUR modeling (amount and shape/placement), may demonstrate that higher enrichments are permissible. Justification of these less conservative HUR modeling approaches should be generated in future work. Some slight improvements may also be realized with more realistic overpack modeling if testing results support such model refinements. There are no known/accepted modeling modifications that will reduce reactivity to an acceptable level at the top of the enrichment range. The only viable approach to allow enrichments approaching $20 \mathrm{wt} . \%{ }^{235} \mathrm{U}$ in a $30 \mathrm{~B}$ cylinder is to decrease $N$, thereby reducing the number of cylinders that may be included in a single shipment. The remainder of this section investigates smaller array options.

The next several figures and tables show the results for more smaller size arrays with the same range of enrichments and the same parameter variations as those included in the $7 \times 2$ and $7 \times 1$ arrays.

- $3 \times 2$ array, HUR spheres at adjacent ends of cylinders: Figure 17, Figure 18, and Table 12 
- $3 \times 1$ array, HUR sphere centered axially: Figure 19, Figure 20, and Table 13

- $2 \times 2$ array, HUR sphere centered axially: Figure 21, Figure 22 and Table 14

- $2 \times 1$ array, HUR sphere centered axially: Figure 23 and Table 15

- $1 \times 2$ array, HUR sphere centered axially: Figure 24 and Table 16

- $1 \times 2$ array, HUR sphere at adjacent ends: Figure 26 and Table 18

- $1 \times 1$ array, HUR sphere centered axially: Figure 26 and Table 18
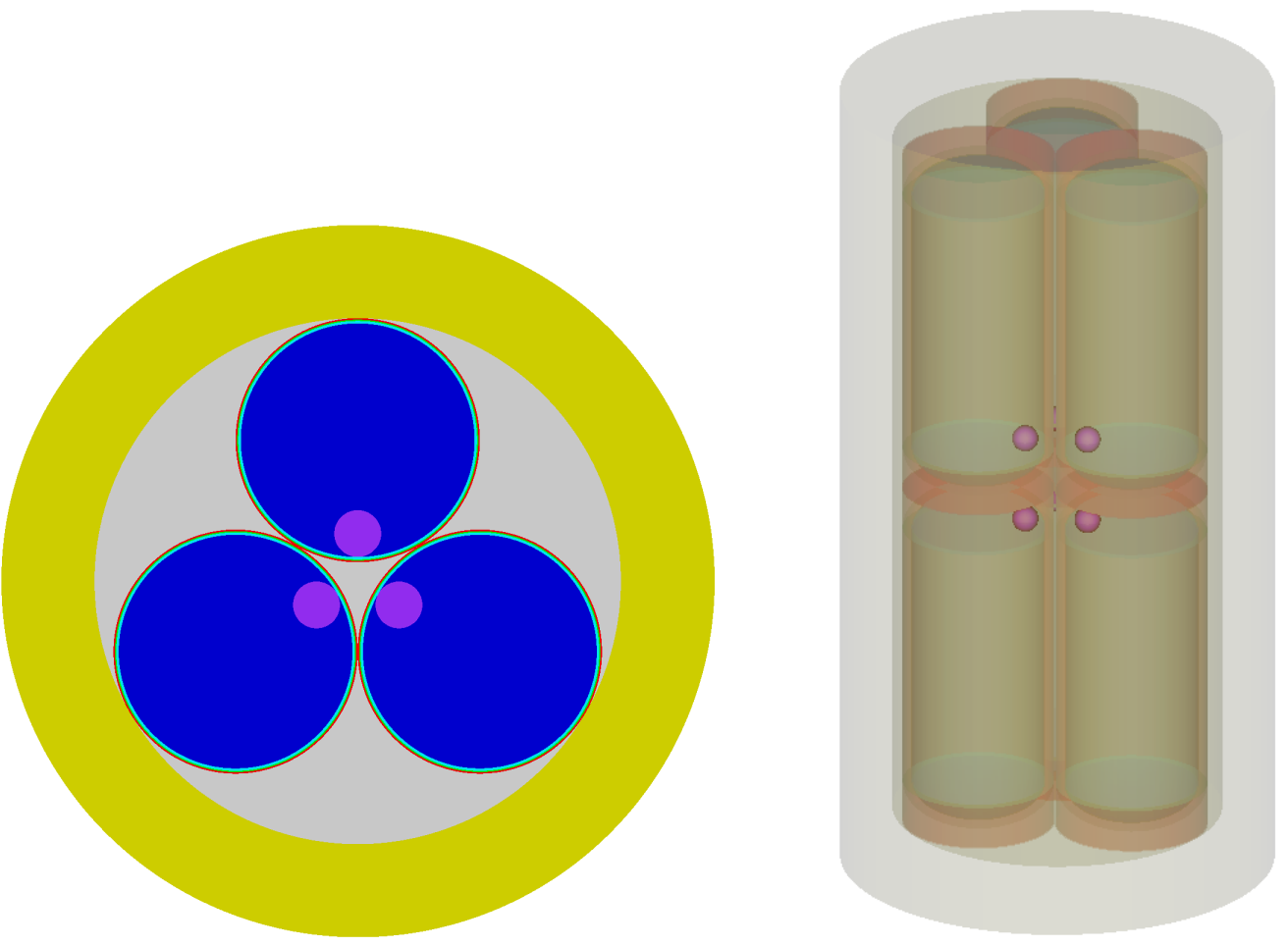

Figure 17. $3 \times 2$ HAC array with HUR sphere towards the adjacent cylinder ends. 


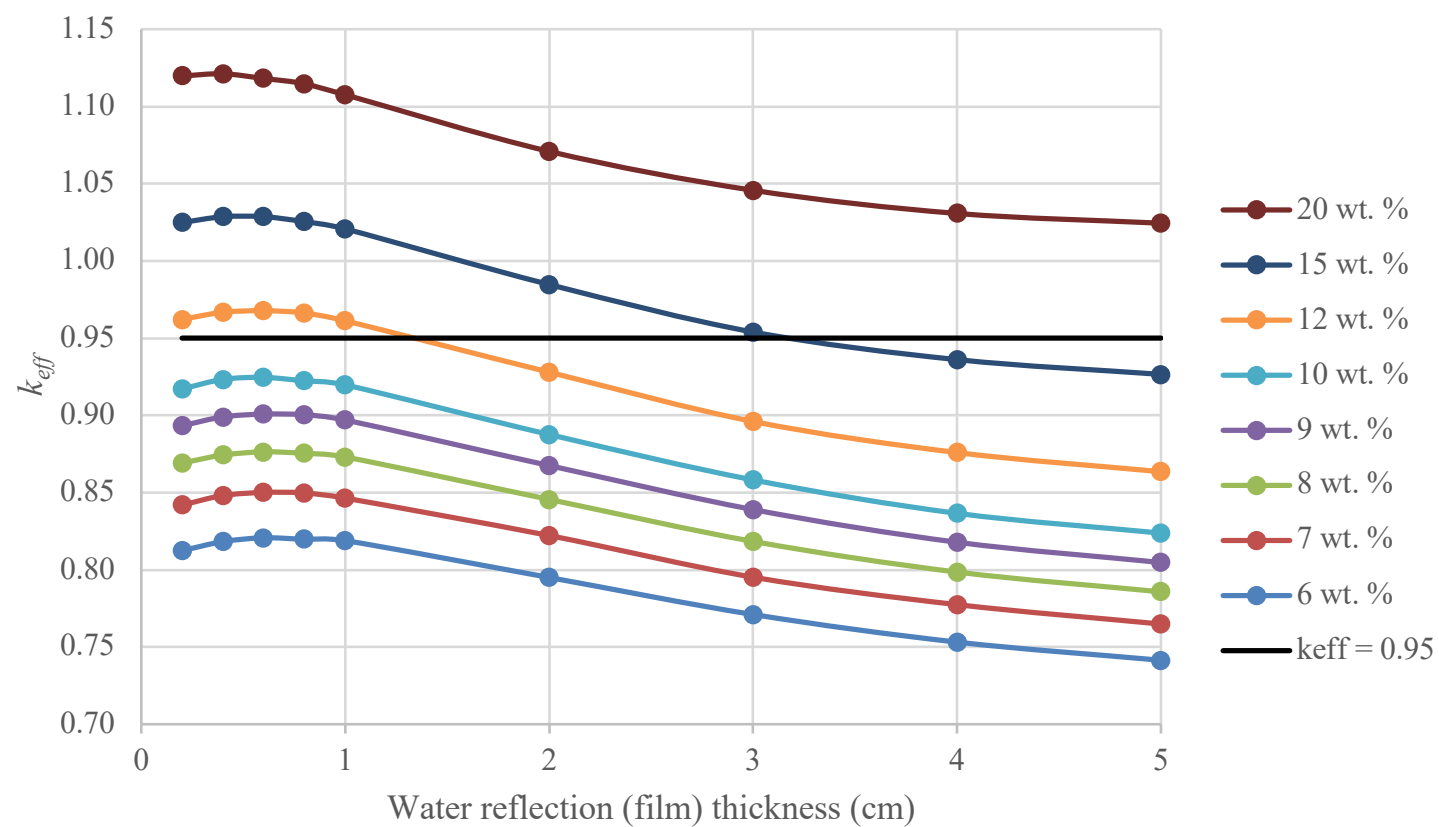

Figure 18. $\boldsymbol{k}_{\text {eff }}$ results for HAC $3 \times 2$ array with variable ${ }^{235} \mathrm{U}$ enrichments and HUR spheres at the adjacent cylinder ends.

Table 12. $k_{\text {eff }}$ values for $3 \times 2$ array model with variable ${ }^{235} U$ enrichment

\begin{tabular}{ccccccccc}
\hline \multirow{2}{*}{$\begin{array}{c}\text { Film thickness } \\
(\mathbf{c m})\end{array}$} & $\mathbf{6}$ & $\mathbf{7}$ & $\mathbf{8}$ & $\mathbf{9}$ & $\mathbf{1 0}$ & $\mathbf{1 2}$ & $\mathbf{1 5}$ & $\mathbf{2 0}$ \\
\cline { 2 - 9 } & $\mathbf{6}$ & $\mathbf{2 3 5}$ enrichment (wt.\%) \\
0.2 & 0.81236 & 0.84191 & 0.86911 & 0.89324 & 0.91708 & 0.96212 & 1.02484 & 1.11972 \\
0.4 & 0.81821 & 0.84805 & 0.87426 & 0.89896 & 0.92324 & 0.96670 & 1.02856 & 1.12111 \\
0.6 & 0.82069 & 0.85003 & 0.87633 & 0.90075 & 0.92452 & 0.96771 & 1.02858 & 1.11809 \\
0.8 & 0.81971 & 0.84976 & 0.87536 & 0.90035 & 0.92229 & 0.96624 & 1.02536 & 1.11469 \\
1 & 0.81886 & 0.84638 & 0.87303 & 0.89697 & 0.91969 & 0.96121 & 1.02070 & 1.10756 \\
2 & 0.79500 & 0.82216 & 0.84556 & 0.86747 & 0.88758 & 0.92793 & 0.98469 & 1.07087 \\
3 & 0.77103 & 0.79519 & 0.81835 & 0.83897 & 0.85817 & 0.89601 & 0.95392 & 1.04568 \\
4 & 0.75316 & 0.77743 & 0.79852 & 0.81782 & 0.83655 & 0.87589 & 0.93606 & 1.03070 \\
5 & 0.74141 & 0.76487 & 0.78572 & 0.80471 & 0.82373 & 0.86349 & 0.92651 & 1.02438 \\
\hline
\end{tabular}



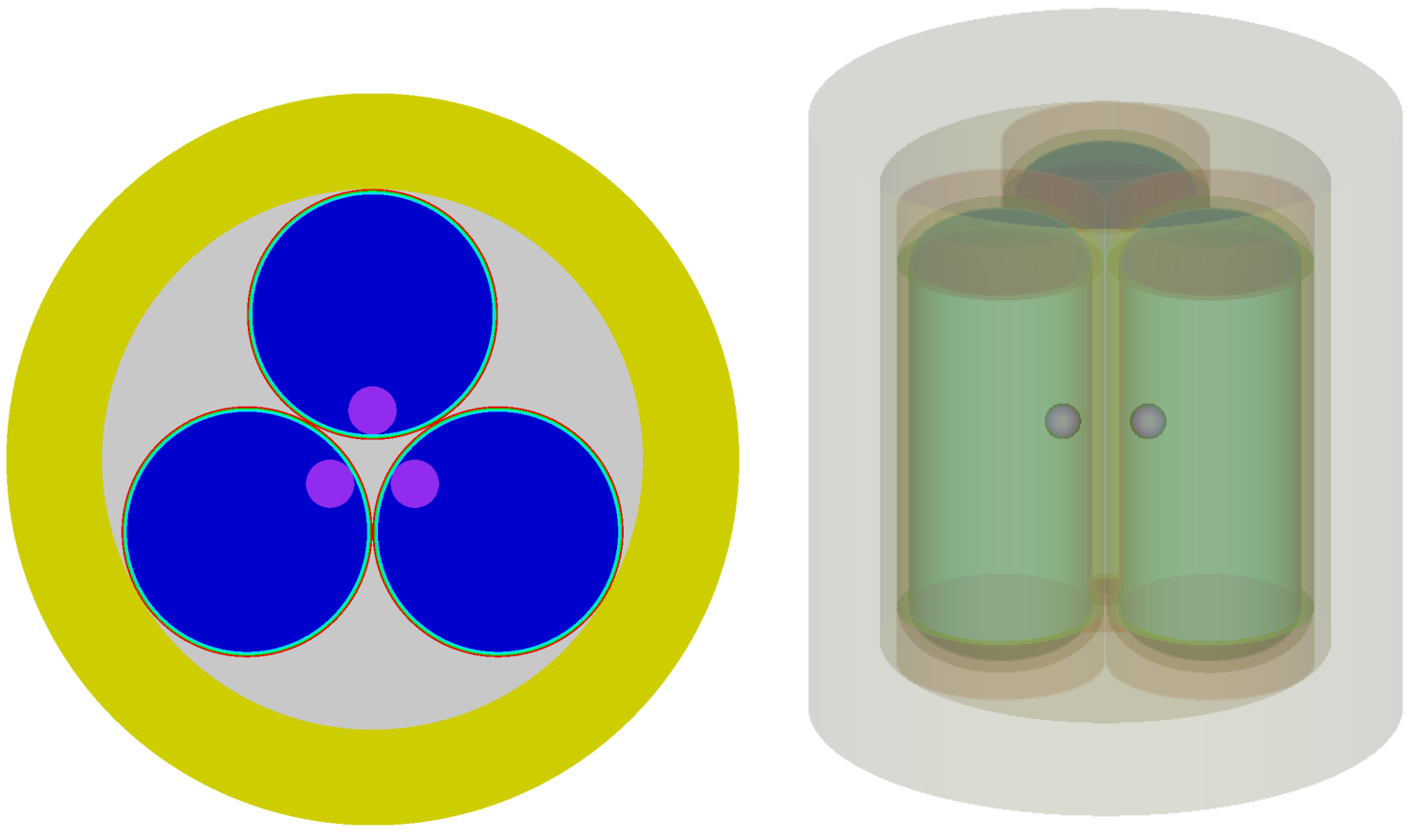

Figure 19.3 × 1 HAC array with axially centered HUR spheres.

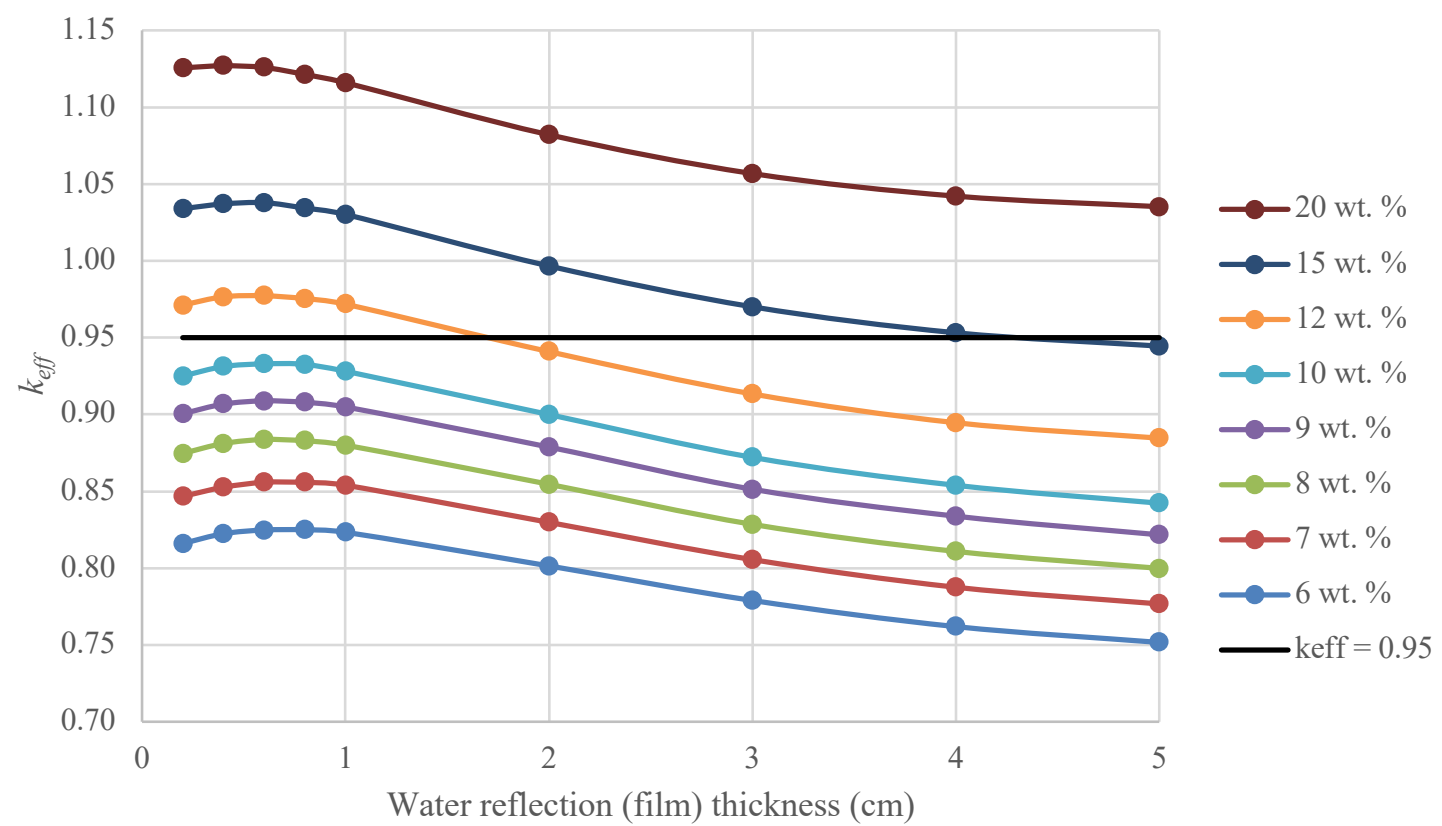

Figure 20. $k_{\text {eff }}$ results for HAC $3 \times 1$ array with variable ${ }^{235} \mathrm{U}$ enrichments and axially centered HUR spheres. 
Table 13. $k_{\text {eff }}$ values for $3 \times 1$ array model with variable ${ }^{235} U$ enrichment and axially centered HUR spheres

\begin{tabular}{ccccccccc}
\hline Film thickness & \multicolumn{7}{c}{${ }^{235} \mathbf{U}$ enrichment (wt.\%) } \\
\cline { 2 - 9 }$(\mathbf{c m})$ & $\mathbf{6}$ & $\mathbf{7}$ & $\mathbf{8}$ & $\mathbf{9}$ & $\mathbf{1 0}$ & $\mathbf{1 2}$ & $\mathbf{1 5}$ & $\mathbf{2 0}$ \\
\hline 0.2 & 0.81603 & 0.84668 & 0.87468 & 0.90050 & 0.92505 & 0.97124 & 1.03397 & 1.12561 \\
0.4 & 0.82239 & 0.85262 & 0.88110 & 0.90674 & 0.93119 & 0.97659 & 1.03702 & 1.12694 \\
0.6 & 0.82478 & 0.85583 & 0.88367 & 0.90883 & 0.93291 & 0.97723 & 1.03785 & 1.12585 \\
0.8 & 0.82493 & 0.85573 & 0.88286 & 0.90791 & 0.93266 & 0.97541 & 1.03432 & 1.12131 \\
1 & 0.82333 & 0.85395 & 0.88003 & 0.90491 & 0.92815 & 0.97181 & 1.03020 & 1.11594 \\
2 & 0.80143 & 0.82978 & 0.85457 & 0.87877 & 0.89996 & 0.94092 & 0.99665 & 1.08207 \\
3 & 0.77894 & 0.80554 & 0.82849 & 0.85135 & 0.87208 & 0.91336 & 0.97008 & 1.05680 \\
4 & 0.76192 & 0.78754 & 0.81087 & 0.83380 & 0.85390 & 0.89463 & 0.95318 & 1.04210 \\
5 & 0.75162 & 0.77670 & 0.79985 & 0.82168 & 0.84226 & 0.88459 & 0.94451 & 1.03525 \\
\hline
\end{tabular}
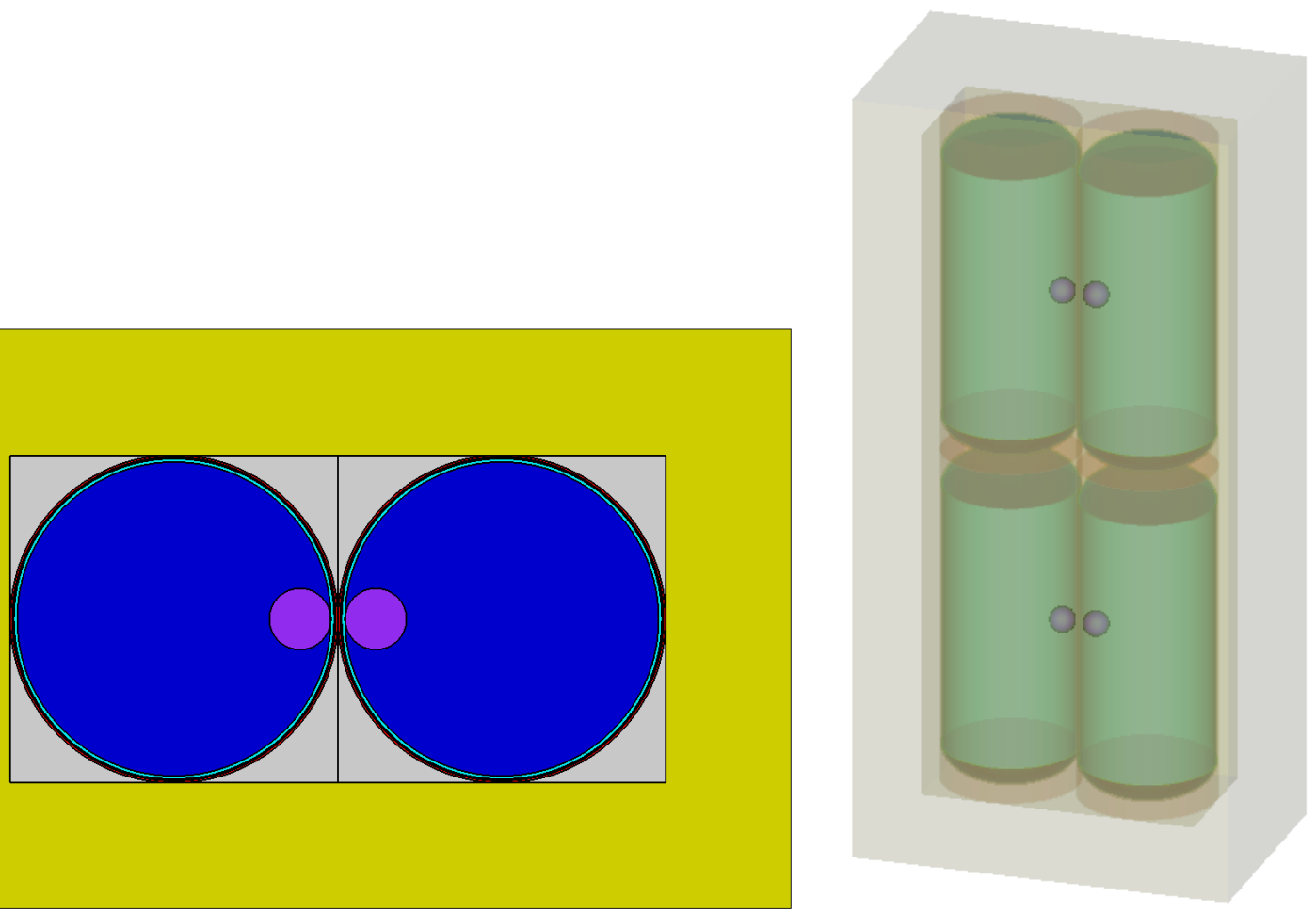

Figure 21. 2 × 2 HAC array with axially centered HUR spheres. 


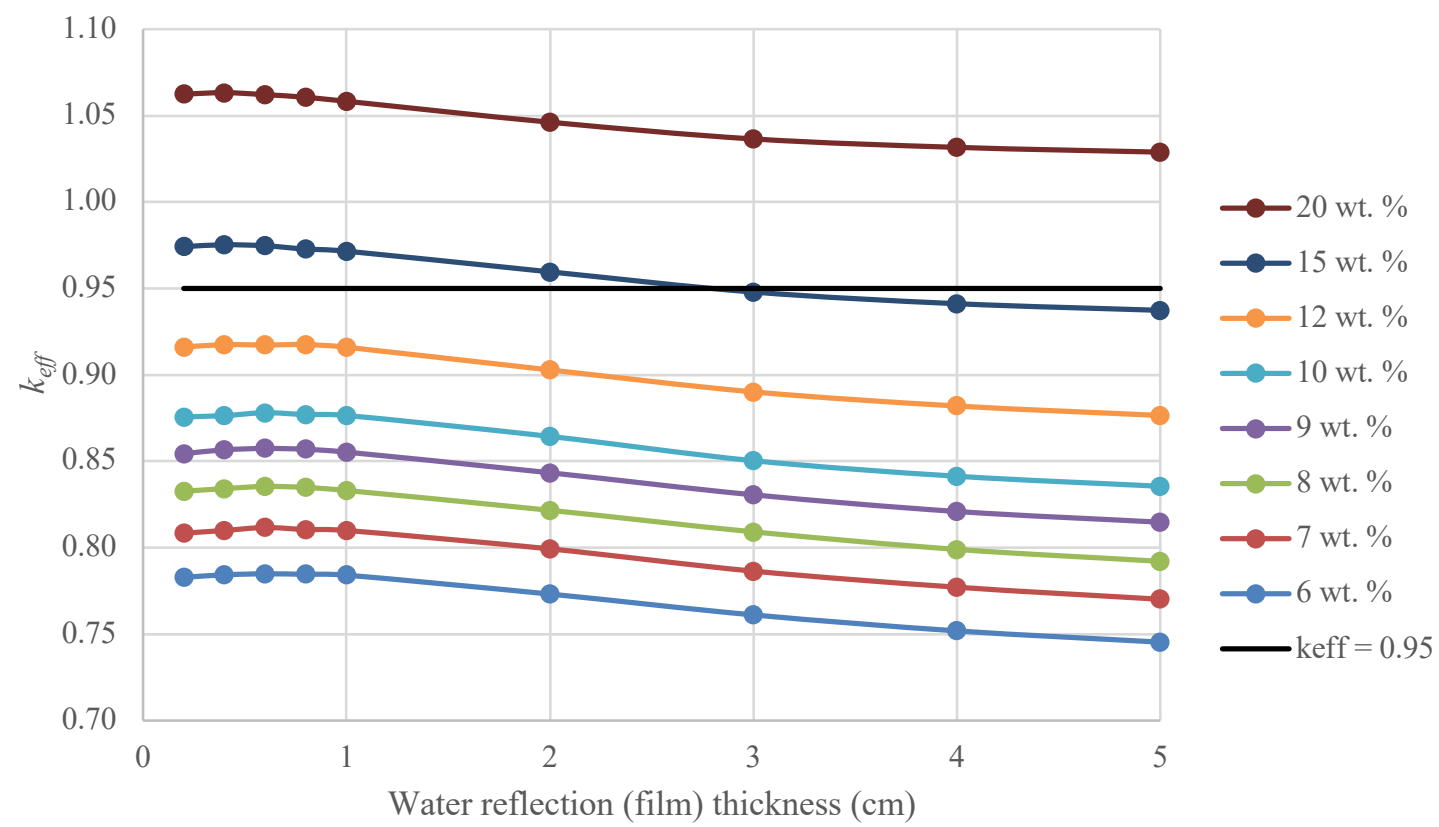

Figure 22. $k_{\text {eff }}$ results for HAC $2 \times 2$ array with variable ${ }^{235} \mathrm{U}$ enrichments and axially centered HUR spheres.

Table 14. $k_{\text {eff }}$ values for $2 \times 2$ array model with variable ${ }^{235} U$ enrichment and axially centered HUR spheres

\begin{tabular}{|c|c|c|c|c|c|c|c|c|}
\hline \multirow{2}{*}{$\begin{array}{l}\text { Film thickness } \\
\text { (cm) }\end{array}$} & \multicolumn{8}{|c|}{${ }^{235} \mathrm{U}$ enrichment (wt.\%) } \\
\hline & 6 & 7 & 8 & 9 & 10 & 12 & 15 & 20 \\
\hline 0.2 & 0.78288 & 0.80842 & 0.83264 & 0.85441 & 0.87573 & 0.91613 & 0.97419 & 1.06242 \\
\hline 0.4 & 0.78432 & 0.80999 & 0.83421 & 0.85664 & 0.87644 & 0.91748 & 0.97528 & 1.06327 \\
\hline 0.6 & 0.78491 & 0.81167 & 0.83545 & 0.85742 & 0.87810 & 0.91729 & 0.97469 & 1.06213 \\
\hline 0.8 & 0.78461 & 0.81053 & 0.83487 & 0.85696 & 0.87703 & 0.91753 & 0.97277 & 1.06059 \\
\hline 1 & 0.78413 & 0.80999 & 0.83312 & 0.85531 & 0.87652 & 0.91600 & 0.97158 & 1.05829 \\
\hline 2 & 0.77319 & 0.79934 & 0.82166 & 0.84337 & 0.86441 & 0.90285 & 0.95961 & 1.04619 \\
\hline 3 & 0.76113 & 0.78645 & 0.80918 & 0.83061 & 0.85035 & 0.89016 & 0.94792 & 1.03649 \\
\hline 4 & 0.75189 & 0.77717 & 0.79903 & 0.82097 & 0.84136 & 0.88200 & 0.94119 & 1.03163 \\
\hline 5 & 0.74537 & 0.77018 & 0.79214 & 0.81477 & 0.83555 & 0.87651 & 0.93734 & 1.02886 \\
\hline
\end{tabular}




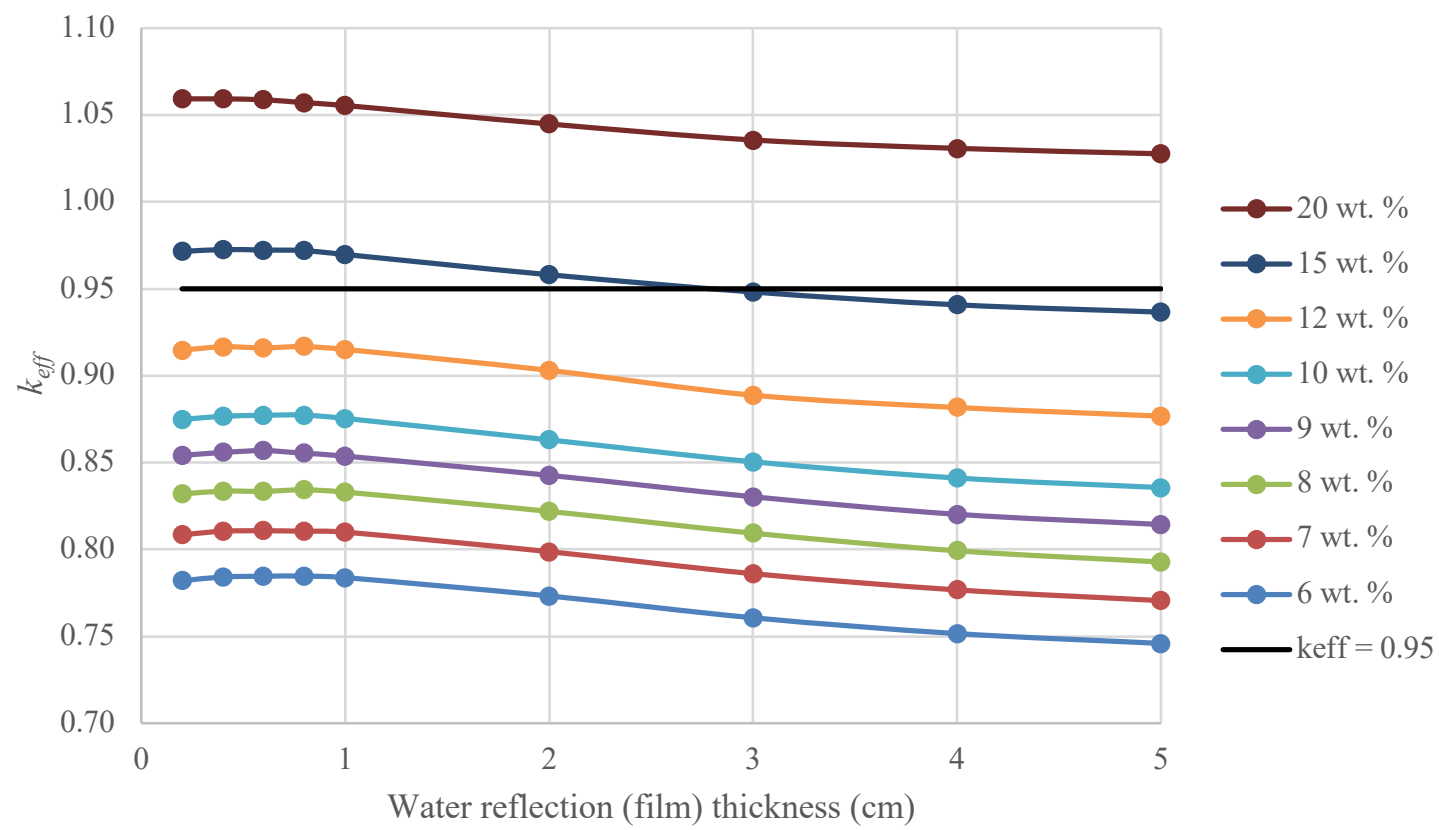

Figure 23. $k_{\text {eff }}$ results for HAC $2 \times 1$ array with variable ${ }^{235} \mathrm{U}$ enrichments and axially centered HUR spheres.

Table 15. $k_{\text {eff }}$ values for $2 \times 1$ array model with variable ${ }^{235} U$ enrichment and axially centered HUR spheres

\begin{tabular}{ccccccccc}
\hline \multirow{2}{*}{$\begin{array}{c}\text { Film thickness } \\
\text { (cm) }\end{array}$} & $\mathbf{6}$ & $\mathbf{7}$ & $\mathbf{8}$ & $\mathbf{9}$ & $\mathbf{1 0}$ & $\mathbf{1 2}$ & $\mathbf{1 5}$ & $\mathbf{2 0}$ \\
\cline { 2 - 9 } & $\mathbf{6}$ & $\mathbf{2 3 5}$ enrichment (wt.\%) \\
0.2 & 0.78200 & 0.80845 & 0.83194 & 0.85416 & 0.87481 & 0.91475 & 0.97150 & 1.05932 \\
0.4 & 0.78416 & 0.81049 & 0.83356 & 0.85582 & 0.87663 & 0.91662 & 0.97259 & 1.05929 \\
0.6 & 0.78459 & 0.81077 & 0.83346 & 0.85687 & 0.87720 & 0.91605 & 0.97232 & 1.05881 \\
0.8 & 0.78469 & 0.81047 & 0.83435 & 0.85535 & 0.87736 & 0.91677 & 0.97201 & 1.05710 \\
1 & 0.78379 & 0.80996 & 0.83299 & 0.85372 & 0.87541 & 0.91513 & 0.96976 & 1.05551 \\
2 & 0.77324 & 0.79873 & 0.82190 & 0.84266 & 0.86306 & 0.90306 & 0.95812 & 1.04486 \\
3 & 0.76068 & 0.78606 & 0.80935 & 0.83031 & 0.85044 & 0.88878 & 0.94816 & 1.03565 \\
4 & 0.75158 & 0.77673 & 0.79924 & 0.82023 & 0.84112 & 0.88171 & 0.94079 & 1.03084 \\
5 & 0.74593 & 0.77055 & 0.79277 & 0.81437 & 0.83561 & 0.87673 & 0.93660 & 1.02771 \\
\hline
\end{tabular}




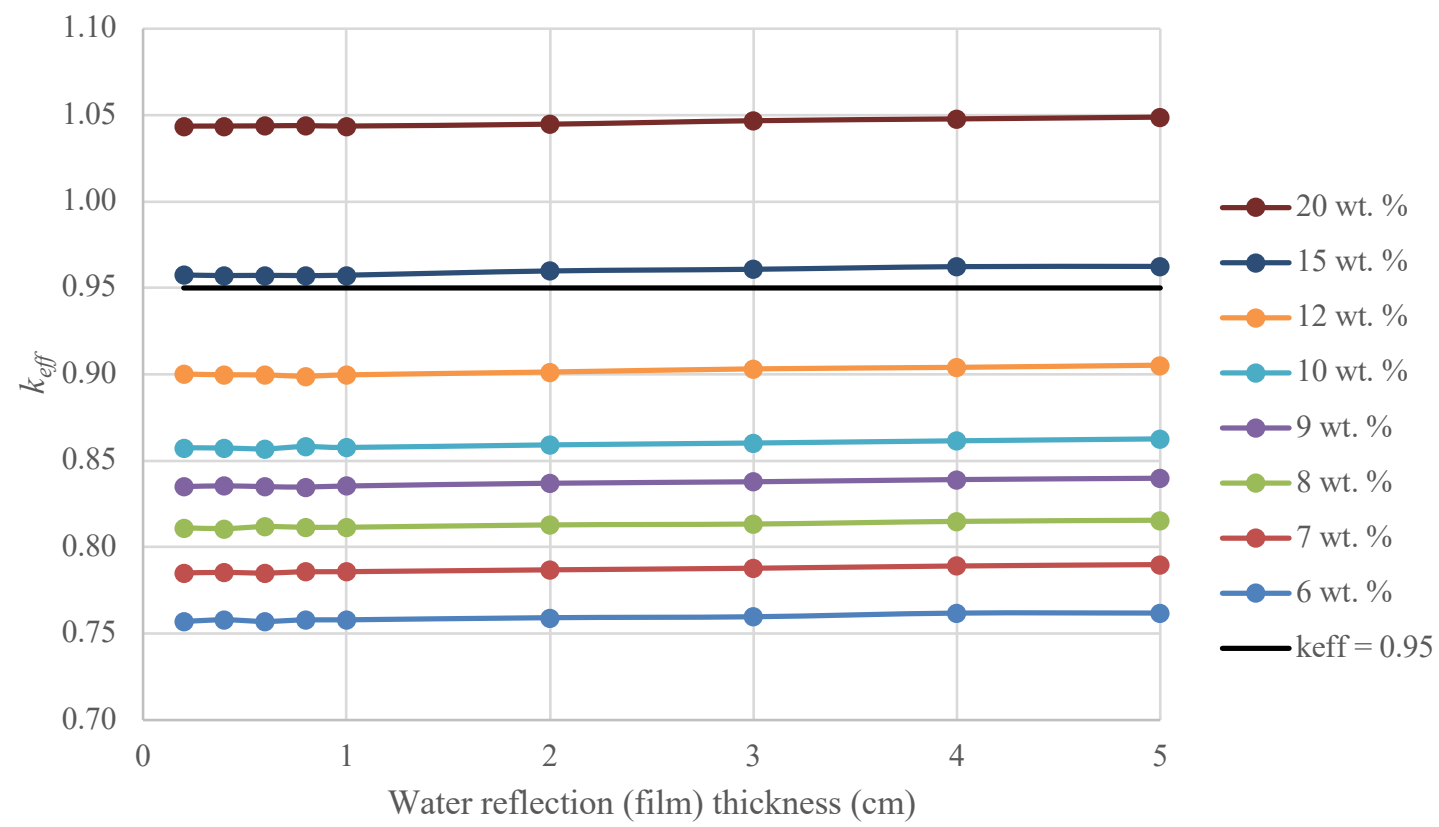

Figure 24. $k_{\text {eff }}$ results for HAC $1 \times 2$ array with variable ${ }^{235} \mathrm{U}$ enrichments and axially centered HUR spheres.

Table $16 . k_{\text {eff }}$ values for $1 \times 2$ array with variable ${ }^{235} U$ enrichment and axially centered HUR spheres

\begin{tabular}{ccccccccc}
\hline Film thickness & \multicolumn{8}{c}{${ }^{235}$ U enrichment (wt.\%) } \\
\cline { 2 - 9 }$(\mathbf{c m})$ & $\mathbf{6}$ & $\mathbf{7}$ & $\mathbf{8}$ & $\mathbf{9}$ & $\mathbf{1 0}$ & $\mathbf{1 2}$ & $\mathbf{1 5}$ & $\mathbf{2 0}$ \\
\hline 0.2 & 0.75710 & 0.78514 & 0.81128 & 0.83508 & 0.85757 & 0.90018 & 0.95749 & 1.04364 \\
0.4 & 0.75800 & 0.78544 & 0.81078 & 0.83551 & 0.85739 & 0.89978 & 0.95719 & 1.04370 \\
0.6 & 0.75710 & 0.78507 & 0.81193 & 0.83506 & 0.85695 & 0.89968 & 0.95730 & 1.04379 \\
0.8 & 0.75800 & 0.78582 & 0.81157 & 0.83480 & 0.85829 & 0.89892 & 0.95717 & 1.04396 \\
1 & 0.75800 & 0.78586 & 0.81156 & 0.83543 & 0.85772 & 0.89972 & 0.95739 & 1.04368 \\
2 & 0.75924 & 0.78692 & 0.81291 & 0.83702 & 0.85921 & 0.90137 & 0.95984 & 1.04476 \\
3 & 0.75978 & 0.78785 & 0.81342 & 0.83787 & 0.86029 & 0.90319 & 0.96081 & 1.04676 \\
4 & 0.76189 & 0.78915 & 0.81495 & 0.83914 & 0.86157 & 0.90407 & 0.96233 & 1.04781 \\
5 & 0.76192 & 0.78995 & 0.81562 & 0.83991 & 0.86268 & 0.90533 & 0.96247 & 1.04883 \\
\hline
\end{tabular}




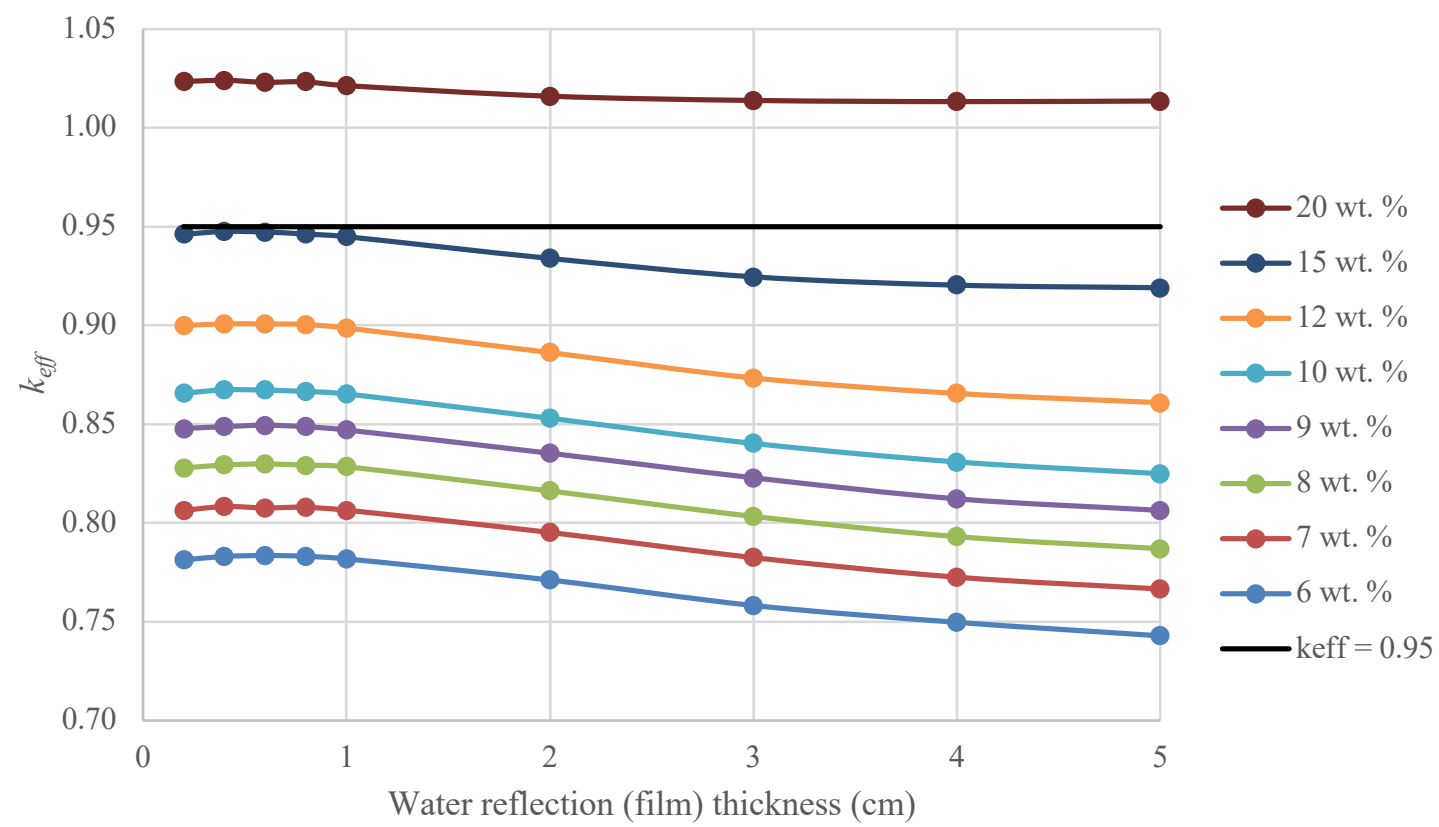

Figure 25. $k_{\text {eff }}$ results for HAC $1 \times 2$ array with variable ${ }^{235} \mathrm{U}$ enrichments and HUR spheres at the adjacent cylinder ends.

Table 17. $k_{\text {eff }}$ values for $1 \times 2$ array with variable ${ }^{235} U$ enrichments and HUR spheres at the adjacent cylinder ends

\begin{tabular}{ccccccccc}
\hline \multirow{2}{*}{$\begin{array}{c}\text { Film thickness } \\
\text { (cm) }\end{array}$} & $\mathbf{6}$ & $\mathbf{7}$ & $\mathbf{8}$ & $\mathbf{9}$ & $\mathbf{1 0}$ & $\mathbf{1 2}$ & $\mathbf{1 5}$ & $\mathbf{2 0}$ \\
\cline { 2 - 8 } & 0.78134 & 0.80643 & 0.82788 & 0.84784 & 0.86572 & 0.89993 & 0.94619 & 1.02354 \\
0.2 & 0.78308 & 0.80834 & 0.82935 & 0.84880 & 0.86743 & 0.90084 & 0.94759 & 1.02410 \\
0.4 & 0.78356 & 0.80768 & 0.82994 & 0.84953 & 0.86730 & 0.90076 & 0.94733 & 1.02313 \\
0.6 & 0.78317 & 0.80798 & 0.82922 & 0.84876 & 0.86659 & 0.90054 & 0.94628 & 1.02337 \\
0.8 & 0.78184 & 0.80650 & 0.82849 & 0.84711 & 0.86533 & 0.89873 & 0.94496 & 1.02142 \\
1 & 0.77116 & 0.79523 & 0.81622 & 0.83532 & 0.85302 & 0.88629 & 0.93395 & 1.01607 \\
2 & 0.75826 & 0.78250 & 0.80335 & 0.82291 & 0.84030 & 0.87343 & 0.92463 & 1.01393 \\
3 & 0.74974 & 0.77259 & 0.79312 & 0.81226 & 0.83093 & 0.86561 & 0.92042 & 1.01334 \\
4 & 0.74290 & 0.76660 & 0.78702 & 0.80640 & 0.82499 & 0.86092 & 0.91911 & 1.01364 \\
5 & & & & & & &
\end{tabular}




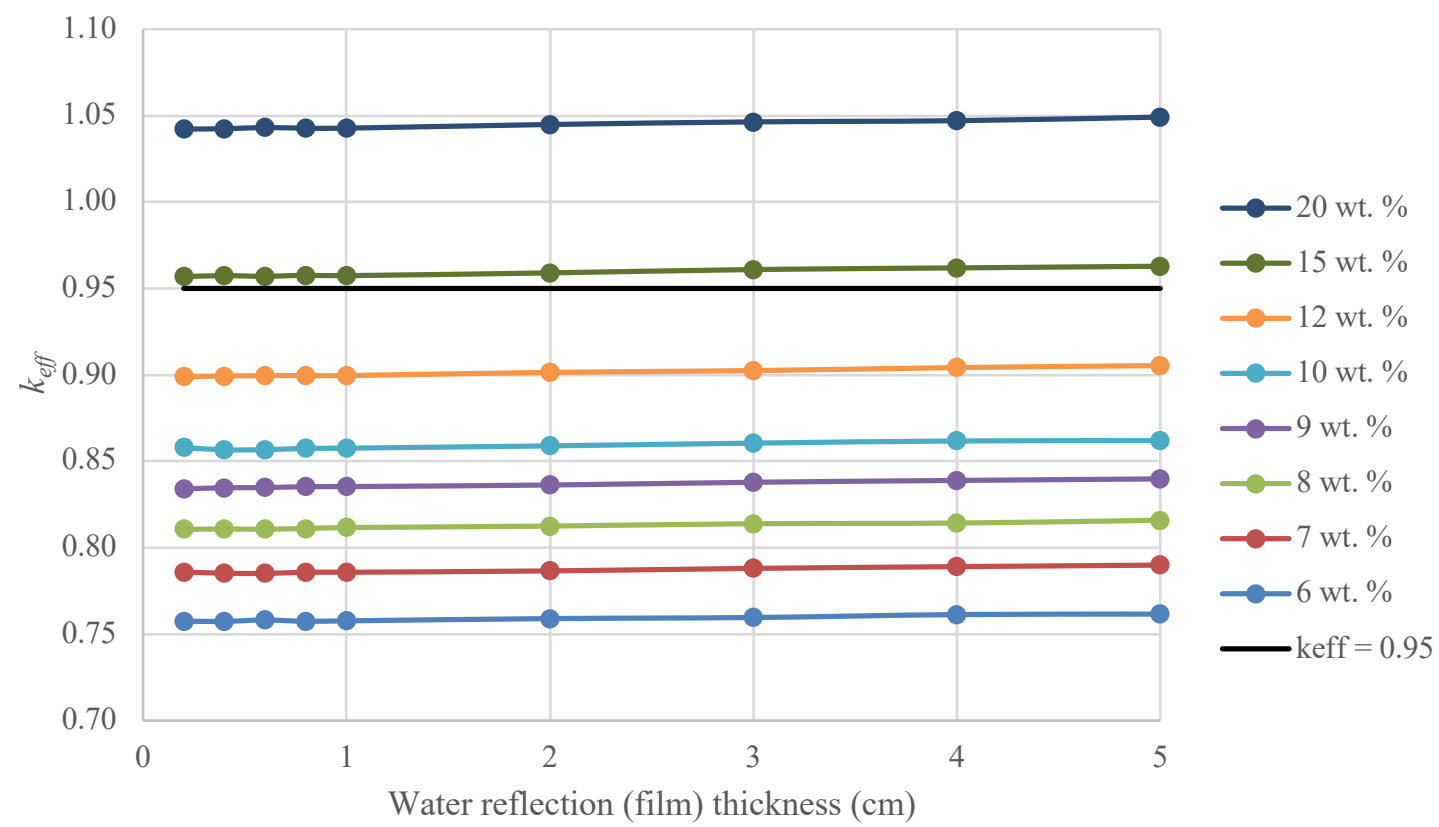

Figure 26. $k_{\text {eff }}$ results for HAC $1 \times 1$ array with variable ${ }^{235} U$ enrichments and axially centered HUR sphere.

Table 18. $k_{\text {eff }}$ values for $1 \times 1$ array with variable ${ }^{235} U$ enrichment and axially centered HUR spheres

\begin{tabular}{ccccccccc}
\hline \multirow{2}{*}{$\begin{array}{c}\text { Film thickness } \\
(\mathbf{c m})\end{array}$} & $\mathbf{6}$ & $\mathbf{7}$ & $\mathbf{8}$ & $\mathbf{9}$ & $\mathbf{1 0}$ & $\mathbf{1 2}$ & $\mathbf{1 5}$ & $\mathbf{2 0}$ \\
\cline { 2 - 8 } & 0.75748 & 0.78591 & 0.81065 & 0.83403 & 0.85796 & 0.89901 & 0.95685 & 1.04224 \\
0.2 & 0.75740 & 0.78526 & 0.81080 & 0.83469 & 0.85665 & 0.89932 & 0.95741 & 1.04241 \\
0.4 & 0.75817 & 0.78513 & 0.81072 & 0.83478 & 0.85671 & 0.89960 & 0.95703 & 1.04309 \\
0.6 & 0.75744 & 0.78585 & 0.81112 & 0.83533 & 0.85749 & 0.89958 & 0.95762 & 1.04270 \\
0.8 & 0.75769 & 0.78582 & 0.81166 & 0.83538 & 0.85761 & 0.89960 & 0.95741 & 1.04274 \\
1 & 0.75900 & 0.78659 & 0.81253 & 0.83628 & 0.85892 & 0.90146 & 0.95901 & 1.04485 \\
2 & 0.75963 & 0.78805 & 0.81389 & 0.83787 & 0.86051 & 0.90246 & 0.96094 & 1.04636 \\
3 & 0.76132 & 0.78905 & 0.81426 & 0.83893 & 0.86175 & 0.90422 & 0.96189 & 1.04707 \\
4 & 0.76162 & 0.78994 & 0.81592 & 0.83982 & 0.86200 & 0.90538 & 0.96286 & 1.04914 \\
5 & & & & & & & & \\
\hline
\end{tabular}

The results show the difficulty in demonstrating enrichments greater than $15 \mathrm{wt} . \%$ can be proven safe for transportation and storage in 30B cylinders as they are currently designed. Depending on the additional margin required by the applicable validation, enrichments as high as 10 , possibly $12 \mathrm{wt} . \%$, may be shown to be safe for transport for very small arrays (potentially up to 2 cylinders maximum in a conveyance).

As the arrays become smaller, the interaction component, especially between the HUR in adjacent cylinders decreases. The magnitude of the variation in $k_{\text {eff }}$ with increasing water film thickness, including peaking at a thickness of about $0.6 \mathrm{~cm}$, decreases with smaller arrays. The $1 \times 2$ array with the HUR at the adjacent ends has some interaction and has the same variation trend. The $1 \times 2$ array with the HUR centered exhibits the same behavior as the $1 \mathrm{x} 1$ array with no HUR interaction - $k_{\text {eff }}$ steadily (although very slightly) increases with increasing water film thickness.

For comparison, the $1 \mathrm{x} 1$ arrays with the $0.6 \mathrm{~cm}$ thick water film thickness were analyzed with no HUR present, with HUR present, and with the HUR present with the spherical HF shell around the HUR 
(similar to the DN-30 analysis [8] and the ORNL assessment [1]). The results shown in Table 19 demonstrate the importance of the HUR and the HF (impurities) configuration to the system. The No $H U R$ and $H U R$, no HF ring values are slightly different than reported above due to slightly different models; difference is not significant. Also included in Table 19 is the energy of the average neutron lethargy causing fission (EALF). The lower the energy, the more thermal the system. As expected, the systems become less thermal with increasing enrichment. The presence of the HUR, with its water content - both with and without the HF spherical ring, moderates the systems, making them more thermal. The HF ring adds more hydrogen to the system, moderating the system even more.

Table 19. $k_{\text {eff }}$ and EALF values for $1 \times 1$ arrays with different HUR considerations

\begin{tabular}{cccc|rrr}
\hline $\begin{array}{c}\text { UF6 } \\
\text { enrichment } \\
\text { (wt.\%) }\end{array}$ & No HUR & $\begin{array}{c}\text { HUR, no HF } \\
\text { ring }\end{array}$ & $\begin{array}{c}\text { HUR with } \\
\text { HF ring }\end{array}$ & No HUR & $\begin{array}{c}\text { HUR, no HF } \\
\text { ring }\end{array}$ & $\begin{array}{c}\text { HUR with } \\
\text { HF ring }\end{array}$ \\
\cline { 2 - 7 } & 0.61483 & 0.75783 & 0.85869 & 952.47 & 184.19 & 47.73 \\
7 & 0.65579 & 0.78542 & 0.88404 & 1166.97 & 268.60 & 69.72 \\
8 & 0.69335 & 0.81146 & 0.90677 & 1389.12 & 371.34 & 98.40 \\
9 & 0.72817 & 0.83479 & 0.92890 & 1644.49 & 499.79 & 132.59 \\
10 & 0.76006 & 0.85777 & 0.94717 & 1891.83 & 646.36 & 178.44 \\
12 & 0.81883 & 0.89976 & 0.98203 & 2470.98 & 1019.25 & 297.85 \\
15 & 0.89505 & 0.95720 & 1.02923 & 3470.77 & 1725.56 & 563.02 \\
20 & 0.99995 & 1.04262 & 1.09765 & 5445.70 & 3280.98 & 1274.50 \\
\hline
\end{tabular}

Several approaches have been identified as options for lowering the system $k_{\text {eff }}$ of the higher end HALEU $\mathrm{UF}_{6}$ systems:

- Crediting a thicker 30B cylinder wall (demonstrated in DN-30 to decrease $k_{\text {eff }}$ values)

- Crediting more of the overpack structure (based on results of package testing)

- Varying the HUR model (for example, along the outside of the 30B as a crust or hemisphere build-up instead of a perfect sphere; this approach would ideally involve research on how and where deposits actually form and what aspects of the formation process could be credited)

- Decreasing the maximum allowed loading of a $30 \mathrm{~B}$ cylinder

- Designing a new cylinder - with embedded poison material and/or smaller size and/or thicker cylinder walls

Most of this analysis has addressed transportation operations. If HALEU enrichment level $\mathrm{UF}_{6}$ is going to be utilized in the nuclear industry, then storage must also be considered. The infinite array calculations in Section 3.3 demonstrate that infinite array calculations for the basis of storage are not a practical path.

However, just as smaller size arrays have shown that HALEU level enriched $\mathrm{UF}_{6}$ in $30 \mathrm{~B}$ cylinders may be deemed safe for transportation, storage of $30 \mathrm{~B}$ cylinders may also be deemed safe up to certain enrichments with limited storage arrays and required spacing between cylinders. Any enriched $\mathrm{UF}_{6}$ above approximately $12 \mathrm{wt} . \%$ will most likely require different modeling approaches and/or different containers/packages for storage and shipment. 



\section{VALIDATION}

Validation of computational methods used in criticality safety analyses is required by consensus standards $[21,22]$ and regulatory guidance [23]. This section addresses the validation basis for the $30 \mathrm{~B}$ cylinder analyses presented above in Section 3. Critical experiment selection is performed using S/U-based similarity assessment as discussed in Rearden et al. [5]. Critical experiment selection has been used in other HALEU validation analyses [24]. This process starts with the generation of sensitivity data for an application. The sensitivity data are combined with the covariance data described in Section 2.4.1.1 to determine the nuclear data-induced uncertainty in $k_{\text {eff }}$ for each application and each critical experiment considered for inclusion in the validation. The similarity assessment is based on how much of this uncertainty is shared between the application and each benchmark, as quantified using the $c_{\mathrm{k}}$ integral index described in Section 2.2.2. The applicable experiments are then used to calculate a bias and bias uncertainty for the computational method.

In this case, no experiments with readily available sensitivity data exceed the desired $c_{\mathrm{k}}$ threshold of 0.8 recommended by Rearden et al. [5]. The lack of experiments with a $c_{k}$ value in excess of 0.8 does not mean that a validation is impossible; a validation must be performed for all computed analysis results. The lack of highly applicable experiments indicates that the bias resulting from these benchmarks might not be representative of the bias for the application system. The solution to this is to apply an additional reactivity margin to ensure that the aggregate margin included in the bias, bias uncertainty, and additional margin conservatively represent the bias expected for the application. This section concludes with a brief discussion of the additional margins that may be needed as part of a license application for a $30 \mathrm{~B}$ cylinder containing $\mathrm{UF}_{6}$ enriched to greater than $5 \mathrm{wt} . \%{ }^{235} \mathrm{U}$.

\subsection{SENSITIVITY COEFFICIENT GENERATION}

The TSUNAMI-3D sequence discussed above in Section 2.2.1 was used to generate sensitivity data for several application cases, beginning with the HAC $7 \times 2$ array with $7 \mathrm{wt} . \%{ }^{235} \mathrm{U}$ enriched $\mathrm{UF}_{6}$. The bounding configuration for this array was with a $U_{6}$ density of $5.5 \mathrm{~g} / \mathrm{cm}^{3}$ and with a $0.6 \mathrm{~cm}$ thick film of water around the cylinder inside the overpack $\left(k_{\text {eff }}\right.$ of $\left.0.88171+0.0003\right)$. Limiting analysis conditions were used because the generation of SDFs requires significantly greater computational resources than the calculations of $k_{\text {eff. }}$ The MG TSUNAMI method is used, which is consistent with the use of MG data in the analyses presented above in Section 3. The mesh modeled was large along the outer edges of the array but finer in the center of the model to allow for the collection of flux moments within memory constraints. The inner fine mesh has 32 mesh intervals in the $\mathrm{X}$ direction, 28 in the $\mathrm{Y}$ direction, and 11 in the $\mathrm{Z}$ direction. The finer radial mesh is essentially a uniform square mesh that is $7.8 \mathrm{~cm}$ on each side. The finer axial mesh was divided into 18.5 -cm segments.

The nuclides with the highest magnitude sensitivities are listed in Table 20. The sensitivities were confirmed through direct perturbation calculations and were acceptable for analyses.

Table 20. Nuclides with the highest sensitivities from the HAC $7 \times 2$ array with 7 wt. $\%{ }^{235} \mathrm{U}^{\text {enriched } \mathrm{UF}_{6}}$

\begin{tabular}{|c|c|c|}
\hline Nuclide & Mixture & Sensitivity \\
\hline${ }^{235} \mathrm{U}$ & $\mathrm{UF}_{6}$ & 0.2235 \\
\hline${ }^{1} \mathrm{H}$ & HUR & 0.1536 \\
\hline${ }^{238} \mathrm{U}$ & $\mathrm{UF}_{6}$ & -0.1500 \\
\hline${ }^{56} \mathrm{Fe}$ & Cylinder & -0.0499 \\
\hline${ }^{238} \mathrm{U}$ & HUR & -0.0349 \\
\hline${ }^{235} \mathrm{U}$ & HUR & 0.0343 \\
\hline${ }^{1} \mathrm{H}$ & $\mathrm{UF}_{6}$ & 0.0175 \\
\hline${ }^{56} \mathrm{Fe}$ & Overpack & -0.0111 \\
\hline
\end{tabular}


Sensitivity data was also generated for the comparison cases listed in Table 19 . Similar to the $7 \times 2$ model, the mesh was larger along the outer edges of the array but finer in the center of the model where the HUR was located.

\subsection{SIMILARITY ASSESSMENT}

\subsubsection{Critical Experiments Considered}

A suite of 3,017 critical experiments from the International Criticality Safety Benchmark Evaluation Project (ICSBEP) Handbook [25] is used with TSUNAMI-IP to identify potentially applicable experiments for $k_{\text {eff }}$ validation. The ICSBEP SDFs are considered sufficiently accurate for experiment selection. The ICSBEP experiment naming convention indicates the enrichment range (highly enriched uranium, intermediate or mixed enrichment uranium, low enriched uranium, mixed plutonium and uranium), material form (metal, solution, compound), and energy spectrum (fast, thermal, intermediate, mixed).

\subsection{2 $\quad c_{k}$ Results}

As discussed in Section 2.2.2 above, $c_{k}$ values are calculated for select applications and compared to each of the critical experiments considered. These $c_{k}$ values are used to determine which applicable benchmarks to use in validation. As mentioned above, none of the benchmark experiments with available sensitivity data achieved the desired $c_{k}$ value of 0.8 or higher. This led to consideration of experiments with $c_{k}$ values in excess of 0.7 and the need for an additional validation margin as a result of the lack of highly applicable benchmarks. The $\mathrm{c}_{\mathrm{k}}$ results are presented here for the $\mathrm{HAC} 7 \times 2$ array with 7 wt. $\%{ }^{235} \mathrm{U}$ enriched $\mathrm{UF}_{6}$.

\subsubsection{Hypothetical accident conditions with 7 wt. $\%{ }^{235} \mathrm{U}$}

The $\mathrm{c}_{\mathrm{k}}$ results for the $7 \times 2 \mathrm{HAC}$ array model with $7 \mathrm{wt} . \%{ }^{235} \mathrm{U}$ enriched $\mathrm{UF}_{6}$ are shown in Figure 27 . As discussed above, there are no experiments with a $c_{k}$ value of 0.8 or higher. Table 21 lists the 19 experiments that were identified with $c_{\mathrm{k}}$ values higher than 0.7 . 


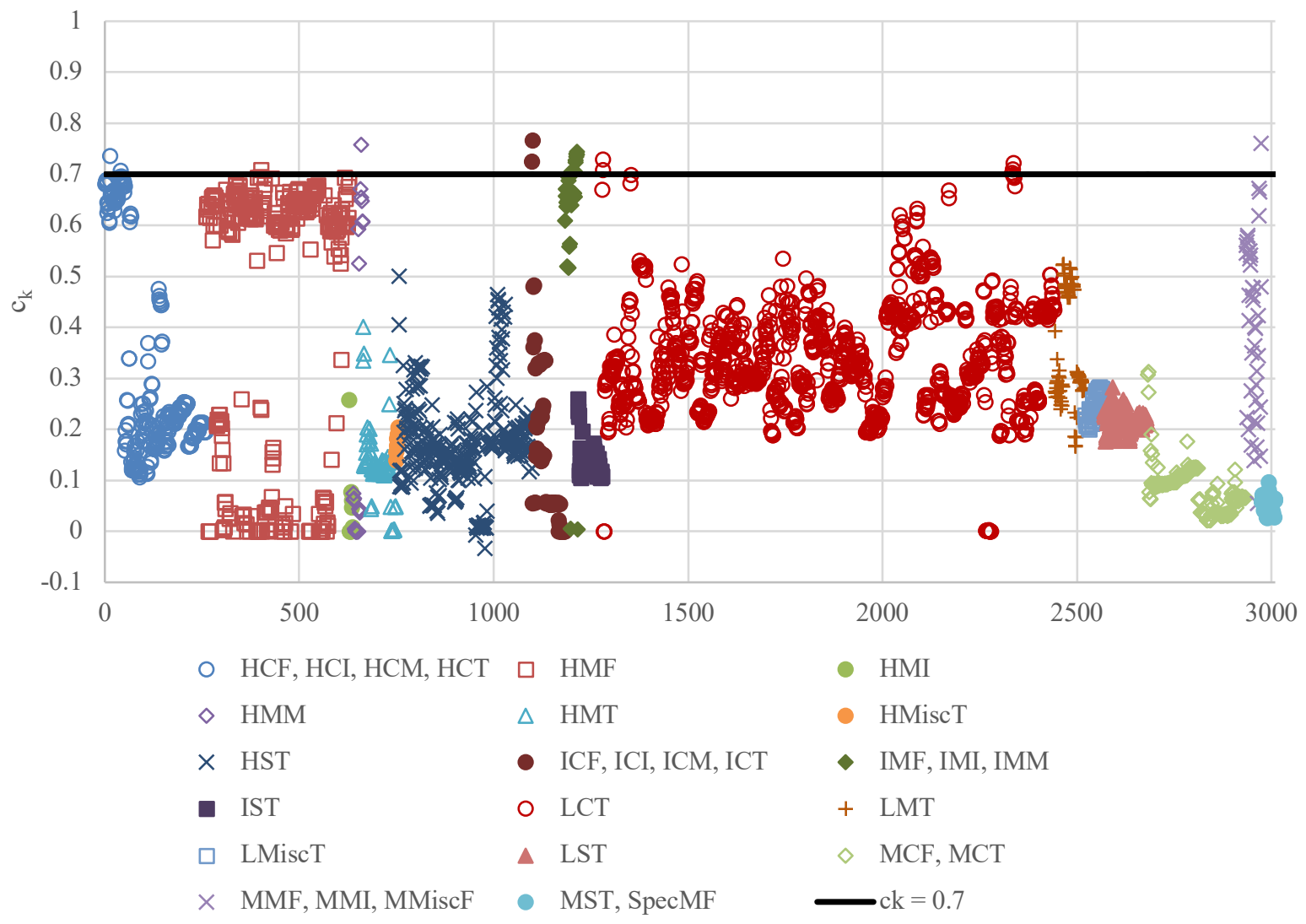

Figure 27. $c_{k}$ values for all experiments compared to the HAC $7 \times 2$ array with 7 wt. $\%{ }^{235} \mathrm{U}$ enrichment.

Table 21. Experiments with $\mathrm{c}_{\mathrm{k}}$ values in excess of 0.7 for the HAC $7 \times 2$ array with $7 \mathrm{wt} . \%{ }^{235} \mathrm{U}$ enrichment

\begin{tabular}{|l|c|}
\hline Experiment & $\mathbf{c}_{\mathbf{k}}$ value \\
\hline IEU-COMP-INTER-005-001 & 0.77 \\
\hline MIX-MISC-FAST-001-009 & 0.76 \\
\hline HEU-MET-MIXED-018-002 & 0.76 \\
\hline IEU-MET-INTER-001-003 & 0.74 \\
\hline IEU-MET-INTER-001-002 & 0.74 \\
\hline IEU-MET-INTER-001-004 & 0.74 \\
\hline HEU-COMP-INTER-004-001 & 0.74 \\
\hline IEU-MET-FAST-022-007 & 0.73 \\
\hline LEU-COMP-MIXED-001-001 & 0.73 \\
\hline IEU-MET-FAST-022-006 & 0.73 \\
\hline IEU-COMP-FAST-004-001 & 0.73 \\
\hline IEU-MET-FAST-022-005 & 0.72 \\
\hline LEU-COMP-THERM-076-004 & 0.72 \\
\hline LEU-COMP-THERM-076-003 & 0.71 \\
\hline HEU-MET-FAST-038-002 & 0.71 \\
\hline LEU-COMP-MIXED-001-002 & 0.71 \\
\hline HEU-COMP-MIXED-002-010 & 0.71 \\
\hline IEU-MET-FAST-022-001 & 0.71 \\
\hline LEU-COMP-THERM-076-001 & 0.70 \\
\hline IEU-MET-FAST-014-002 & 0.70 \\
\hline
\end{tabular}


For comparison, $\mathrm{c}_{\mathrm{k}}$ values were also generated for additional enrichments in the HAC $7 \times 2$ array-6, 8, $9,10,12,15$, and $20 \mathrm{wt} . \%$. Even though several of these enrichments are not acceptable, they are included in Table 22 for information. Also included is the total data-induced uncertainty $(\% \Delta k / k)$. The limited number of benchmark experiments in the intermediate energy ranges is evident in the number of $\mathrm{c}_{\mathrm{k}}$ 's found $>0.8$.

Table 22. $c_{k}$ values HAC $7 \times 2$ array with various ${ }^{235} \mathrm{U}$ enrichments

\begin{tabular}{|c|c|c|c|c|c|c|c|c|}
\hline & \multicolumn{8}{|c|}{${ }^{235} \mathrm{U}$ enrichment (wt.\%) } \\
\hline & 6 & 7 & 8 & 9 & 10 & 12 & 15 & 20 \\
\hline$c_{k}>0.9$ & 0 & 0 & 0 & 0 & 1 & 10 & 38 & 110 \\
\hline $0.9>c_{k}>0.8$ & 0 & 0 & 4 & 19 & 80 & 232 & 282 & 219 \\
\hline $0.8>c_{k}>0.7$ & 13 & 20 & 174 & 290 & 252 & 107 & 34 & 27 \\
\hline Total $c_{k}>0.7$ & 13 & 20 & 178 & 309 & 333 & 349 & 354 & 356 \\
\hline $\begin{array}{l}\text { Total data-induced } \\
\text { uncertainty }(\% \Delta k / k)\end{array}$ & 0.7796 & 0.8588 & 0.9573 & 1.0550 & 1.1570 & 1.3660 & 1.6500 & 2.0530 \\
\hline
\end{tabular}

\subsection{BIAS AND BIAS UNCERTAINTY DETERMINATION}

Figure 28 is the trending analysis plot generated by the USLSTATS program with no additional margin included for the HAC $7 \times 2$ array with $7 \mathrm{wt} . \% \mathrm{UF}_{6}$. The experiments identified by TSUNAMI-IP (Table 21) were used for generating the USLSTATS input for determining the upper subcritical limit based on the SDF results of the HAC $7 \times 2$ array.

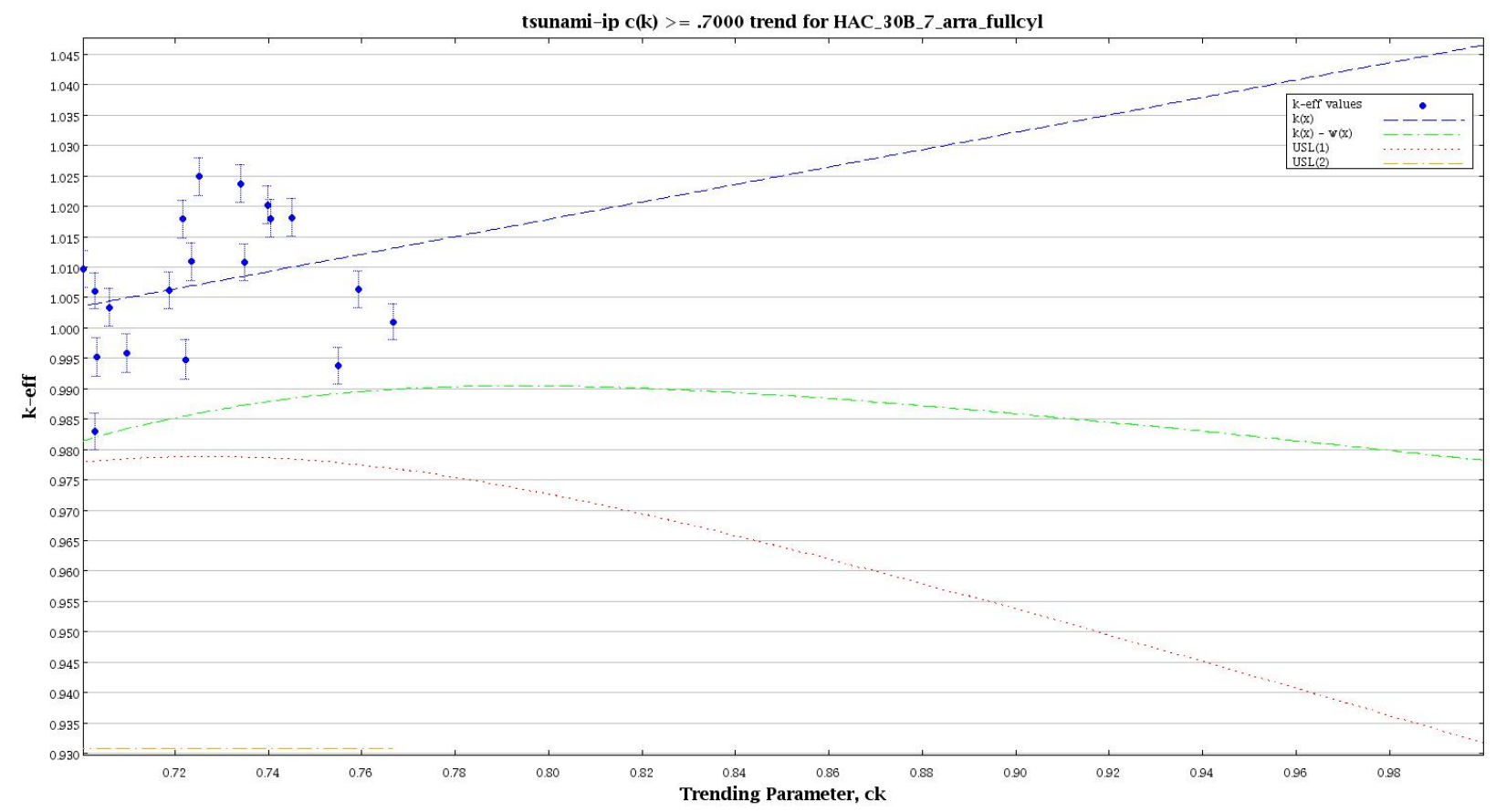

Figure 28. $c_{k}$ Trending analysis plot for the $\mathrm{HAC}_{7} \times 2$ array with $7 \mathrm{wt} \% \mathrm{UF}_{6}$.

From USLSTATS, the bias is 0.0465 (positive bias), and the uncertainty in the bias is 0.0683 .

The validation results (bias and bias uncertainty) were used to determine an upper subcritical limit (USL). Determination of the USL can also include an additional margin of subcriticality to account for dissimilarities between the experiments used and the application and identified gaps in the nuclear data 
(for example when using $c_{\mathrm{k}}$ 's $<0.8$ ). The USL can be considered as the magnitude of the sum of the biases, uncertainties, and administrative and/or statistical margins applied to a set of critical benchmarks. Because a positive bias may be nonconservative, all positive biases are set to zero. An allowance to use a positive bias, if the cause of the positive bias is well understood and justified, has been established in [22], but is not applicable for this evaluation. Calculated results (including an applicable calculational uncertainty) below the USL are considered subcritical. The USL can be represented by the following:

$$
\begin{gathered}
\mathrm{USL}=1.0+\text { bias }- \text { bias uncertainty }- \text { administrative margin } \\
\mathrm{k}_{\text {eff-calc }}+\text { calculational uncertainty }<\mathrm{USL}
\end{gathered}
$$

Prior to applying any additional margin, the USL is 0.9317 (if starting from a value of 1.0). If starting from a value of 0.95 (applying an administrative margin of 0.05 ), the USL is 0.8817.

\subsection{ADDITIONAL VALIDATION MARGINS}

$\mathrm{S} / \mathrm{U}$ techniques provide tools for generating a quantitative, defensible estimate of what an appropriate margin might be. Examining the nuclides and reactions that contribute significantly to data-induced uncertainty will indicate the important processes to be validated. Elements such as F might be entirely absent from the validation set or only poorly represented. For these nuclides, the data-induced uncertainty provides an estimate for the magnitude of the bias that could occur in the application. This approach has been used in several other applications [26, 27, 28].

The magnitude of the data-induced uncertainty in the application also bounds the expected magnitude of the bias if there are no applicable benchmarks. Using this value might be more efficient than investing effort in developing and defending a lower additional margin. A demonstration that the data-induced uncertainty bounds the bias manifested for most fast or thermal spectrum benchmark systems is provided in Section 3.2.5 of Scaglione et al. [29]. It is not clear if the bias of intermediate spectrum systems is also bounded by the nuclear data-induced uncertainty in $k_{\text {eff. }}$ It is likely that the most applicable benchmark experiments would be used to develop a bias and bias uncertainty, and this additional margin would be added to ensure sufficient conservatism in the USL.

A more complex approach could be to justify an additional margin based on the fact that the available benchmarks provide validation for some incident neutron energies. This approach could be useful for important nuclides that are present in the validation suite but that have energy-dependent sensitivity profiles that differ significantly from the application model. These profiles can be reviewed to determine whether validation exists for an energy range or perhaps multiple energy ranges. For example, it might be evident that high-energy cross sections are validated because fission neutrons are born at high energies in all systems. Thermal cross sections are generally well validated due to the many available thermal benchmark experiments. Therefore, an estimate of the unvalidated portion of the profile may be generated and used to estimate the magnitude of the remaining potential bias in the application in the energy ranges with weaker validation. In some cases, an energy range in the application might have significantly less sensitivity than that present in relevant benchmarks. An additional margin for these situations would likely not be needed because the low sensitivity directly indicates a low potential for bias.

For the $7 \times 2 \mathrm{HAC}$ array model with an enrichment of $7 \mathrm{wt} . \%{ }^{235} \mathrm{U}$, the total data-induced uncertainty is $0.874 \% \Delta k / k$. Given the system $k_{\text {eff }}$ value of 0.8817 , the absolute data-induced uncertainty is $0.787 \% \Delta k$. When combined with this additional margin, the bias and bias uncertainty derived above yield a USL of 0.9239 for the $c_{k}$ trend (or 0.8739 when starting from a value of 0.95 ). Note that there is not much consideration for fluorine in the validation set used in the derivation of the bias and bias uncertainty. The absolute data-induced uncertainty in the $7 \times 2$ HAC model with $7 \mathrm{wt} . \%$ enrichment is, on a one-sigma 
basis, approximately $0.120 \% \Delta k$. The magnitude of the difference between these two margin estimates is approximately $0.667 \% \Delta k$; a portion of this difference may be eliminated by a detailed review of energydependent sensitivity data in the application and benchmarks.

\section{5 $c_{\mathrm{k}}$ COMPARISONS BETWEEN SINGLE CYLINDER MODELS}

As mention above, sensitivity data was also generated for the comparison cases listed in Table 19-the 1x1 arrays with the $0.6 \mathrm{~cm}$ thick water film thickness analyzed with no HUR present, with HUR present, and with the HUR present with the spherical HF shell around the HUR - at various enrichments $(6,7,8,9,10$, 12,15 , and $20 \mathrm{wt} . \%{ }^{235} \mathrm{U}$ ). For comparison, $\mathrm{c}_{\mathrm{k}}$ values were also calculated for these cases to determine variations caused by different HUR considerations. Results are shown in Table 23, Table 24, and Table 25 . The less complicated the HUR model, the lower the $k_{\text {eff }}$ in Table 19, and the higher the total datainduced uncertainty (larger additional margin based on data-induced uncertainty). As with the HAC $7 \times 2$ array, the limited number of benchmark experiments in the intermediate energy ranges is evident in the number of $\mathrm{c}_{\mathrm{k}}$ 's found $>0.8$ for all modeling considerations. From Table 19 these correspond to EALFs from $\sim 50$ to $\sim 5500 \mathrm{eV}$.

Table 23. $c_{k}$ values $1 \times 1$ array, no HUR present, various ${ }^{235} \mathrm{U}$ enrichments

\begin{tabular}{|c|c|c|c|c|c|c|c|c|}
\hline & \multicolumn{8}{|c|}{${ }^{235}$ U enrichment (wt.\%) } \\
\hline & 6 & 7 & 8 & 9 & 10 & 12 & 15 & 20 \\
\hline$c_{k}>0.9$ & 0 & 0 & 2 & 6 & 10 & 26 & 79 & 143 \\
\hline $0.9>c_{k}>0.8$ & 5 & 21 & 33 & 121 & 207 & 290 & 251 & 192 \\
\hline $0.8>c_{k}>0.7$ & 31 & 149 & 267 & 208 & 126 & 35 & 22 & 20 \\
\hline Total $c_{k}>0.7$ & 36 & 170 & 302 & 335 & 343 & 351 & 352 & 355 \\
\hline $\begin{array}{l}\text { Total data-induced } \\
\text { uncertainty }(\% \Delta k / k)\end{array}$ & 1.2740 & 1.3190 & 1.3880 & 1.4500 & 1.5400 & 1.7130 & 1.9820 & 2.3700 \\
\hline
\end{tabular}

Table 24. $c_{k}$ values $1 \times 1$ array, HUR sphere, various ${ }^{235} U$ enrichments

\begin{tabular}{|c|c|c|c|c|c|c|c|c|}
\hline & \multicolumn{8}{|c|}{${ }^{235} \mathrm{U}$ enrichment (wt.\%) } \\
\hline & 6 & 7 & 8 & 9 & 10 & 12 & 15 & 20 \\
\hline $\mathrm{c}_{\mathrm{k}}>0.9$ & 0 & 0 & 0 & 0 & 0 & 0 & 54 & 150 \\
\hline $0.9>c_{k}>0.8$ & 11 & 4 & 4 & 7 & 69 & 195 & 252 & 182 \\
\hline $0.8>c_{k}>0.7$ & 594 & 118 & 117 & 140 & 184 & 149 & 52 & 23 \\
\hline Total $c_{k}>0.7$ & 605 & 122 & 121 & 147 & 253 & 344 & 358 & 355 \\
\hline $\begin{array}{l}\text { Total data-induced } \\
\text { uncertainty }(\% \Delta k / k)\end{array}$ & 0.8149 & 0.8283 & 0.8673 & 0.9179 & 0.9824 & 1.151 & 1.454 & 1.915 \\
\hline
\end{tabular}

Table 25. $c_{k}$ values $1 \times 1$ array, HUR sphere with spherical HF shell, various ${ }^{235} \mathrm{U}$ enrichments

$\mathrm{c}_{\mathrm{k}}>0.9$

$0.9>\mathrm{c}_{\mathrm{k}}>0.8$

$0.8>\mathrm{c}_{\mathrm{k}}>0.7$

Total $c_{k}>0.7$

Total data-induced

uncertainty $(\% \Delta k / k)$

\begin{tabular}{cccccccc}
\hline \multicolumn{8}{c}{${ }^{235}$ U enrichment (wt. \%) } \\
\hline $\mathbf{6}$ & $\mathbf{7}$ & $\mathbf{8}$ & $\mathbf{9}$ & $\mathbf{1 0}$ & $\mathbf{1 2}$ & $\mathbf{1 5}$ & $\mathbf{2 0}$ \\
\hline 0 & 0 & 0 & 0 & 0 & 0 & 0 & 86 \\
20 & 10 & 4 & 4 & 4 & 52 & 189 & 222 \\
724 & 448 & 121 & 106 & 111 & 183 & 156 & 49 \\
744 & 458 & 125 & 110 & 115 & 235 & 345 & 357 \\
$\mathbf{0 . 7 8 6 3}$ & $\mathbf{0 . 7 9 6 5}$ & $\mathbf{0 . 8 1 1 5}$ & $\mathbf{0 . 8 3 8 0}$ & $\mathbf{0 . 8 7 1 2}$ & $\mathbf{0 . 9 6 0 8}$ & $\mathbf{1 . 1 3 7 0}$ & $\mathbf{1 . 4 6 9}$ \\
\end{tabular}




\section{CONCLUSIONS AND FUTURE WORK}

\subsection{CONCLUSIONS}

A summary of the key results of this study, previously presented in Section 3, is presented below. A summary table of the configurations analyzed is included in Appendix A. The limited analysis provided in this study indicates that enrichments up to $10 \mathrm{wt} . \%{ }^{235} \mathrm{U}$ or slightly higher (maybe $12 \mathrm{wt} . \%$ ) may be feasible in 30B cylinders in small arrays but use of the 30B cylinder for the entire LEU+ and HALEU enrichment range appears difficult at best. With the current modeling assumptions, enrichments above 15 wt. $\%{ }^{235} \mathrm{U}$ in arrays as small as 1 or 2 cylinders have system $k_{\text {eff }}$ values greater than 0.95 . $k_{\text {eff }}$ values tended to peak at the maximum $\mathrm{UF}_{6}$ density $\left(5.5 \mathrm{~g} / \mathrm{cm}^{3}\right)$ with about a $0.6 \mathrm{~cm}$ thick layer of water between the $30 \mathrm{~B}$ cylinder and the overpack. Table 26 lists the peak $k_{\text {eff }}$ for each enrichment considered in the arrays modeled. Entries shaded in blue have $k_{\text {eff }}$ values greater than 1.0, and those shaded in gray have $k_{\text {eff }}$ values between 0.95 and 1.0. As the arrays decreased in size, the magnitude of the change in $k_{\text {eff }}$ with changes in water film thickness decreased, increasing to a maximum around a film thickness of $0.6 \mathrm{~cm}$ and then decreasing with further increases in thickness in most arrays. In the arrays that had no interaction between HUR spheres $(1 \times 1$ and $1 \times 2$ arrays $), k_{\text {eff }}$ did not peak with a film thickness of 0.6 , instead it remained statistically constant.

Table 26. Maximum $k_{\text {eff values for select }}{ }^{235} \mathrm{U}$ enrichments in varying-size arrays

\begin{tabular}{ccccccccc}
\hline \multirow{2}{*}{ Array size } & \multicolumn{8}{c}{${ }^{235}$ U enrichment (wt.\%) } \\
\cline { 2 - 9 } & $\mathbf{6}$ & $\mathbf{7}$ & $\mathbf{8}$ & $\mathbf{9}$ & $\mathbf{1 0}$ & $\mathbf{1 2}$ & $\mathbf{1 5}$ & $\mathbf{2 0}$ \\
\hline $7 \times 2$ & 0.84491 & 0.88171 & 0.91450 & 0.94552 & 0.97576 & 1.03105 & 1.10218 & 1.20317 \\
$7 \times 1$ & 0.83230 & 0.86957 & 0.90492 & 0.93708 & 0.96711 & 1.02189 & 1.09412 & 1.19411 \\
$3 \times 2$ & 0.82069 & 0.85003 & 0.87633 & 0.90075 & 0.92452 & 0.96771 & 1.02858 & 1.11809 \\
$3 \times 1$ & 0.82478 & 0.85583 & 0.88367 & 0.90883 & 0.93291 & 0.97723 & 1.03785 & 1.12585 \\
$2 \times 2$ & 0.78491 & 0.81167 & 0.83545 & 0.85742 & 0.87810 & 0.91729 & 0.97469 & 1.06213 \\
$2 \times 1$ & 0.78459 & 0.81077 & 0.83346 & 0.85687 & 0.87720 & 0.91605 & 0.97232 & 1.05881 \\
$1 \times 2$ & 0.75710 & 0.78507 & 0.81193 & 0.83506 & 0.85695 & 0.89968 & 0.95730 & 1.04379 \\
$1 \times 1$ & 0.75817 & 0.78513 & 0.81072 & 0.83478 & 0.85671 & 0.89960 & 0.95703 & 1.04309 \\
\hline
\end{tabular}

Section 4 above examines some of the issues related to the validation of criticality safety calculations for the 30B cylinders with LEU+ and HALEU material. The ICSBEP Handbook does not include any benchmark critical experiments that have readily available sensitivity data with sufficient similarity to provide validation for the cylinders without including some additional margin in the development of the USL. Some potential approaches to using $\mathrm{S} / \mathrm{U}$ techniques to develop quantitative estimates of what these margins may be are presented in Section 4.4 and may be on the order of $0.75 \% \Delta k$.

\subsection{FUTURE WORK}

The scope of this study was limited to the investigation of the feasibility of using existing $30 \mathrm{~B}$ cylinders for the storage and transportation of LEU+ and HALEU UF 6 . There are many issues yet to be resolved in establishing the maximum enrichment material that could be introduced into a 30B cylinder consistent with the current regulatory considerations discussed in Section 1.3. Highlighted areas for future work are listed below:

- Determination of realistic HUR configurations to justify less conservative modeling approaches (realistic placement of HUR deposits);

- Research on justifying crediting more of the overpack configuration (more realistic spacing scenarios for transportation); 
- More benchmark experiments in applicable ranges (intermediate energy ranges, experiments with $\mathrm{UF}_{6}$ specifically);

- Research into quantifying added safety margins based on data-induced uncertainty (taking credit for analyzed energy ranges);

- Consideration of overpack design changes to introduce reactivity-reducing features; and/or

- Research on justifying crediting a thicker cylinder wall. 


\section{REFERENCES}

1. R. Hall, B. J. Marshall, W. A. Wieselquist, Assessment of Existing Transportation Packages for Use with HALEU, ORNL/TM-2020-1725, Oak Ridge, TN (2020).

2. Daher-TLI, Safety Analysis Report of the DN30 Package, Rev. 3, ADAMS Accession number ML19200A133 (2019).

3. US NRC, Certificate of Compliance 9362, Revision 2 (2019).

4. W. A. Wieselquist, R. A. Lefebvre, and M. A. Jessee, Eds., SCALE Code System, ORNL/TM2005/39, Version 6.2.4, Oak Ridge National Laboratory, Oak Ridge, TN (2020).

5. B. T. Rearden, M. L. Williams, M. A. Jessee, D. E. Mueller, and D. A. Wiarda, "Sensitivity and Uncertainty Analysis Capabilities and Data in SCALE," Nucl. Technol. 174 (2), pp. 236-288 (2011).

6. American National Standards Institute (ANSI), The American National Standard for Nuclear Materials - Uranium Hexafluoride - Packagings for Transport, ANSI N14.1-2019, New York, NY, (2019).

7. Columbia Hi Tech, Safety Analysis Report for Model UX-30 Package, Rev. 4, ADAMS Accession number ML18298A068 (2018).

8. “DN30 Package," Daher Nuclear Technologies; https://daher-nuclear-technologies.com/en/dn30package (current as of Nov. 4, 2020).

9. [10CFR71] Code of Federal Regulations Title 10 Part 71, "Packaging and Transportation of Radioactive Materials;" http://www.ecfr.gov.

10. [49CFR173) Code of Federal Regulations Title 49 Part 173, "Shippers - General Requirements for Shipments and Packagings;" http://www.ecfr.gov.

11. W.J. Marshall, T.M. Greene, B.D. Brickner, and R.A. Hall, "Description and Use of SCALE Sampler Parametric Capability for Engineering Analysis and Optimization," Trans. Am. Nucl. Soc. 122, 471-474 (2020).

12. E.M. Saylor, W.J. Marshall, J.B. Clarity, Z.J. Clifton, and B.T. Rearden, Criticality Safety Validation of SCALE 6.2.2, ORNL/TM-2018/884, Oak Ridge, TN (2018).

13. R. Little, T. Kawano, G. D. Hale, M. T. Pigni, M. Herman, P. Oblozinsky, M. L. Williams, M. E. Dunn, G. Arbanas, D. Wiarda, R. D. McKnight, J. N. McKamy, and J. R. Felty, "Low-fidelity Covariance Project," Nuclear Data Sheets, 109 (12), 2828-2833 (2008).

14. M. L. Williams, D. Wiarda, and W. J. Marshall, "Consistency between ENDF/B Cross sections and Covariances," presented at US National Nuclear Data Week 2017, Upton, NY (2017).

15. B. L. Broadhead, Criticality Safety Review of 21/2-, 10, and 14-Ton UF6 Cylinders, ORNL/TM11947, Oak Ridge, TN, (1991). 
16. Begue, L., Milin, M., Caplin, G., and Evo, S., "Criticality Safety of Enriched UF 6 Cylinders," Proceedings of the $17^{\text {th }}$ International Symposium on the Packaging and Transportation of Radioactive Materials, Paper No. 204, PATRAM 2013 (2013).

17. O’Connor, G., "Regulatory Criticality Safety Review of Uranium Hexafluoride Transport Package Applications," Proceedings of the $17^{\text {th }}$ International Symposium on the Packaging and Transportation of Radioactive Materials, Paper No. 366, PATRAM 2013 (2013).

18. Rezgui, S. and Hilbert, F., "Criticality Analyses of Enriched Uranium-Hexafluoride Containing Impurities," Proceedings of the $17^{\text {th }}$ International Symposium on the Packaging and Transportation of Radioactive Materials, Paper No. 130, PATRAM 2013 (2013).

19. Milin, M., Rannou, J., Viaulle, L., Caplin, G., and Evo, S., "Hydration of Uranium Residues Contained in Enriched UF 6 Cylinders," Proceedings of the $18^{\text {th }}$ International Symposium on the Packaging and Transportation of Radioactive Materials, Paper No. 2029, PATRAM 2016, (2016).

20. W. C. Jordan, J. C. Turner, Estimated Critical Conditions for UO2H2O Systems in Fully WaterReflected Spherical Geometry, ORNL/TM-12292, Oak Ridge, TN (1992).

21. American Nuclear Society, Nuclear Criticality Safety in Operations with Fissionable Materials Outside Reactors, ANSI/ANS-8.1-2014, R2018, La Grange Park, IL (2018).

22. American Nuclear Society, Validation of Neutron Transport Methods for Nuclear Criticality Safety Calculations, ANSI/ANS-8.24-2017, American Nuclear Society, La Grange Park, IL (2017).

23. J. Borowski et al., Standard Review Plan for Transportation Packages for Spent Fuel and Radioactive Material: Final Report, NUREG-2216, US Nuclear Regulatory Commission (2020).

24. R. A. Hall, W. J. Marshall, E. Eidelpes, and B. M. Hom, "Assessment of Critical Experiment Benchmark Applicability to a Large-Capacity HALEU Transportation Package Concept," Nucl. Sci. Eng. 195(3), 310-319 (2021).

25. International Handbook of Evaluated Criticality Safety Benchmark Experiments, NEA/NSC/DOC(95)03, NEA Nuclear Science Committee (2020).

26. Division of Spent Fuel Storage and Transportation, Interim Staff Guidance-8, Revision 3, Burnup Credit in the Criticality Safety Analyses of PWR Spent Fuel in Transportation and Storage Casks, US Nuclear Regulatory Commission (2012).

27. W. J. Marshall, B. J. Ade, S. M. Bowman, I. C. Gauld, G. Ilas, U. Mertyurek, and G. Radulescu, Technical Basis for Peak Reactivity Burnup Credit for BWR Spent Nuclear Fuel in Storage and Transportation Systems, NUREG/CR-7194 (ORNL/TM-2014/240), prepared for the US Nuclear Regulatory Commission by Oak Ridge National Laboratory, Oak Ridge, TN (2015).

28. W. J. Marshall, J. B. Clarity, and S. M. Bowman, Validation of $k_{\text {eff }}$ Calculations for Extended BWR Burnup Credit, NUREG/CR-7252 (ORNL/TM-2018/797), prepared for the US Nuclear Regulatory Commission by Oak Ridge National Laboratory, Oak Ridge, TN (2018). 
29. J. M. Scaglione, D. E. Mueller, J. C. Wagner, and W. J. Marshall, An Approach for Validating Actinide and Fission Product Burnup Credit Criticality Safety Analyses-Criticality ( $\left.k_{\mathrm{eff}}\right)$ Predictions, NUREG/CR-7109 (ORNL/TM-2011/514), prepared for the US Nuclear Regulatory Commission by Oak Ridge National Laboratory, Oak Ridge, TN (2012). 

APPENDIX A

\section{CALCULATIONAL SUMMARY}





\section{APPENDIX A. CALCULATIONAL SUMMARY}

Table A.1 is a summary of the configurations analyzed in this report. 
TABLE A-1. 30B cylinder calculational summary

\begin{tabular}{|c|c|c|c|c|c|c|c|}
\hline Configuration & $\begin{array}{c}\text { Number in } \\
\text { array }\end{array}$ & $\begin{array}{c}\text { Film } \\
\text { range }\end{array}$ & $\begin{array}{l}\text { Enrichment } \\
\text { range }\end{array}$ & $\begin{array}{c}\text { Density } \\
\text { range }\end{array}$ & Overpack & HUR & Notes \\
\hline $\begin{array}{l}\text { Single 30B } \\
\text { cylinder }\end{array}$ & 1 & $\begin{array}{l}\text { Infinite } \\
\text { reflection }\end{array}$ & 6-20 wt.\% & $2.5-5.5$ & No & Not present & $k_{\text {eff }}$ increased with increasing enrichment \\
\hline $\begin{array}{l}\text { Single } 30 \mathrm{~B} \\
\text { cylinder with } \\
\text { overpack }\end{array}$ & 1 & $\begin{array}{l}\text { Infinite } \\
\text { reflection }\end{array}$ & $6-20$ wt. $\%$ & $2.5-5.5$ & Yes, collapsed & Not present & $\begin{array}{l}\text { Gap between cylinder and overpack, } k_{\text {eff }} \text { increased with } \\
\text { increasing enrichment }\end{array}$ \\
\hline Inf array & $\inf$ & $0-5 \mathrm{~cm}$ & $\begin{array}{l}6-10 \text { wt.\%, } \\
7 \text { and } 10 \\
\text { wt.\% shown }\end{array}$ & $2-5.5$ & No & Not present & $\begin{array}{l}k_{e f f} \text { higher for larger densities for film thicknesses above } 3 \\
\mathrm{~g} / \mathrm{cc}\end{array}$ \\
\hline Inf array & Inf & $1 \mathrm{~cm}$ & 6-10 wt.\%, & $2-5.5$ & No & Not present & $\begin{array}{l}k_{\text {eff }} \text { increases with enrichment and decreases with density, all } \\
\text { system } k_{\text {eff }} \text { values greater than } 0.95 \text {, infinite array not } \\
\text { acceptable for safety basis }\end{array}$ \\
\hline HAC array & $\begin{array}{l}7 \times 2 \text { array } \\
\text { HAC }\end{array}$ & $0-5 \mathrm{~cm}$ & $7 \%$ & $2.5-5.5$ & Collapsed & Yes & $\begin{array}{l}k_{\text {eff }} \text { peaks at } \sim 0.5 \mathrm{~cm} \text { film thickness and increases with } \\
\text { density, maximum system } k_{\text {eff }} \text { less than } 0.89\end{array}$ \\
\hline NCT array & $\begin{array}{l}19 \times 2 \text { under } \\
\text { HAC } \\
\text { assumptions }\end{array}$ & $0-1 \mathrm{~cm}$ & $7 \%$ & $3.5-5.5$ & $\begin{array}{l}\text { Collapsed } \\
\text { (HAC } \\
\text { configuration) }\end{array}$ & Yes & $\begin{array}{l}k_{\text {eff }} \text { peaks at } \sim 0.5 \mathrm{~cm} \text { film thickness and increases with } \\
\text { density, maximum system } k_{\text {eff }} \text { is less than } 0.92\end{array}$ \\
\hline HAC array & $7 \times 2$ & $0.2-5 \mathrm{~cm}$ & $6-20$ wt. $\%$ & $5.5 \%$ & Collapsed & Yes & $\begin{array}{l}k_{\text {eff }} \text { peaks at } 0.6 \mathrm{~cm} \text { film thickness, greater than } \sim 0.95 \\
\text { starting around } 9 \% \text { enrichment }\end{array}$ \\
\hline HAC array & $7 \times 1$ & $0.2-5 \mathrm{~cm}$ & $6-20 \%$ & $5.5 \%$ & Collapsed & Yes, cylinder end & $\begin{array}{l}k_{\text {eff }} \text { peaks at } 0.6 \mathrm{~cm} \text { film thickness, greater than } \sim 0.95 \\
\text { starting around } 10 \% \text { enrichment }\end{array}$ \\
\hline HAC array & $7 \times 1$ & $0.2-5 \mathrm{~cm}$ & $6-20 \%$ & $5.5 \%$ & Collapsed & Yes, centered on side & $\begin{array}{l}k_{\text {eff }} \text { peaks at } 0.6 \mathrm{~cm} \text { film thickness, greater than } \sim 0.95 \\
\text { starting around } 10 \% \text { enrichment, higher than configuration } \\
\text { with HUR spheres at ends of cylinders, thus spheres driving } \\
\text { system }\end{array}$ \\
\hline HAC array & $3 \times 2$ & $0.2-5 \mathrm{~cm}$ & $6-20 \%$ & $5.5 \%$ & Collapsed & End of cylinder & $\begin{array}{l}k_{\text {eff }} \text { peaks at } 0.6 \mathrm{~cm} \text { film thickness, greater than } \sim 0.95 \\
\text { starting at greater than } 10 \% \text { enrichment }\end{array}$ \\
\hline HAC array & $3 \times 1$ & $0.2-5 \mathrm{~cm}$ & $6-20 \%$ & $5.5 \%$ & Collapsed & Axially centered & $\begin{array}{l}k_{\text {eff }} \text { peaks at } 0.6 \mathrm{~cm} \text { film thickness, greater than } \sim 0.95 \\
\text { starting at greater than } 10 \% \text { enrichment }\end{array}$ \\
\hline HAC array & $2 \times 2$ & $0.2-5 \mathrm{~cm}$ & $6-20 \%$ & $5.5 \%$ & Collapsed & Axially centered & $\begin{array}{l}k_{\text {eff }} \text { peaks at } 0.6 \mathrm{~cm} \text { film thickness, greater than } \sim 0.95 \\
\text { starting at greater than } 12 \% \text { enrichment }\end{array}$ \\
\hline HAC array & $2 \times 1$ & $0.2-5 \mathrm{~cm}$ & $6-20 \%$ & $5.5 \%$ & Collapsed & Axially centered & $\begin{array}{l}k_{\text {eff }} \text { peaks at } 0.6 \mathrm{~cm} \text { film thickness, greater than } \sim 0.95 \\
\text { starting around at greater than } 12 \% \text { enrichment }\end{array}$ \\
\hline HAC array & $1 \times 2$ & $0.2-5 \mathrm{~cm}$ & $6-20 \%$ & $5.5 \%$ & Collapsed & Axially centered & $\begin{array}{l}k_{\text {eff }} \text { peaks at } 0.6 \mathrm{~cm} \text { film thickness, greater than } \sim 0.95 \\
\text { starting at greater than } 12 \% \text { enrichment }\end{array}$ \\
\hline HAC array & $1 \times 1$ & $0.2-5 \mathrm{~cm}$ & $6-20 \%$ & $5.5 \%$ & Collapsed & Axially centered & $\begin{array}{l}k_{\text {eff }} \text { peaks at } 0.6 \mathrm{~cm} \text { film thickness, greater than } \sim 0.95 \\
\text { starting around } 15 \% \text { enrichment }\end{array}$ \\
\hline HAC array & $1 \times 1$ & $0.2-5 \mathrm{~cm}$ & $6-20 \%$ & $5.5 \%$ & Collapsed & $\begin{array}{l}\text { Comparison between no } \\
\text { HUR, HUR, and HUR } \\
\text { with HF shell, HUR } \\
\text { axially centered }\end{array}$ & $\begin{array}{l}k_{e f f} \text { increases with increasing complexity of HUR model, } \\
\text { HUR }<\text { HUR }<\text { HUR with HF shell. Emphasizes the } \\
\text { importance of the HUR spheres and the conservatisms } \\
\text { assumed in the HUR model }\end{array}$ \\
\hline
\end{tabular}



